\title{
Classificação de imagens de plâncton usando múltiplas segmentações
}

\author{
Mariela Atausinchi Fernandez
}

DisSERTAÇÃO APRESENTADA

AO

Instituto DE MATEMÁtica E EstatísticA

DA

Universidade de SÃo Paulo

PARA

OBTENÇÃO DO TÍTULO

$\mathrm{DE}$

Mestre em CiênCias

\author{
Programa: Ciência da Computação \\ Orientadora: Prof ${ }^{\mathrm{a}}$. Dr ${ }^{\mathrm{a}}$. Nina S. T. Hirata
}

Durante o desenvolvimento deste trabalho a autora recebeu auxílio financeiro da CAPES 


\section{Classificação de imagens de plâncton usando múltiplas segmentações}

Esta versão da dissertação contém as correções e alterações sugeridas pela Comissão Julgadora durante a defesa da versão original do trabalho, realizada em 27/03/2017. Uma cópia da versão original está disponível no

Instituto de Matemática e Estatística da Universidade de São Paulo.

Comissão Julgadora:

- Prof ${ }^{\mathrm{a}}$. Dr ${ }^{\mathrm{a}}$. Nina Sumiko Tomita Hirata (orientadora) - IME-USP

- Prof. Dr. Rubens Lopes - IO-USP

- Prof. Dr. João Paulo Papa - FC-UNESP 


\section{Agradecimentos}

Esta dissertação não teria sido possível sem o apoio e colaboração de muitas pessoas. Em primeiro lugar gostaria de agradecer a minha orientadora Profa. Dra. Nina S. T. Hirata e ao Prof. Dr. Rubens M. Lopes. Agradeço a Nina pelo apoio, estímulo, por compartilhar comigo seus conhecimentos e experiência, ler minhas redações, por me aconselhar, me escutar e especialmente pela orientação com que pude contar e valiosas lições que pude aprender ao longo deste mestrado.

Agradeço ao professor Rubens M. Lopes do Laboratório de Sistemas Planctônicos do Instituto Oceanográfico pela orientação e trabalho de colaboração durante o desenvolvimento deste mestrado. Também gostaria de agradecer a Leandro T. De La Cruz e a Maiá G. Medeiros por seu apoio na aquisição e rotulação das imagens utilizadas neste trabalho.

Gostaria de agradecer ao professor Roberto Hirata por sua confiança, apoio, e por ter me motivado e aconselhado para fazer o mestrado.

Gostaria de agradecer a minha família: meus pais Victoria e Hilario, pelo exemplo que me deram, pois me ensinaram que sem trabalho e dedicação não conseguimos nossas metas; pelo amor, o esforço e sacrifício por meus irmãos e por mim e por todo o que significa ser pais.

Agradeço a minha irmã Rossana, quem considero como uma mãe e amiga; meu irmão Richarth por me ensinar o que significa a perseverança e paixão pelas coisas que você faz, e que me motivou escolher minha profissão.

Também gostaria de agradecer de uma forma super especial a meu noivo, Miguel, quem me apoio infinitas vezes emocionalmente nesse caminho. Cada dia que passa eu tenho mais certeza que você é o companheiro ideal, sempre leal, carinhoso e amigo. Obrigada por me incentivar sempre, mesmo quando nós ficamos separados pela distância, mas sempre unidos de pensamento. Estendo meus agradecimentos aos seus pais, Miguel Tulio e Fely, sua avó Saturnina e irmã Sheyla, por me acolherem dentro de sua família como se fosse uma filha.

Agradeço a minha amiga Noemi e aos meus amigos de laboratório Grover, Hans, Nury, Christian, Evelyn, Waldir, Erika, Talita, Jihan, Leandro, Leissi, Jorge, Anderson, Lucy, Sabrina e Juan por criar um ambiente agradável e bem-humorado. Tenho um carinho especial 
por todos vocês, e obrigada por deixarem fruta no lab para matar a fome durante as noites de estudo.

Agradeço também aos meus amigos do apartamento, Chio, Jaime, Mirla, Meli, Martin, Urpy e Nancy, pelos momentos de descontração e brincadeiras que tornaram mais divertido o tempo que tomou fazer o mestrado.

Também gostaria de agradecer a Edu, quem me fez entender que passar momentos com os amigos é tão importante quanto o estudo, e que podem andar de mãos dadas.

Fico grata com todos os amigos que fiz no vôlei sábados, com os quais comparti tardes maravilhosas.

Agradeço às inúmeras pessoas que conheci no Brasil, pois elas se tornaram cúmplices desta meta, agora alcançada.

Finalmente agradeço à CAPES pelo apoio financeiro, por meio da concessão da bolsa de Mestrado. 


\section{Resumo}

\section{ATAUSINCHI-FERNANDEZ, MARIELA. Classificação de imagens de plâncton}

usando múltiplas segmentações. 78 f. Dissertação (Mestrado) - Instituto de Matemática e Estatística, Universidade de São Paulo, São Paulo, 2017.

Plâncton são organismos microscópicos que constituem a base da cadeia alimentar de ecossistemas aquáticos. Eles têm importante papel no ciclo do carbono pois são os responsáveis pela absorção do carbono na superfície dos oceanos. Detectar, estimar e monitorar a distribuição das diferentes espécies são atividades importantes para se compreender o papel do plâncton e as consequências decorrentes de alterações em seu ambiente. Parte dos estudos deste tipo é baseada no uso de técnicas de imageamento de volumes de água. Devido à grande quantidade de imagens que são geradas, métodos computacionais para auxiliar no processo de análise das imagens estão sob demanda. Neste trabalho abordamos o problema de identificação da espécie. Adotamos o pipeline convencional que consiste dos passos de deteç̧ão de alvo, segmentação (delineação de contorno), extração de características, e classificação. Na primeira parte deste trabalho abordamos o problema de escolha de um algoritmo de segmentação adequado. Uma vez que a avaliação de resultados de segmentação é subjetiva e demorada, propomos um método para avaliar algoritmos de segmentação por meio da avaliação da classificação no final do pipeline. Experimentos com esse método mostraram que algoritmos de segmentação distintos podem ser adequados para a identificação de espécies de classes distintas. Portanto, na segunda parte do trabalho propomos um método de classificação que leva em consideração múltiplas segmentações. Especificamente, múltiplas segmentações são calculadas e classificadores são treinados individualmente para cada segmentação, os quais são então combinados para construir o classificador final. Resultados experimentais mostram que a acurácia obtida com a combinação de classificadores é superior em mais de $2 \%$ à acurácia obtida com classificadores usando uma segmentação fixa. Os métodos propostos podem ser úteis para a construção de sistemas de identificação de plâncton que sejam capazes de se ajustar rapidamente às mudanças nas características das imagens.

Palavras-chave: Detecção de plâncton, extração de características, segmentação de imagens de plâncton, classificação de imagens de plâncton, avaliação de algoritmos de segmentação. 



\section{Abstract}

\section{ATAUSINCHI-FERNANDEZ, MARIELA. Plankton image classification using multi-}

ple segmentations. 78 p. Dissertation (Master) - Instituto de Matemática e Estatística, Universidade de São Paulo, São Paulo, 2017.

Plankton are microscopic organisms that constitute the basis of the food chain of aquatic ecosystems. They have an important role in the carbon cycle as they are responsible for the absorption of carbon in the ocean surfaces. Detecting, estimating and monitoring the distribution of plankton species are important activities for understanding the role of plankton and the consequences of changes in their environment. Part of these type of studies is based on the analysis of water volumes by means of imaging techniques. Due to the large quantity of generated images, computational methods for helping the process of image analysis are in demand. In this work we address the problem of species identification. We follow the conventional pipeline consisting of target detection, segmentation (contour delineation), feature extraction, and classification steps. In the first part of this work we address the problem of choosing an appropriate segmentation algorithm. Since evaluating segmentation results is a subjective and time consuming task, we propose a method to evaluate segmentation algorithms by evaluating the classification results at the end of the pipeline. Experiments with this method showed that distinct segmentation algorithms might be appropriate for identifying species of distinct classes. Therefore, in the second part of this work we propose a classification method that takes into consideration multiple segmentations. Specifically, multiple segmentations are computed and classifiers are trained individually for each segmentation, which are then combined to build the final classifier. Experimental results show that the accuracy obtained with the combined classifier is superior in more than $2 \%$ to the accuracy obtained with classifiers using a fixed segmentation. The proposed methods can be useful to build plankton identification systems that are able to quickly adjust to changes in the characteristics of the images.

Keywords: detection of plankton, feature extraction, plankton image segmentation, plankton image classification, segmentation algorithms assessment. 



\section{Sumário}

Lista de Abreviaturas $\quad$ ix

Lista de Figuras $\quad$ xi

Lista de Tabelas $\quad$ xiii

1 Introdução $\quad 1$

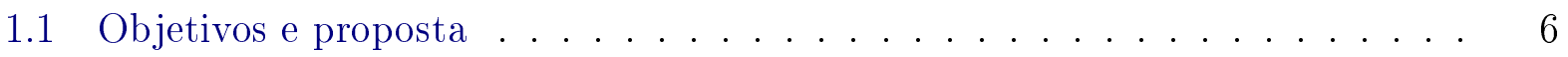

1.2 Contribuições . . . . . . . . . . . . . . . . . . . 7

1.3 Organização do trabalho . . . . . . . . . . . . . . . 7

2 Pipeline típico para classificação de imagens de plâncton 9

2.1 Aquisição de imagens . . . . . . . . . . . . . . . . . . . . . . 9 9

2.2 Detecção de alvos . . . . . . . . . . . . . . . . . . . 11

2.3 Segmentação . . . . . . . . . . . . . . . . . . . . 12

2.4 Extração de características . . . . . . . . . . . . . . . . . . . . 14

2.5 Classificação . . . . . . . . . . . . . . . . . . . 15

3 Fundamentos sobre classificação $\quad 17$

3.1 Classificação . . . . . . . . . . . . . . . . . . . . . . 17

3.2 Normalização e seleção de características . . . . . . . . . . . . . . . 18

3.2 .1 Seleção de características . . . . . . . . . . . . . . . . 19

3.3 Classificação multi-classe . . . . . . . . . . . . . . . . . 20

3.4 Avaliação de classificadores . . . . . . . . . . . . . . . . . . . . . 21

3.4.1 Medidas de avaliação . . . . . . . . . . . . . . . 22

4 Segmentação de imagens de plâncton $\quad 25$

4.1 Avaliação de segmentação . . . . . . . . . . . . . . . . . 25

4.2 Uma proposta para a avaliação indireta da segmentação . . . . . . . . . . . 28

4.2 .1 Descrição do método . . . . . . . . . . . . . . . . 29

4.3 Exemplos de avaliação usando o método proposto . . . . . . . . . . . . . 31

4.3.1 Avaliação visando a escolha de um algoritmo de segmentação . . . . . 31 
4.3.2 Avaliação de outros aspectos da segmentação . . . . . . . . . . . . 35

5 Classificação de imagens de plâncton $\quad 39$

5.1 Notações . . . . . . . . . . . . . . . . . . . . . . 39

5.2 Combinação de múltiplas segmentações na classificação . . . . . . . . . . . 40

5.3 Método proposto . . . . . . . . . . . . . . . . . . 41

5.4 Exemplos de aplicação . . . . . . . . . . . . . . . . . . 44

5.4.1 Segmentação apropriada para cada classe . . . . . . . . . . . . . . 44

5.4 .2 Avaliação do potencial . . . . . . . . . . . . . . . 45

5.4 .3 Método de combinação . . . . . . . . . . . . . . . 46

6 Resultados Experimentais $\quad 49$

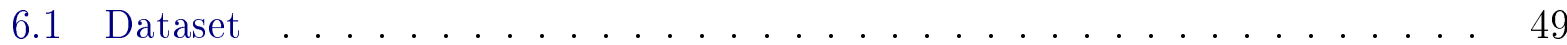

6.2 Configuração dos experimentos . . . . . . . . . . . . . 51

6.2.1 Segmentação . . . . . . . . . . . . . . . . . 51

6.2.2 Extração de características . . . . . . . . . . . . . . . 51

6.2.3 Classificadores . . . . . . . . . . . . . . . . 51

6.3 Experimentos e resultados . . . . . . . . . . . . . . . 53

6.3 .1 Avaliação da segmentação . . . . . . . . . . . . . . . 53

6.3.2 Potencial da combinação de múltiplas segmentações . . . . . . . . . 55

6.3.3 Classificação . . . . . . . . . . . . . . . . 58

6.3.4 Sumário e discussão . . . . . . . . . . . . . . . . 60

7 Conclusões $\quad 61$

7.1 Sugestões para pesquisas futuras . . . . . . . . . . . . . . . . 62

A Dataset usado no trabalho de Matuszewski (2014) 63

B Algoritmos de Segmentação $\quad 65$

$\begin{array}{ll}\text { Referências Bibliográficas } & 71\end{array}$ 


\section{Lista de Abreviaturas}

SMCP Sistema de Monitoramento Contínuo de Plâncton

(Continuous Plankton Monitoring System)

BFM Microscopia de contraste de fase (Bright Field Microscopy)

PCM Microscopia de campo claro (Phase Contrast Microscopy)

RV Ritmo Visual (Visual Rhythm)

IO Instituto Oceanográfico da USP

(Oceanographic Institute of the University of São Paulo)

SVM Máquinas de Vectores de Suporte (Support Vector Machines)

RF Floresta Aleatória (Random Forest)

OVR One vs the Rest (One vs the Rest)

OvO One vs One (One vs One) 



\section{Lista de Figuras}

1.1 Imagens obtidas usando o Zooscan: (a) Calanoida, (b) Chaetognatha, e (c)

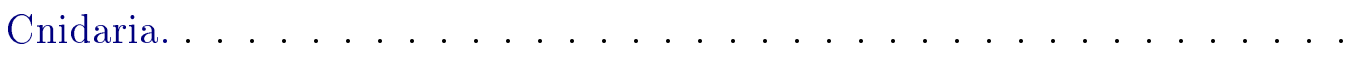

1.2 Imagens obtidas usando o SMCP: (a) Cladocera, (b) Cnidaria, (c) Diatomea, e (d) Filamento. . . . . . . . . . . . . . . . . . . . 3

1.3 Pipeline do procedimento típico para a classificação de plâncton. . . . . . . 5 5

2.1 Imagens adquiridas pelo SMCP usando MCC ou do inglês Bright Field Microscopy - BFM. Fonte: Matuszewski (2014). . . . . . . . . . . . . . . 10

2.2 Processo de detecção de alvos em um fluxo contínuo de amostras usando o FlowCAM. O quadro de borda preta representa o campo de visão da câmera e os quadros de borda vermelha indicam dois objetos-alvo detectados em sequência pelo software do FlowCAM. Fonte: http://info.fluidimaging.com/how-the-flowcam-works. . . . . . . . . . .

2.3 Fluxo de dados do método de processamento de sequência de vídeo baseado na técnica de Ritmo Visual. Fonte: Matuszewski et al. (2013) . . . . . . . .

2.4 Exemplos de objetos recortados pelo SMCP: (a) (c) detrito, (d) aglomerado planctônico, (e) aglomerado não planctônico, (f) objeto não identificado, (g) objeto irreconhecível, $(\mathrm{h}) \sim(\mathrm{j})$ plâncton. . . . . . . . . . . . . 13

2.5 Exemplos de imagens de plâncton (adquiridas pelo SMCP) segmentadas. . . 13

4.1 Da esquerda para a direita: Calanoida, Cyclopoida, Filamento grosso, e Neoceratium. As duas primeiras imagens apresentam contraste relativamente bom e contorno suficientemente claro enquanto as duas últimas estão borradas e sem contorno claro. . . . . . . . . . . . . . . . . 27

4.2 Exemplos de 2 binarizações levemente diferentes. . . . . . . . . . . . 28

4.3 Diagrama de uma cadeia de processamento. . . . . . . . . . . . . . . 29

4.4 Amostras de 4 classes de plâncton e suas respectivas segmentações usando os 6 métodos. De cima para baixo, Neoceratium, Chaetoceros fora de foco, Copepoda morto, e Chaetoceros. (a) imagem de entrada, e segmentações pelos métodos (b) Yen, (c) Otsu, (d) Isodata, (e) Fixo, (f) Dinâmico, e (g) Watershed. . . . . . . . . . . . . . . . . . . . . 
4.5 Amostras de 3 classes de plâncton, segmentadas usando o método Fixo, com valores de limiarização 170 e 180. De cima para baixo: filamentos grossos (primeira e segunda linhas), Neoceratium fora de foco (terceira e quarta linhas), e Neoceratium (quinta e sexta linhas). Melhores resultados são obtidos com

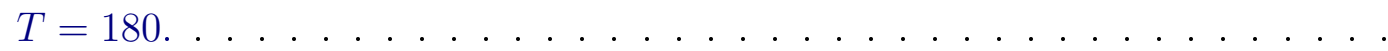

4.6 Amostras de 5 classes de plâncton, segmentadas usando o método Fixo, com valores de limiarização 170 e 180. De cima para baixo, Coscinodiscus Thalassiosira, Neoceratium, chaetoceros desfocados, filamentos finos e Odontella sinensis. Melhores resultados são obtidos com $T=170 \ldots \ldots$. . . . . . . . 38

5.1 Diagrama do método de classificação proposto MultSeg. Dado J métodos de segmentação e um dataset de $\mathrm{C}$ classes. $\mathrm{O}$ dataset correspondente a cada método de segmentação passa por um processo de extração de características, o qual gera um vetor de características $\mathrm{X}_{i}, 1 \leq i \leq J$. Para cada $\mathrm{X}_{i}$, classificadores binários são treinados utilizando o esquema OVR. Para predizer a classe de um exemplo x', o classificador final calcula CJ scores. A classe predita para x' é a classe c do $f_{c}^{j}\left(x^{\prime}\right)$ cujo score foi o maior entre os CJ classificadores binários. . . . . . . . . . . . . . . . . .

6.1 Exemplares das 18 classes do dataset. A identificação da classe, número de exemplares na classe (e percentagem com repeito ao total de 5074 amostras) são apresentados abaixo de cada exemplar. . . . . . . . . . . . .

6.2 Exemplos de similaridade de amostras da classe Detritus e de outras classes. (a) - (e) amostras da classe detritus; (f) Appendicularia; (g) Dinoflagellate; (h) Cop.(no antenna); (i) Nauplii; (j) Penilia. . . . . . . . . . . . . . 57

A.1 Exemplares do dataset com 16 classes, cedido por Matuszewski (2014). . . 64

B.1 Amostras de 8 classes de plâncton e suas respectivas segmentações usando os 6 métodos. De cima para baixo, Pyrocystis, Coscinodiscus, Odontella sinesis, Copepoda Cyclopoida, Chaetoceros, Copepoda (Oithona) fora de foco, Neoceratium fora de foco, e Copepoda sem antena. . . . . . . . . . . .

B.2 Amostras de 8 classes de plâncton e suas respectivas segmentações usando os 6 métodos. De cima para baixo, Neoceratium, Copepoda Calanoida (Acartia), Copepoda pulando, filamentos finos, Chaetoceros fora de foco, Copepoda morto, Filamento grosso, e Nauplius fora de foco. . . . . . . . . . . . 


\section{Lista de Tabelas}

3.1 Matriz de confusão de um problema multi-classe. . . . . . . . . . . . . 22

4.1 10-fold CV usando o SVM. . . . . . . . . . . . . . . . . . 32

4.2 CV por classe usando SVM. . . . . . . . . . . . . . . . . . 33

4.3 Acurácia 10-fold CV: modelos de classificadores $\times$ métodos de segmentação. 34

4.4 Acurácia da CV 10-fold usando SVM com subconjuntos de características selecionadas. . . . . . . . . . . . . . . . . . 35

4.5 Acurácia da CV 10-fold usando SVM sobre imagens segmentadas com/sem pre-processamento. . . . . . . . . . . . . . 36

4.6 Acurácia da CV 10-fold usando SVM sobre imagens segmentadas com o método Fixo, para diferentes limiares $(\mathrm{T}) \ldots \ldots$. . . . . . . . . . . . 36

5.1 Avaliação das segmentações usando 10-fold CV sobre o conjunto de dados $S$.

5.2 Estimação do potencial usando informação privilegiada. Segmentação fixa versus segmentação "correta" para cada classe (de acordo com os resultados da tabela 5.1). . . . . . . . . . . . . . . . . . 46

5.3 Acurácia da classificação calculada sobre T: comparação entre uso de segmentação fixa e método MultSeg. . . . . . . . . . . . . . . . . . . 47

6.1 Características extraídas de uma imagem de plâncton segmentada. . . . . . 52

6.2 Avaliação global dos métodos de segmentação. . . . . . . . . . . . . . . . . 54

6.3 Avaliação das segmentações usando 10-CV sobre $S_{1} \ldots \ldots \ldots$. . . . . . 54

6.4 Avaliação das segmentações usando 4-CV sobre $S_{1}$. . . . . . . . . . . 55

6.5 Classificação de plâncton usando segmentações fixas versus o potencial sobre $T_{1}$ usando 10-fold CV na avaliação das segmentações. . . . . . . . . . . 56

6.6 Médias das acurácias globais obtidas nas 4 iterações. Em todos os casos foi utilizada 10-fold CV na avaliação de segmentações. . . . . . . . . . . . . 57

6.7 Médias das acurácias obtidas nas 4 iterações, detalhadas por classe. . . . . . 58

6.8 Acurácia sobre $T_{1}$ usando o método Multseg versus segmentação fixa. . . 59

6.9 Tabela resumo das acurácias obtidas: classificação usando métodos de segmentação fixo, avaliação do potencial e classificação final. . . . . . . . . . . . 60 
B.1 Métodos de segmentação considerados neste trabalho. . . . . . . . . . . . 67 


\section{Capítulo 1}

\section{Introdução}

Plâncton são organismos geralmente microscópicos, medindo poucos micrômetros ou alguns milímetros. Por exemplo, temos o femtoplâncton de tamanho menor que $0.2 \mu \mathrm{m}$, o picoplâncton entre 0.2 e $2 \mu \mathrm{m}$, nanoplâncton entre 2 e $20 \mu \mathrm{m}$, microplâncton entre 20 e 200 $\mu \mathrm{m}$ e mesoplâncton de 200 a $2000 \mu \mathrm{m}$ (Finkel et al., 2010; Sieburth et al., 1978). Assim, podemos observá-los com auxílio de um microscópio ou através de um equipamento especializado (Gorsky et al., 2010; Grosjean et al., 2004; Le Bourg et al., 2015; Marcolin et al. , 2015; Matuszewski et al., 2013; Álvarez et al., 2012). Eles podem ser encontrados tanto na água do mar, quanto na água doce. Segundo seu tipo de alimentação, esses organismos podem ser divididos em fitoplâncton - aqueles que fazem a fotossíntese, e zooplâncton aqueles que se alimentam de outros organismos vivos (Falkowski, 2012).

Os organismos planctônicos têm uma grande importância para o ecossistema marinho e no geral, para o planeta, uma vez que constituem a base da cadeia alimentar e são os maiores produtores de oxigênio na terra (Henson et al., 2012; Zeebe, 2012). Sabe-se que danos que afetam direta ou indiretamente esses organismos, tais como a descarga de esgotos e o derramamento de petróleo, podem causar mudanças climáticas (Barange, 2010; Falkowski, 2012; Hays et al., 2005; Hooff e Peterson, 2006; Richardson , 2008) e desestruturação do equilíbrio trófico (Castellani, 2009). Além disso, existem estudos nos quais o plâncton têm sido pesquisado para outros fins, como por exemplo: a produção de biocombustíveis (Brennan e Owende, 2010; Mata et al., 2010), tratamento de águas residuais (Aslan e Kapdan, 2006; Hoffmann, 1998; Martinez et al., 2000), aquicultura (Chuntapa et al., 2003), entre outros (Brennan e Owende, 2010; Mata et al., 2010). Por isso, cientistas estão interessados no estudo da ecologia e biologia do plâncton marinho, incluindo a análise dos padrões de distribuição em variadas escalas espaciais e temporais, bem como em estudos comportamentais do fito e zooplâncton em resposta às interações biológicas e problemas ambientais. 
Uma das tecnologias cada vez mais utilizadas no estudo de plâncton são os equipamentos de imageamento, incluindo scanners e câmeras de vídeo, aliados a técnicas ópticas como microscopia, holografia e laser. Entre alguns equipamentos bastante citados na literatura da área estão o Zooscan e FlowCAM (Gorsky et al., 2010; Grosjean et al., 2004; Le Bourg et al., 2015; Marcolin et al., 2015; Matuszewski et al., 2013; Álvarez et al., 2012) e equipamentos de holografia digital (Culverhouse et al., 2006; Dominguez-Caballero et al., 2007; Dyomin et al., 2011; Malkiel et al., 1999; Sun et al., 2008).

Este trabalho é fruto de uma colaboração entre o Laboratório e-Science do IME/USP que, entre outras áreas, desenvolve pesquisa em análise de imagens e aprendizado de máquina, e o Laboratório de Sistemas Planctônicos (LAPS) do IO/USP que estuda organismos planctônicos. O problema concreto abordado nesta dissertação é a classificação (identificação de espécie) de plâncton observados nas imagens obtidas pelos pesquisadores do LAPS-IO/USP. Esse problema é denominado simplesmente de classificação de plâncton neste trabalho.

O LAPS vem utilizando equipamentos comerciais tais como o FlowCAM (Le Bourg et al. , 2015) e o ZooScan (Gorsky et al., 2010; Grosjean et al., 2004; Marcolin et al., 2015; Álvarez et al., 2012). Além disso, ao longo dos últimos anos, o LAPS vem também desenvolvendo vários equipamentos para imageamento de volumes de água tais como os baseados em holografia digital, LOPC (Laser Optical Particle Counter), Sistema de Monitoramento Contínuo de Plâncton (SMCP) (Matuszewski, 2014), e microscopia usando filmagem (Mattiello , 2014). As figuras 1.1 e 1.2 mostram imagens de plâncton obtidas respectivamente pelo Zooscan e pelo SMCP.

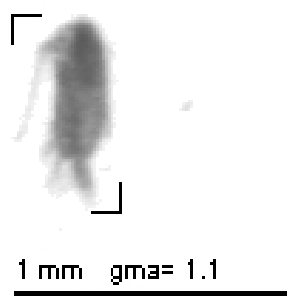

(a)

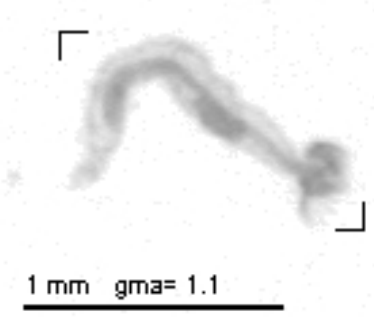

(b)

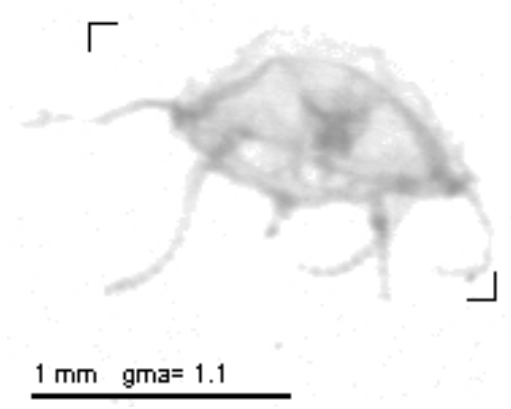

(c)

Figura 1.1: Imagens obtidas usando o Zooscan: (a) Calanoida, (b) Chaetognatha, e (c) Cnidaria.

A análise de imagens adquiridas pelos equipamentos comerciais é feita usando softwares específicos que acompanham o equipamento. Além do custo envolvido, os mesmos muitas vezes não oferecem flexibilidade para serem adaptados para diferentes tipos de imagens.

Já em relação aos equipamentos desenvolvidos no próprio laboratório, softwares de análises existentes precisam ser adaptados ou novos softwares precisam ser desenvolvidos. O desenvolvimento do SMCP, juntamente com uma proposta de um pipeline de processamento 


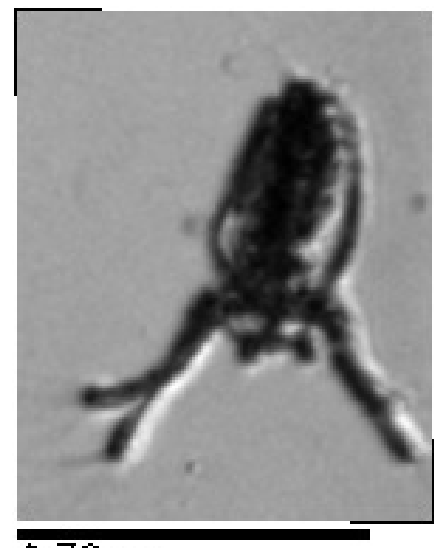

(a)

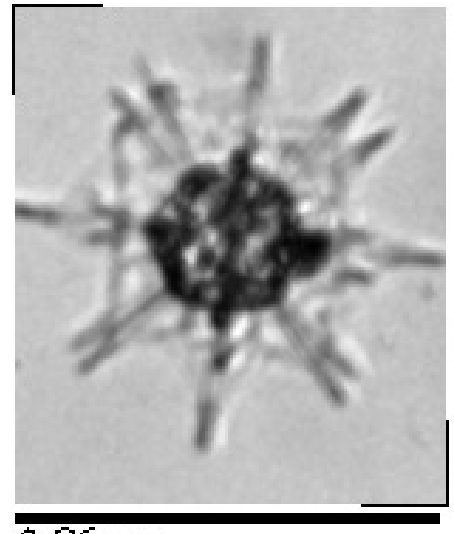

(b)

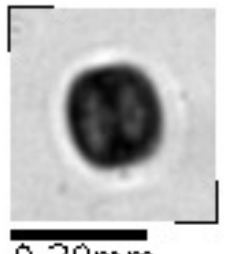

(c)

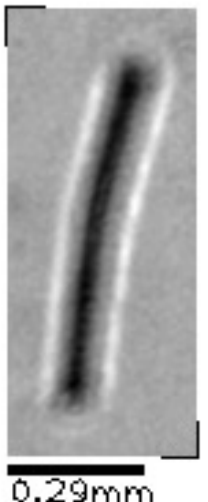

(d)

Figura 1.2: Imagens obtidas usando o SMCP: (a) Cladocera, (b) Cnidaria, (c) Diatomea, e (d) Filamento.

para a análise de imagens e identificação de espécie (classificação de plâncton), é abordado na dissertação de Matuszewski (2014). Em termos de software, foi desenvolvido um sistema que contempla desde o controle da aquisição de imagens até a classificação dos alvos capturados nas imagens. No entanto, as imagens processadas foram obtidas em laboratório e o tratamento dado ao problema de identificação de espécies (classificação) foi apenas preliminar. Portanto, verificou-se uma clara necessidade de prosseguimento ao desenvolvimento de métodos computacionais para a classificação de plâncton observados nas imagens obtidas por esse tipo de equipamento. Os principais desafios relacionam-se à classificação de imagens coletadas in situ.

Um levantamento inicial dos requisitos de um sistema computacional para a análise de imagens de plâncton, visando a identificação das espécies, levou-nos a considerar alguns aspectos importantes, dos quais destacamos dois:

- robustez à variação nas características das imagens: coletas realizadas in situ podem gerar imagens com diferentes características uma vez que não se pode controlar o ambiente. Diferenças no ambiente tais como quantidade de luz, profundidade na água, densidade de organismos na água, presença ou ausência de detritos na região, acúmulo de resíduos na lente do equipamento, entre outros fatores podem afetar as características das imagens. Além disso, diferentes sistemas de imageamento tendem a gerar imagens com características distintas.

- espécies desconhecidas: um classificador para identificar espécies é em geral projetado considerando-se um conjunto finito de espécies a serem reconhecidas. Porém, na prática, uma imagem pode capturar uma espécie desconhecida (pelo sistema classificador ou até mesmo pelos especialistas da área). Além disso, detritos podem aparecer nas mais diversas formas e, muito possivelmente, com aparências e formas não previstas 
pelo sistema classificador.

Neste trabalho examinamos o problema de classificação de plâncton tendo esse pano de fundo geral descrito acima em vista. Em outras palavras, o método de classificação de plâncton deve ser flexível no sentido de permitir sua adaptação para imagens com diferentes características.

Ao analisarmos as abordagens utilizadas para classificação de imagens de plâncton descritas na literatura (Gorsky et al., 2010; Grosjean et al., 2004; Le Bourg et al., 2015; Matuszewski, 2014), observamos que a maioria deles segue um procedimento comum. O procedimento amplamente adotado consiste das cinco etapas descritas a seguir e ilustradas na figura 1.3:

- aquisição de imagens: as imagens podem ser obtidas por meio de escaneamento ou uma câmera acoplada ao microscópio, por exemplo;

- detecção de alvos: uma imagem tipicamente pode conter mais de um objeto. O isolamento consiste em recortar cada alvo individualmente, gerando imagens contendo apenas um alvo;

- segmentação: consiste no delineamento do contorno dos alvos;

- extração de características: descrição dos alvos por meio de um conjunto de atributos (visuais, geométricos, etc);

- classificação propriamente dita: associação de um rótulo (classe) que identifica a espécie. A classificação é realizada por classificadores previamente definidos, usando o conjunto de características que descrevem o alvo.

Enquanto a aquisição de imagens e a detecção de alvos estão altamente relacionadas ao equipamento utilizado e ao tipo de dado gerado por ele (imagem, vídeo, holograma, etc), as demais etapas podem ser tratadas de forma independente do equipamento em questão. No entanto, os resultados de segmentação podem depender das características da imagem (resolução, contraste, foco, etc). A escolha de um bom método de segmentação é importante uma vez que as etapas subsequentes dependem dela. 


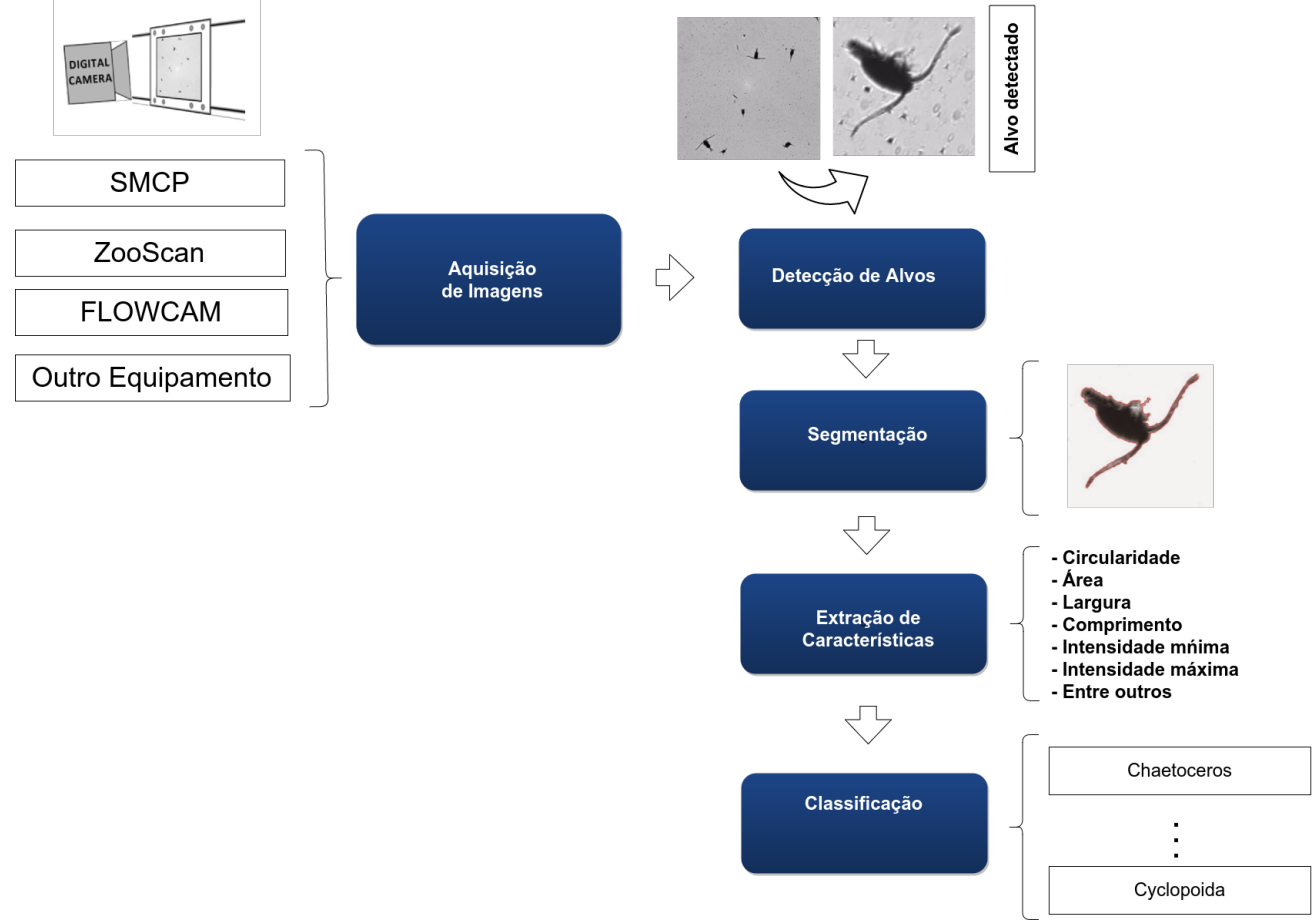

Figura 1.3: Pipeline do procedimento típico para a classificação de plâncton. 


\subsection{Objetivos e proposta}

O principal objetivo deste trabalho é o desenvolvimento de um método computacional para a classificação de imagens de plâncton que seja versátil o suficiente para ser adaptado para diferentes sistemas de imageamento.

Conforme mencionado acima, um dos principais assuntos a serem tratados na classificação de imagens de plâncton é a escolha do método de segmentação. Portanto, uma primeira questão considerada neste trabalho é a avaliação da qualidade de uma segmentação.

Na literatura, usualmente essa avaliação é realizada por meio de inspeção visual, mediante a comparação da imagem segmentada e correspondente Ground-Truth, ou avaliando-se o valor de uma função objetivo. Todos esses métodos tem suas limitações: precisam do usuário para a avaliação manual, ou para a definição do Ground-Truth, ou para incorporar propriedades da segmentação desejada na função objetivo. Além disso, qualquer inspeção visual exigiria a análise de um grande número de segmentações. Considerando-se que o número de classes pode ser muito grande (centenas) e que cada classe pode ter centenas ou milhares de imagens, a carga de trabalho poderá ser imensa. Mais do que isso, no caso da geração do Ground-Truth, teríamos que lidar com questões críticas que não se restringem apenas à carga de trabalho, mas também à necessidade de se repetir o trabalho sempre que houver mudanças significativas nas características das imagens.

Por outro lado, tarefas de alto-nível tais como a detecção ou classificação de objetos podem ser realizadas com menos dificuldade do que uma tarefa de baixo-nível tal como a delineação dos contornos de um objeto-alvo. Baseado nesse fato, propomos na parte inicial do trabalho, um método para avaliar métodos de segmentação de forma indireta; isto é, usamos a acurácia da classificação como uma forma de avaliação de métodos de segmentação. Experimentos iniciais usando essa forma de avaliação indicaram que o método de segmentação que resulta em melhor taxa de classificação sobre todas as classes não necessariamente resulta em melhor taxa de classificação para cada uma das classes. Ao analisarmos as taxas de acerto por classe, é possível identificarmos para cada classe um melhor método de segmentação, que não necessariamente é o mesmo de uma outra classe.

A partir dessa observação, uma segunda questão que abordamos é como utilizar essa informação no processo de classificação. É possível, ao utilizarmos múltiplos métodos de segmentação, obter classificadores com melhor taxa de classificação do que quando usamos um único método de segmentação ?

Na segunda parte do trabalho propomos um método de classificação que utiliza as informações provenientes de múltiplos métodos de segmentação. Especificamente, em vez de fixar um método de segmentação, os resultados de classificadores treinados a partir de diferentes segmentações são combinados, na expectativa de que o classificador final utilize 
implicitamente a melhor segmentação para cada objeto-alvo a ser classificado.

\subsection{Contribuições}

Esta dissertação apresenta duas contribuições importantes.

1. Um método para a avaliação de segmentações a partir da acurácia da classificação, visando a escolha de um método de segmentação a ser usado no pipeline de classificação de imagens de plâncton. Esse método resultou em um artigo (Fernandez et al., 2015), apresentado no SIBGRAPI 2015 (Conference on Graphics, Patterns and Images).

2. Um método para a classificação de imagens de plâncton baseado em múltiplas segmentações. Esse método resultou em um artigo (Hirata et al., 2016) apresentado no CVAUI 2016 (2nd Workshop on Computer Vision for Analysis of Underwater Imagery).

\subsection{Organização do trabalho}

O presente trabalho consiste desta introdução e de mais 6 capítulos. No capítulo 2 descrevemos cada uma das etapas do pipeline típico para classificação de imagens de plâncton, e examinamos como elas são tratadas em alguns dos trabalhos relacionados da literatura e que serviram como referências para esta dissertação.

No capítulo 3 apresentamos algumas notações, conceitos e terminologias relacionadas à classificação, no contexto de aprendizado de máquina, e que serão utilizadas ao longo do texto.

No capítulo 4 fazemos uma breve descrição dos principais métodos sobre avaliação de segmentações e comentamos as características desses métodos que os fazem inadequados para as necessidades deste trabalho. Em seguida apresentamos também o método proposto nesta dissertação para avaliar a segmentação de forma indireta. A avaliação é feita por meio da avaliação do desempenho na classificação. Ao final, ilustramos a aplicação da avaliação proposta em um conjunto de imagens de plâncton e mostramos algumas das informações que podem ser obtidas a partir dos resultados da avaliação.

No capítulo 5 conjecturamos que se de alguma forma fosse possível escolher para cada alvo a ser classificado um método de segmentação que favoreça o seu reconhecimento, uma melhor taxa de reconhecimento global poderia ser atingido. Investigamos essa questão e propomos um método para combinar o resultados de múltiplas segmentações na classificação e ilustramos a aplicação do método no mesmo conjunto de dados usado no capítulo anterior. 
No capítulo 6 apresentamos e discutimos os resultados experimentais do método de avaliação da segmentação e do uso de múltiplas segmentações na classificação de imagens de plâncton coletadas in situ.

No Capítulo 7 apresentamos as conclusões deste trabalho e fazemos sugestões para trabalhos futuros. 


\section{Capítulo 2}

\section{Pipeline típico para classificação de imagens de plâncton}

O problema de classificação automática de imagens de plâncton (reconhecimento ou identificação de plâncton a partir de imagens), vem sendo trabalhado há vários anos (por exemplo, Jeffries et al. (1984, 1980); Tang et al. (1998)). Com o desenvolvimento de equipamentos capazes de gerar imagens de melhor qualidade e em grande escala, percebe-se o crescimento do interesse por esse problema. Excetuando-se os trabalhos mais recentes (Py et al., 2016b) que utilizam métodos de classificação baseados em redes convolucionais, a maioria segue um pipeline de processamento padrão para a classificação. O procedimento consiste de basicamente 5 etapas: (i) aquisição de imagens, (ii) detecção de alvos, (iii) segmentação, (iv) extração de características e (v) classificação, conforme já mencionado na introdução (Fig. 1.3). Neste capítulo apresentamos uma descrição de cada uma dessas etapas, examinando como elas são tratadas em alguns dos trabalhos relacionados da literatura e que serviram como referências para esta dissertação.

\subsection{Aquisição de imagens}

Na etapa de aquisição de imagens, um conjunto de imagens de plâncton é gerado por meio de sistemas de imageamento desenvolvidos para processar grandes ou pequenos volumes de água com partículas e organismos microscópicos. Esse procedimento pode ser realizado in situ (por exemplo, no mar) ou em ambientes controlados (por exemplo, nos laboratórios).

Os sistemas de imageamento surgiram influenciados pela necessidade de resolver as limitações dos métodos tradicionais de coleta de amostras (redes de plâncton ou as garrafas de Niskin) (De Bernardi, 1984). Um dos principais desafios era reduzir o tempo de processamento por amostra, o qual é realizado manualmente por um especialista bem treinado. $\mathrm{O}$ 
processamento manual, além de ser laborioso, intenso e demorado, é sujeito a erros devido à fadiga associada à análise de um grande número de partículas (objetos-alvos).

No intuito de resolver essas dificuldades, distintos sistemas de imageamento baseados em distintas técnicas ópticas foram e estão sendo desenvolvidos para serem usados in situ ou com amostras preservadas. Entre eles, temos os filmes fotográficos (Ortner et al., 1979), imageamento de vídeo (Jeffries et al., 1984, 1980), scanner de mesa (Little e Copley, 2003), câmeras fixas colocadas em redes de plâncton ${ }^{1}$ (Ortner et al., 1981), câmeras de vídeo acopladas a uma rede de plâncton (Froese et al., 1990), sistema de vídeo-microscópio sem auxílio de uma rede de plâncton (Davis et al., 1992), scanners customizados para amostras preservadas (Bell e Hopcroft, 2008; Gorsky et al., 2010; Grosjean et al., 2004), sistemas baseados em gravações de vídeo em tempo real (Davis et al., 2004; Luo et al., 2004; Matuszewski et al. , 2013), sistemas com câmera integrada para amostras preservadas (Blaschko et al., 2005; Le Bourg et al., 2015) e sistemas holográficos (Chalvidan et al., 1998; Watson et al., 2003). Particularmente tem aumentado o interesse pelo desenvolvimento de sistemas de imageamento in situ (Benfield et al., 2007).

Por exemplo, em um trabalho prévio realizado no LAPS/IO-USP (Matuszewski, 2014), o imageamento de volumes de água foi realizado por meio de um sistema aqui denominado de SMCP (Sistema de Monitoramento Contínuo de Plâncton) usando microscopia de campo claro $(\mathrm{MCC})^{2}$, a qual permite conservar detalhes morfológicos dos objetos, úteis para uma melhor identificação, com menos objetos desfocados. Na figura 2.1 podemos ver alguns exemplos de imagens adquiridas pelo SMCP.
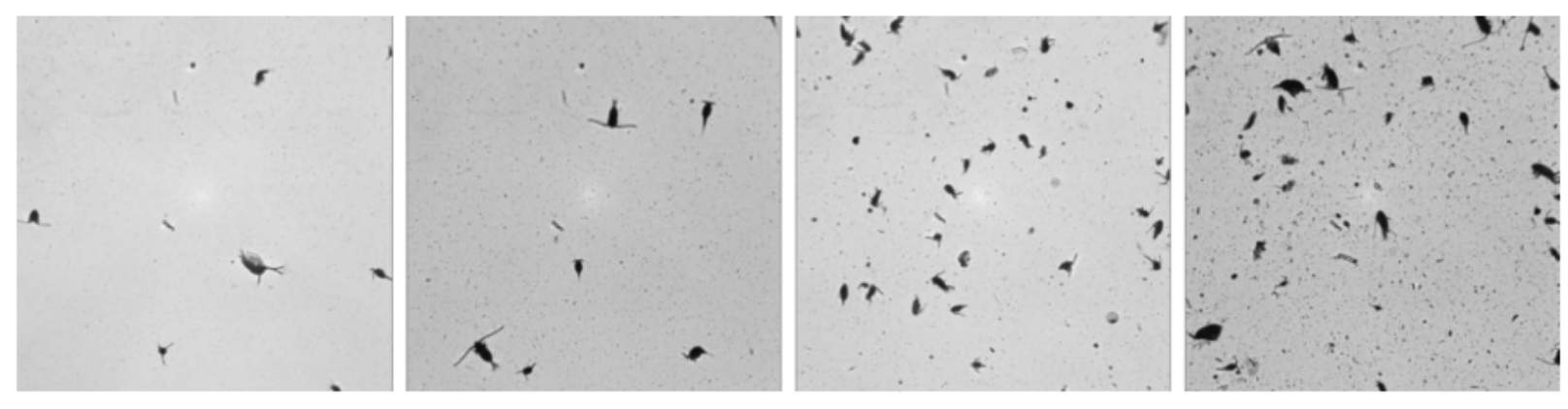

Figura 2.1: Imagens adquiridas pelo SMCP usando MCC ou do inglês Bright Field Microscopy BFM. Fonte: Matuszewski (2014).

\footnotetext{
${ }^{1}$ Redes de plâncton, do inglês plankton nets, são redes em forma cônica para capturar plâncton in situ.

${ }^{2}$ MCC (microscopia de campo claro, do inglês Bright Field Microscopy - BFM) é uma técnica de imageamento que usa um diodo emissor de luz azul de 1 watt e $455 \mathrm{~nm}$ de comprimento de onda.
} 


\subsection{Detecção de alvos}

Uma imagem adquirida pelos sistemas citados acima pode tipicamente conter mais de um alvo (por exemplo, as mostradas na figura 2.1). Portanto, na etapa de detecção de alvos o objetivo é o isolamento de cada alvo, gerando-se subimagens consistindo de recortes retangulares contendo apenas um alvo.

Existem sistemas de imageamento nos quais a deteç̧ão de alvos funciona de forma implícita na aquisição de imagens, ou seja, a detecção de alvos é um processo que é realizado durante a aquisição de imagens. Por isso, não é incomum a aquisição de imagens e a detecção de alvos serem consideradas uma única etapa. Por exemplo, o FlowCAM (http://www.fluidimaging.com/products/flowcam-vs), bastante citado na literatura (Blaschko et al., 2005; Le Bourg et al., 2015; Álvarez et al., 2011), combina as tecnologias de citometria de fluxo, microscopia e detecção de fluorescência. Medidas e imagens das partículas em um fluxo contínuo com amostras de organismos são obtidas simultaneamente. A partir de cada imagem digital gerada são isolados e segmentados os objetos-alvo e esses podem ser armazenados individualmente juntamente com as medidas extraídas de cada objeto-alvo. O processo de detecção de objetos-alvo é feito em tempo real utilizando processamento de imagens.

A figura 2.2 ilustra esse procedimento. À esquerda, é mostrado o fluxo na direção vertical, de cima para baixo, e a ativação de uma câmera em resposta à passagem de alvos. À direita, o quadro de borda preta representa o campo de visão da câmera, e os quadros de borda vermelha ilustram dois exemplos de recortes realizados sequencialmente e em tempo-real pelo software do FlowCAM.

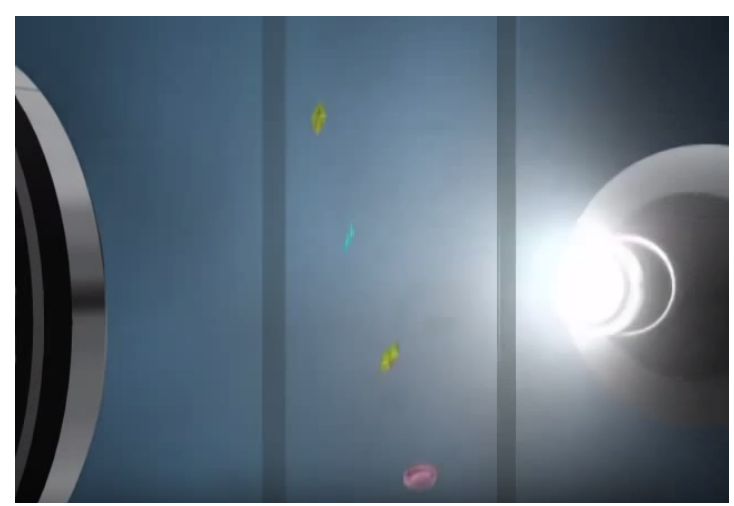

(a)

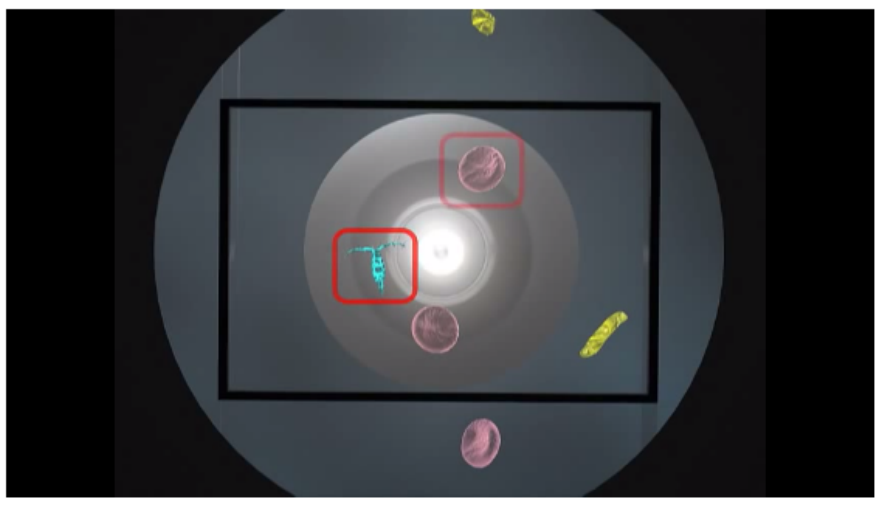

(b)

Figura 2.2: Processo de detecção de alvos em um fluxo contínuo de amostras usando o FlowCAM. O quadro de borda preta representa o campo de visão da câmera e os quadros de borda vermelha indicam dois objetos-alvo detectados em sequência pelo software do FlowCAM. Fonte: http://info.fluidimaging.com/how-the-flowcam-works. 
Já outros sistemas como o SMCP realizam a aquisição de imagens e a detecção de alvos de forma independente. Após a aquisição das imagens, no SMCP a detecção dos alvos é realizada usando um método denominado Ritmo Visual (RV) em lugar de uma abordagem frame-by-frame. O método RV melhora o tempo de cálculo por frame e evita eventuais capturas repetidas de um mesmo objeto (Matuszewski et al. (2013)). A figura 2.3 mostra o fluxo de dados no método de processamento de sequência de vídeo baseado na técnica de RV. A técnica de RV pode ser aplicada a sequências de vídeo nas quais há um fluxo em uma determinada direção. No exemplo da figura 2.3, na sequência de frames mostrada à esquerda, o fluxo está na direção vertical de cima para baixo. A imagem de RV é tal que cada uma de suas linhas corresponde a uma linha de um frame, em uma altura previamente fixada. Desta forma, dada uma sequência de $n$ frames, obtém-se uma imagem de ritmo visual com exatamente $n$ linhas. Quando um objeto encontra-se na altura fixada num dado frame da sequência, a linha correspondente na imagem de RV apresenta valores mais claros, indicando a presença de um objeto. Como pode ser visto na figura 2.3, na imagem processada do RV, a presença desses objetos são destacados, e uma vez que a linha corresponde ao número do frame, o objeto pode ser facilmente recortado do frame correspondente.

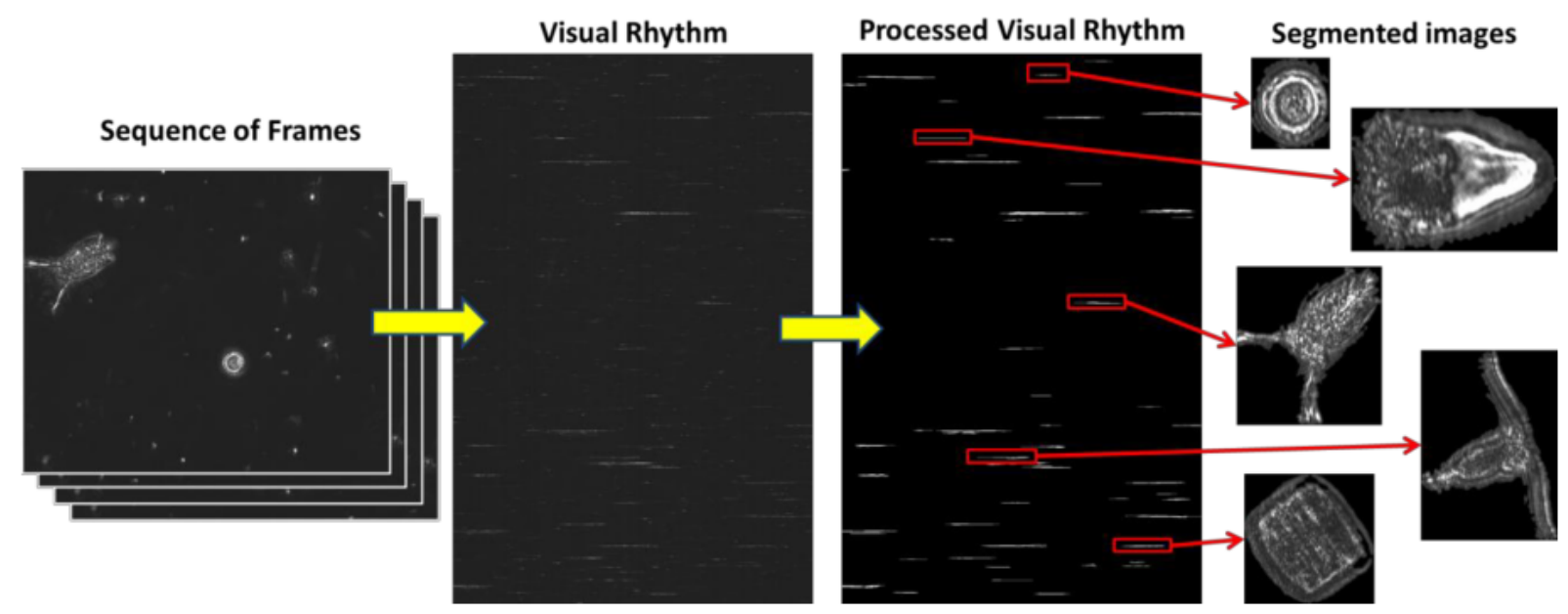

Figura 2.3: Fluxo de dados do método de processamento de sequência de vídeo baseado na técnica de Ritmo Visual. Fonte: Matuszewski et al. (2013)

Em imagens de fundo claro pode-se aplicar a mesma técnica. A única diferença é que os alvos são escuros, como nos exemplos mostrados na figura 2.4 .

\subsection{Segmentação}

Após os objetos-alvos serem isolados, o próximo passo é a segmentação, que consiste na separação do objeto-alvo do fundo. A segmentação pode ser tratada como um problema de delineação dos contornos do objeto a ser segmentado ou, equivalentemente, como um problema de identificação da região (pixels) que formam o objeto. A região do alvo e seus 


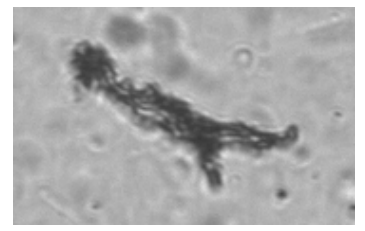

(a)

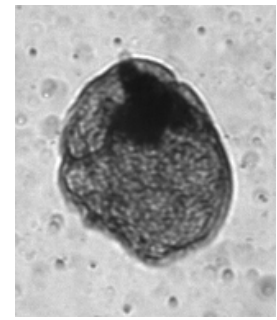

(f)

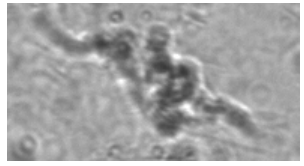

(b)

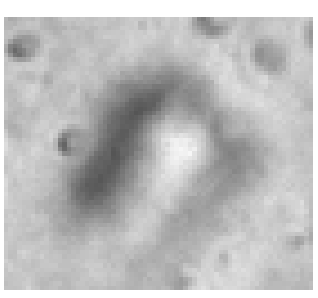

(g)

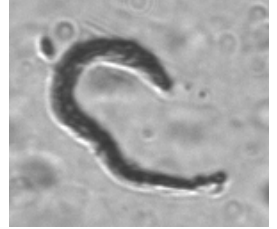

(c)

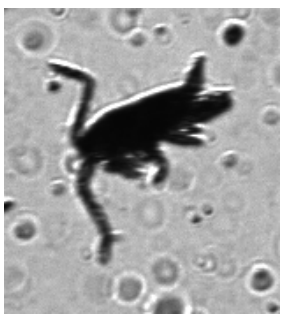

(h)

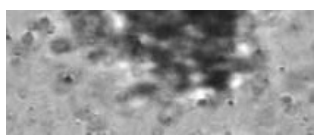

(d)

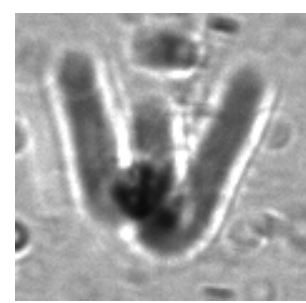

(i)

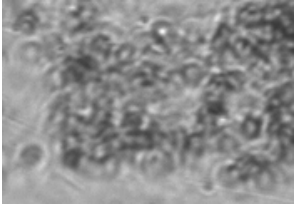

(e)

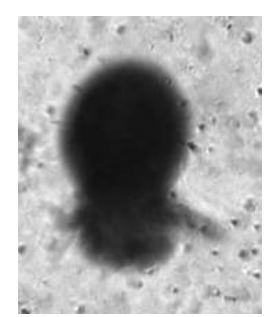

(j)

Figura 2.4: Exemplos de objetos recortados pelo SMCP: (a) (c) detrito, (d) aglomerado planctônico, (e) aglomerado não planctônico, $(f)$ objeto não identificado, $(g)$ objeto irreconhecível, $(h) \sim(j)$ plâncton.

contornos são importantes para a identificação do plâncton. A Fig. 2.5 mostra exemplos de imagens de plâncton e sua respectiva segmentação, nos quais o contorno é mostrado em vermelho, enquanto o plâncton é mantido conforme a imagem original e o fundo é trocado pela cor branca.

A segmentação pode opcionalmente incluir uma etapa de pré-processamento na qual procura-se melhorar a qualidade da imagem por meio de técnicas de remoção de ruído, realce de contraste, ou tratamento das imagens fora de foco, para facilitar a posterior segmentação.

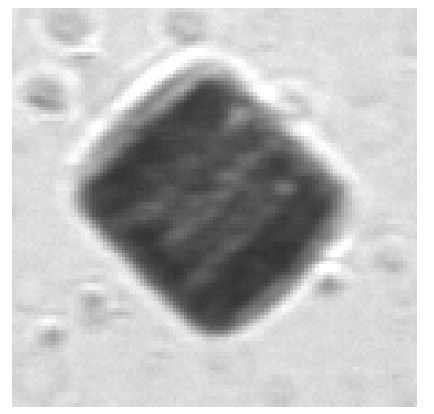

(a)

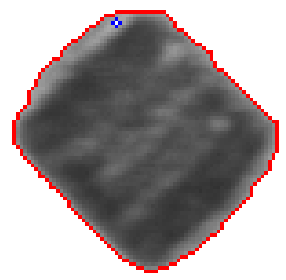

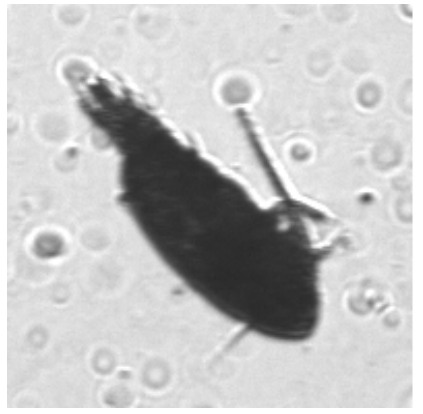

(b)

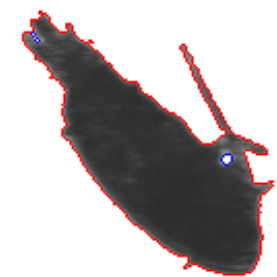

Figura 2.5: Exemplos de imagens de plâncton (adquiridas pelo SMCP) segmentadas.

No trabalho de Blaschko et al. (2005) foi usada uma simples segmentação bimodal global pois o fundo das imagens consideradas era claro e relativamente uniforme. No entanto, em imagens com fundo ruidoso e com objetos sem foco ou com muitos detalhes, a escolha de um método de segmentação torna-se uma tarefa não trivial. Por exemplo, no trabalho de Matuszewski (2014), foram testados 4 métodos de segmentação: limiarização fixa, limiarização dinâmica (limiar variável segundo a média das intensidades dos pixels), Wa- 
tershed (Deng et al., 1999), e Grab-cut (Boykov e Jolly, 2001; Rother et al., 2004). Para evitar a supersegmentação, as imagens sofreram uma filtragem inicial de suavização. $\mathrm{O}$ autor, após analisar os 4 métodos de segmentação sobre 20 imagens, baseado em uma avaliação visual dos resultados e comparação do tempo de processamento, conclui que o Watershed e a limiarização dinâmica ofereceram os melhores resultados.

No reconhecimento de plâncton, a segmentação é considerada um passo importante porque a partir da imagem segmentada serão extraídas as características que posteriormente serão utilizadas na classificação. A escolha de um método de segmentação é influenciada por diferentes fatores tais como o tipo de sistema/equipamento que foi usado para adquirir as imagens, variação da iluminação, resolução, contraste, foco, variação da escala, entre outros.

\subsection{Extração de características}

A extração de características consiste no cálculo de medidas referentes a diversos atributos do objeto em análise, resultando em uma descrição numérica do mesmo. Cada atributo é tipicamente representado por uma variável, denominada geralmente característica no contexto de aprendizado de máquina.

O conjunto de características extraídas é usado posteriormente por técnicas de classificação que visam a identificação da espécie.

As características extraídas relacionam-se em geral com aspectos morfológicos, de cores (intensidade de níveis de cinzas), espectrais, entre outros. Os softwares associados a alguns sistemas/equipamentos de imageamento tais como o FlowCAM (Blaschko et al., 2005) e ZooProcess (Gorsky et al., 2010) incluem diversos extratores na parte de análise de imagens. Na categoria morfológica temos medidas como o comprimento, largura, perímetro, circularidade, dimensão fractal, área do esqueleto, área, perímetro, número de cantos (corners), número de holes, medidas baseadas na curvatura, orientação preferencial dos pontos de contorno, entre outros. Entre as medidas calculadas a partir de níveis de cinzas temos a intensidade mínima, intensidade máxima, intensidade média, transparência, informação de cor, coeficiente de assimetria (skewness), coeficiente de Curtose (kurtosis), entre outros. Outro tipo de medidas que podem também ser obtidas a partir das imagens são os momentos invariantes de $\mathrm{Hu}(\mathrm{Hu}, 1962)$. Na categoria espectral temos por exemplo a frequência, área e largura dos sinais detectadas por canais de fluorescência, as quais podem ser extraídas por equipamentos de imageamento desenhados para extrair esse tipo de características (FlowCAM). Esse tipo de medidas (espectrais) poderiam ser utilizados para discernir tipos de objeto-alvos específicos (por exemplo, detritos) (Álvarez et al., 2012), o qual é um dos grandes desafios na classificação de plâncton. 
Determinar qual tipo de características devem ser extraídas do objeto-alvo depende do tipo de informação que se quer obter ou de cada problema em específico bem como das formas envolvidas (da Fontoura Costa e Cesar, 2009). No geral, em problemas de reconhecimento de plâncton, informações relativas à forma são mais confiáveis, principalmente em imagens de baixa qualidade.

\subsection{Classificação}

A última etapa do pipeline é a classificação, a qual consiste na associação de um rótulo de classe (que identifica as espécies) ao objeto-alvo. A classificação é realizada por meio de classificadores previamente definidos, e que utilizam o conjunto de características que descrevem o objeto.

A classificação de plâncton é uma tarefa desafiadora, abordada na literatura por diversos estudos (Bell e Hopcroft, 2008; Bi et al., 2015; Blaschko et al., 2005; Castellani , 2010; Culverhouse et al., 2006; Davis et al., 2005; Fernandes et al., 2009; Gorsky et al., 2010; Grosjean et al., 2004; Matuszewski, 2014; Álvarez et al., 2012). A dificuldade deve-se em geral à baixa qualidade das imagens, devido a problemas tais como borramento, iluminação irregular, oclusão (organismos sobrepostos), deformação perspectiva (orientações dos organismos), resolução, variação da escala, presença de detritos (partículas de organismos mortos e sujeira), águas turvas (Álvarez et al., 2012), entre outros. Além disso, diferentes dispositivos produzem diferentes tipos de imagens (por exemplo, imagens estáticas, sequência de vídeos, ou hologramas) e poderiam afetar também a qualidade da imagem.

Na literatura, em relação à classificação de imagens de plâncton são relatadas acurácias de 70\% - 90\% para problemas com 10 - 20 classes taxonômicas (Benfield et al., 2007). Por exemplo, Matuszewski (2014) relata uma acurácia de 91\% sobre um conjunto com 16 classes.

No entanto, uma comparação entre as taxas de classificação de diferentes estudos é pouco informativo pois cada estudo utiliza um dataset específico (tipo de imagem, número de classes, número de amostras), diferentes processamentos ao longo do pipeline, e algoritmos de classificação com parâmetros diferentes. Portanto é bastante claro que este tema de pesquisa ainda não atingiu um estágio de convergência e portanto o problema de reconhecimento de plâncton e todos os processos que isso implica (etapas do pipeline) devem continuar sendo pesquisados. 



\section{Capítulo 3}

\section{Fundamentos sobre classificação}

Neste capítulo apresentamos algumas notações, conceitos e terminologias relacionadas à classificação, no contexto de aprendizado de máquina, e que serão utilizadas ao longo do texto.

\subsection{Classificação}

No contexto de reconhecimento de padrões, classificação é o processo de atribuir um rótulo a um objeto auxiliado por medidas (atributos/características) que descrevem o objeto (Kuncheva, 2004). Existem dois grandes tipos de problemas de reconhecimento de padrões: o supervisionado ( supervised learning) e o não-supervisionado ( unsupervised learning). Nos problemas não-supervisionados procura-se verificar se existe alguma estrutura no conjunto de dados analisado, enquanto nos supervisionados um classificador é "treinado", a partir de amostras de dados pré-classificados, a atribuir um rótulo de classe aos objetos. O tipo de classificação considerado nesta dissertação é o supervisionado.

Os classificadores são treinados usando o conjunto de características que descrevem os objetos. Formalmente, se denotamos por $X$ o espaço de características (geralmente o espaço $n$-dimensional $\mathbb{R}^{n}$ ) e por $Y$ o conjunto de rótulos das classes, um exemplo de treinamento é um par $(x, y)$ no qual um elemento $x \in X$ representa um objeto-alvo e o elemento $y \in Y$ é o rótulo que identifica a classe de $x$. Usando essas notações, um classificador pode ser entendido como uma função $f: X \rightarrow Y$.

Na prática, os modelos de classificadores existentes representam a função $f$ implicitamente. Alguns modelos bem conhecidos são, por exemplo, SVM, redes neurais, e árvores de decisão. Esses classificadores recebem em sua entrada um elemento $x$ a ser classificado e produzem em sua saída um rótulo de classe $y$ ou valores que podem ser usados para determinar $y$. 
O processo de treinamento de um classificador consiste em, a partir de um conjunto de amostras de treinamento $S=\left\{\left(x^{(i)}, y^{(i)}\right): i=1,2, \ldots, N\right\}$, ajustar os parâmetros de um modelo, de tal forma que o classificador resultante seja capaz de associar o rótulo correto para os demais elementos em $X$.

Por exemplo, no caso de classificação de plâncton, uma imagem de plâncton pode ser representada por uma tupla $x=\left(x_{1}, x_{2}, \ldots, x_{n}\right)$ na qual $x_{i}$ representa uma característica extraída da imagem (ou a partir da imagem segmentada, conforme descrito na seção 2.4). Um rótulo de classe y é um inteiro que representa uma determinada espécie.

O desenho de um classificador por meio de treinamento envolve algumas questões importantes. Entre elas, destacamos o problema de seleção de características, o treinamento para problemas com múltiplas classes, e a avaliação de classificadores, que são descritos a seguir.

\subsection{Normalização e seleção de características}

Vários dos algoritmos de classificação são baseados em algum critério de distância ou similaridade, explorando a intuição de que objetos similares serão representados por elementos próximos em $X$. Por exemplo, o inverso da distância euclideana mais um (i.e., $\left.\frac{1}{d+1}\right)$ é uma medida de similaridade; a similaridade é máxima quando $d=0$ e descrece à medida que $d$ cresce.

Porém, quando as características consideradas correspondem a medidas de diferentes unidades e escalas, a medida de similaridade calculada matematicamente pode não corresponder à similaridade dos objetos em questão pois características com magnitudes de diferentes escalas podem ter diferentes influências no valor calculado. Para amenizar esse efeito indesejado, uma prática comum é a normalização ou padronização de dados.

Antes de descrever duas possíveis normalizações, introduzimos algumas notações:

- $x_{i}$ denota um componente de $x=\left(x_{1}, x_{2}, \ldots, x_{n}\right)$ e corresponde a uma característica

- $m_{i}$ corresponde ao mínimo entre todos os valores observados para a característica $x_{i}$

- $M_{i}$ corresponde ao máximo entre todos os valores observados para a característica $x_{i}$

- $\tilde{x}_{i}$ denotará o valor normalizado de $x_{i}$

Uma primeira normalização, que mapeia todos os valores ao intervalo [0,1], é dada pela equação 3.1:

$$
\tilde{x}_{i}=\frac{\left(x_{i}-m_{i}\right)}{M_{i}-m_{i}}
$$


Uma segunda normalização, que mapeia todos os valores ao intervalo $[-1,1]$, é dada pela equação 3.2:

$$
\tilde{x}_{i}=\frac{x_{i}-\left(\frac{M_{i}+m_{i}}{2}\right)}{\left(\frac{M_{i}-m_{i}}{2}\right)} .
$$

A normalização, além de mapear todas as características para uma mesma escala de magnitude, permitindo comparações de desvios padrões por exemplo, atende o requisito de alguns algoritmos de aprendizado. Por exemplo, a formulação da função objetivo a ser otimizada em algoritmos (tal como o SVM com kernel RBF) assume que todas as características estão centradas em torno do 0 e tem variância de mesma ordem.

\subsubsection{Seleção de características}

As características interessantes em problemas de classificação são aquelas que ajudam a discriminar objetos de uma classe dos de outras classes. Nesse sentido, elas podem não ser igualmente relevantes. Por exemplo, duas características altamente correlacionadas podem ter alta redundância. Por outro lado, características que individualmente não possuem relevância podem tornar-se relevantes quando consideradas em conjunto com outras. Portanto, a escolha do conjunto de características é um aspecto importante na solução de um problema de classificação.

Características podem ser definidas a partir de conhecimento prévio, por exemplo, de especialistas do domínio considerado. Porém, em muitas situações diversas características são extraídas, com ou sem a ajuda de especialistas, pois existe um certo entendimento de que quanto mais informações forem coletadas, melhores resultados poderão ser obtidos na classificação. No entanto, características irrelevantes podem afetar o desempenho e a acurácia do classificador (Gorsky et al., 2010). O uso de características redundantes aumenta o custo computacional, sem ganhos na acurácia do classificador, e o uso de características irrelevantes ou ruidosos pode resultar em degradação da acurácia. A seleção de características visa a escolha de um novo conjunto de características $X^{\prime}$ que é um subconjunto de $X$ (conjunto original), que seja suficiente para uma boa discriminação de classes.

A seleção de características pode ser global ou local. A seleção local é realizada por cada classe existente. Isto é, a seleção de características é realizada considerando como classe positiva uma classe e o resto como negativas. Portanto teremos $X_{c}^{\prime}$ para cada classe $c, c=$ $1,2, \ldots, C$ (Li et al., 2008). Os subconjuntos obtidos podem ser usados para classificações no domínio binário. Já na seleção global são consideradas todas as classes de uma só vez gerando apenas um único subconjunto de características $X^{\prime}$ (Chen et al., 2009), podendo esta ser usada para classificações em domínios binários e multi-classe.

O processo de seleção de características é baseado em métodos de filtragem ou wrappers. 
Os métodos de filtragem (Yu e Liu, 2003) selecionam as características a partir de um algoritmo ou característica presente nos dados. Já os métodos wrapper (Kohavi e John, 1997) selecionam as características utilizando classificadores que avaliam diferentes subconjuntos de características de $X$, de modo que selecionam um subconjunto que apresenta melhor resultado em relação ao conjunto de treinamento. O segundo tipo de método (wrappers) consegue geralmente melhores seleções do que os métodos de filtragem. No entanto seu custo computacional é mais elevado.

\subsection{Classificação multi-classe}

Na maioria dos problemas de classificação, o número de classes é superior a dois. Alguns modelos de classificação são intrinsecamente binários (como o SVM) enquanto outros são flexíveis em relação ao número de classes. Independentemente disso, qualquer problema de classificação com múltiplas classes pode ser decomposto em um conjunto de problemas de classificação binária. Os métodos de decomposição mais conhecidos são o um-contra-todos (One vs Rest - OVR ou também One vs All - OVA) e o um-contra-um (One vs One-OVO).

Seja $C$ o número de classes. O método OVR (Bishop, 2006) consiste em desenhar $C$ classificadores, cada um especializado em discriminar exemplos de uma dada classe $c$ específica de exemplos das demais classes. Para treinar um classificador $f_{c}$ para reconhecer instâncias de uma dada classe $c$ são tomados como positivos apenas os exemplos da classe $c$. Todas as demais amostras são tomadas como exemplos negativos. A decisão da classificação final de uma observação $x$ qualquer é baseada na resposta dos $C$ classificadores $f_{1}(x), f_{2}(x)$, $\ldots, f_{C}(x)$. Em geral, consideram-se classificadores soft que retornam um score normalizado $\left(0 \leq f_{c}(x) \leq 1\right)$ em vez de classificadores que retornam uma resposta binária. O score pode ser interpretado como a verossimilhança de $x$ ser da classe $c$. Nesse caso, o rótulo da classe atribuído a uma instância $x$ é dado por:

$$
z_{x}=\underset{c}{\arg \max }\left\{f_{c}(x)\right\}
$$

O método OVO (Bishop, 2006), por sua vez, consiste em criar classificadores especializados em separar amostras de duas classes. Portanto, para cada par de classes, um classificador é treinando usando amostras de uma classe como exemplos positivos, amostras da outra classe como exemplos negativos, e ignorando-se as amostras das demais classes. Portanto, um problema multi-classes com $C$ classes é decomposto em $C^{\prime}=\frac{C(C-1)}{2}$ problemas binários. Neste caso, a decisão final consiste em atribuir o rótulo da classe que recebeu maior número de votos (no caso de classificador que devolve um valor binário) ou recebeu maior score acumulado (no caso de classificadores soft). 


\subsection{Avaliação de classificadores}

No processo de treinamento de classificadores, obter uma alta taxa de acerto em relação aos dados de treinamento não necessariamente implica que um bom classificador foi obtido. O treinamento pode ter provocado um super-ajuste do modelo aos dados de treinamento, ou os dados de treinamento podem ser pouco representativos da distribuição real amostrada.

Portanto, quando avaliamos a qualidade de um modelo, é importante medir o erro em um conjunto independente, distinto do conjunto de treinamento. As práticas comumente utilizadas para avaliar o desempenho de classificadores consistem em dividir o conjunto de amostras rotuladas, e utilizar uma parte (conjunto de treinamento) para o treinamento e outra (conjunto de teste) para estimar o erro esperado.

Entre as principais práticas de avaliação temos o método hold-out, a validação cruzada (cross-validation) e o bootstrapping (Efron e Tibshirani, 1994).

O hold-out é normalmente utilizado quando há uma grande quantidade de dados rotulados. Nesse método uma parte dos dados é usada para treinamento e o restante para teste, tipicamente na proporção $50 \%: 50 \%$ ou $2 / 3: 1 / 3$.

A validação cruzada (Cross validation - CV) considera subconjuntos resultantes da divisão do conjunto de dados $S$ em $k$ partes de tamanhos aproximadamente iguais. Sejam $S_{1}, S_{2}$, $\ldots, S_{k}$ as $k$ partes de $S$. No método $\mathrm{CV}, k$ rodadas de treinamento são repetidos, deixando-se uma das $k$ partes como conjunto de teste e usando-se as demais $k-1$ partes para treinamento em cada rodada. Este processo resulta em $k$ estimativas de erro, referentes a cada uma das rodadas de treinamento. A média desses $k$ erros é considerada o erro de validação cruzada ( $C V$ error). Esse método é comumente utilizado, principalmente quando o conjunto de dados não é muito grande (Arlot e Celisse, 2010). Ele também é usado frequentemente para comparação de dois classificadores, para a seleção de um modelo.

A validação cruzada pode ser realizada de 3 formas: leave-one-out, $k$-fold ou $k$-fold estratificada. A validação cruzada leave-one-out corresponde ao caso $k=N$ ( $N$ é a quantidade de dados disponível), no qual o conjunto de teste em cada rodada consiste de um único exemplo. Na validação k-fold os valores comumente usados são $k=5$ ou $k=10$ (Kohavi, 1995). Já a validação cruzada k-fold estratificada é uma variação da $k$-fold. A diferença é que a partição do conjunto $S$ não é feita aleatoriamente, mas sim respeitando a proporção de ocorrências de cada uma das classes. Desta forma, garante-se que todos os subconjuntos $S_{i}$ contém uma proporção de amostras de cada uma das classes que é aproximadamente igual a do conjunto geral $S$. 


\subsubsection{Medidas de avaliação}

O desempenho de um classificador pode ser expresso por meio de diferentes tipos de informações, sendo uma das mais importantes a acurácia da classificação. Se fosse possível aplicar o classificador sobre todas as possíveis observações, poderíamos calcular a sua acurácia real. Porém, isto é praticamente impossível. Na prática, em geral uma estimativa do desempenho é calculada, usando-se métodos como os descritos acima.

Os erros e acertos de um classificador multi-classes sobre um conjunto de teste podem ser expressos por meio de uma matriz de confusão, também denominada matriz de contingência. Nessa matriz, as linhas indicam as classes verdadeiras e as colunas indicam as classes preditas. No exemplo abaixo (tabela 3.1) ilustramos uma matriz dessas, para o caso de $C$ classes. As classes são identificadas pelo rótulo $i, i=1,2, \ldots, C$.

\begin{tabular}{|c|c|c|c|c|c|c|}
\hline & \multicolumn{5}{|c|}{ Classe predita } \\
\hline & & 1 & 2 & . & 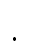 & $C$ \\
\hline \multirow{5}{*}{ Classe real } & 1 & $n_{11}$ & $n_{12}$ & & & $n_{1 C}$ \\
\hline & 2 & $n_{21}$ & $n_{22}$ & & & $n_{2 C}$ \\
\hline & . & . & . & & & . \\
\hline & - & - & - & & & $\cdot$ \\
\hline & $C$ & $n_{C 1}$ & $n_{C 2}$ & . & . & $n_{C C}$ \\
\hline
\end{tabular}

Tabela 3.1: Matriz de confusão de um problema multi-classe.

Uma entrada $n_{i j}$ indica a quantidade de exemplos da classe $i$ que foram classificados como sendo da classe $j$. Os números de exemplos corretamente classificados encontram-se na diagonal principal. As demais entradas indicam os erros de classificação.

A partir desta matriz, diferentes métricas de desempenho, tanto global como relativas a uma classe em particular, podem ser calculadas.

Com relação a uma dada classe $i, T P(i)=n_{i i}$ é o número de verdadeiros positivos enquanto $F P(i)=\sum_{j=1, j \neq i}^{C} n_{j i}$ são os falsos positivos. Assim, podemos definir

$$
T P=\sum_{i=1}^{C} T P(i)=\sum_{i=1}^{C} n_{i i}
$$

e

$$
F P=\sum_{i=1}^{C} F P(i)=\sum_{i=1}^{C} \sum_{j=1, j \neq i}^{C} n_{j i}
$$

Além disso, com respeito à classe $i$ definimos também recall $R_{i}$ e precisão $P_{i}$ :

$$
R_{i}=\frac{n_{i i}}{\sum_{j=1}^{C} n_{i j}}
$$




$$
P_{i}=\frac{n_{i i}}{\sum_{j=1}^{C} n_{j i}}
$$

O recall indica a proporção de amostras de uma classe $i$ que foram efetivamente reconhecidas como sendo da classe $i$, e portanto é uma medida de cobertura. Já a precisão indica qual a proporção de exemplos, dentre todos que foram classificados como da classe $i$, que de fato são da classe $i$. Um recall alto não necessariamente indica um bom resultado pois pode estar associado a uma baixa precisão. A F-measure (He e Garcia, 2009), dada pela equação 3.6, integra as duas medidas:

$$
F_{i}=\frac{2 * R_{i} * P_{i}}{R_{i}+P_{i}}
$$

O valor da F-measure tende a ser alto quando tanto o recall como a precisão são altos.

O recall e a precisão são conceitos usados em situações de duas classes. Para uma avaliação de desempenho global do classificador sobre todas as classes, utiliza-se a acurácia (ou taxa de acerto), dada por:

$$
A c c=\frac{\sum_{i=1}^{C} n_{i i}}{\sum_{i, j=1}^{C} n_{i j}}
$$





\section{Capítulo 4}

\section{Segmentação de imagens de plâncton}

Conforme mencionado na introdução, um pipeline padrão para a classificação de imagens de plâncton inclui uma etapa de segmentação do objeto-alvo (candidato a plâncton). A escolha de um algoritmo que produza boas segmentações é particularmente importante neste trabalho, dado que as imagens consideradas são de baixa qualidade. Para fazer uma escolha, torna-se necessário algum critério de avaliação.

Neste capítulo descrevemos algumas formas comumente empregadas para avaliação de segmentações e comentamos as características desses métodos que os fazem inadequados para as necessidades deste trabalho. Em seguida apresentamos o método proposto nesta dissertação. Ele explora o fato de que a segmentação é uma etapa de um pipeline de processamento cujo resultado final é a classificação. Mais especificamente, propomos um método para a avaliação de segmentação por meio da avaliação dos resultados de classificação. Ao final, ilustramos a aplicação da avaliação proposta em um conjunto de imagens de plâncton e mostramos algumas das informações que podem ser obtidas a partir dos resultados da avaliação.

\subsection{Avaliação de segmentação}

A segmentação é um dos problemas mais estudados em Visão Computacional e Análise de Imagens. Existe uma grande variedade de algoritmos para segmentação de imagens e, igualmente, uma variedade de métricas para sua avaliação (Cardoso e Corte-Real, 2005; Martin et al., 2006; Udupa et al., 2006; Unnikrishnan et al., 2007; Zhang et al., 2008; Zhang, 1996). A maior parte das abordagens para avaliar uma segmentação faz parte de uma destas 3 categorias: subjetiva, supervisionada e não-supervisionada (Zhang et al., 2008).

A avaliação subjetiva consiste na avaliação dos resultados de uma segmentação de forma qualitativa e visual por um usuário humano. Essa característica sugere uma primeira 
desvantagem do método, uma vez que a avaliação pode variar de um avaliador a outro. Além disso, através deste método, é difícil avaliar a efetividade dos algoritmos de segmentação, pois seria necessário um grande esforço particularmente quando o número de imagens é significativamente grande, o que torna esse método demorado e cansativo. Consequentemente os métodos subjetivos não podem ser usados em sistemas/aplicações em tempo real para escolher algoritmos de segmentação ou para parametrizações de um algoritmo de segmentação.

Os métodos de avaliação supervisionada (Chabrier et al., 2004b; Yang et al., 1995) avaliam algoritmos de segmentação comparando as imagens segmentadas com imagens de referência segmentadas manualmente, usualmente chamadas de gold standard ou de ground truth. A comparação é baseada em diferentes tipos de métricas de similaridade calculadas sobre o par de imagens. Quanto maior for a similaridade entre elas, melhor qualidade é associada à imagem segmentada. No entanto, a segmentação manual das imagens de referência pode ser difícil, demorada e ser influenciada pela interpretação subjetiva da pessoa que a realiza.

Os métodos de avaliação não-supervisionada (Chabrier et al., 2004a) são métodos empíricos caracterizados por não utilizar o ground truth no processo de avaliação da segmentação. Esses métodos avaliam a qualidade da imagem segmentada de forma quantitativa através de métricas objetivas (critérios pré-definidos) as quais são calculadas unicamente sobre a imagem segmentada. Por exemplo, um critério poderia ser o desvio padrão dos níveis de cinza nas regiões ou a disparidade de cada região calculada pela diferença entre as médias dos níveis de cinza em cada região (Chabrier et al., 2006). No entanto, a definição do critério pode não ser trivial quando a segmentação é complexa e, da mesma forma do caso supervisionado, pode sofrer influência da interpretação da pessoa que realiza a definição.

No contexto da aplicação considerada neste trabalho, a necessidade de avaliação de segmentação surge em situações quando ocorrem mudanças nas características das imagens. Tais mudanças podem ser devidas à mudanças no ambiente aquático, ou mudanças na técnica ou sistema de imageamento. Em tais situações, criar um novo conjunto de imagens de referência, ou definir uma nova função-objetivo para o caso não supervisionado, não são práticos pois são tarefas demoradas e complexas.

Por exemplo, a construção do ground truth pode ser difícil quando o contorno do objeto alvo não está claro em uma inspeção visual, tal como podemos ver na Fig. 4.1. As duas primeiras imagens apresentam bom contraste e contorno claro enquanto as últimas duas estão borradas e com contorno indefinido. Além disso, a delimitação manual de contornos seria crítica especialmente por causa da carga de trabalho em situações onde se tem muitos tipos de alvos e um grande número de imagens. Um número relativamente grande de imagens ground truth para cada variação da entrada deveria estar disponível para que uma avaliação tenha significado estatístico. 

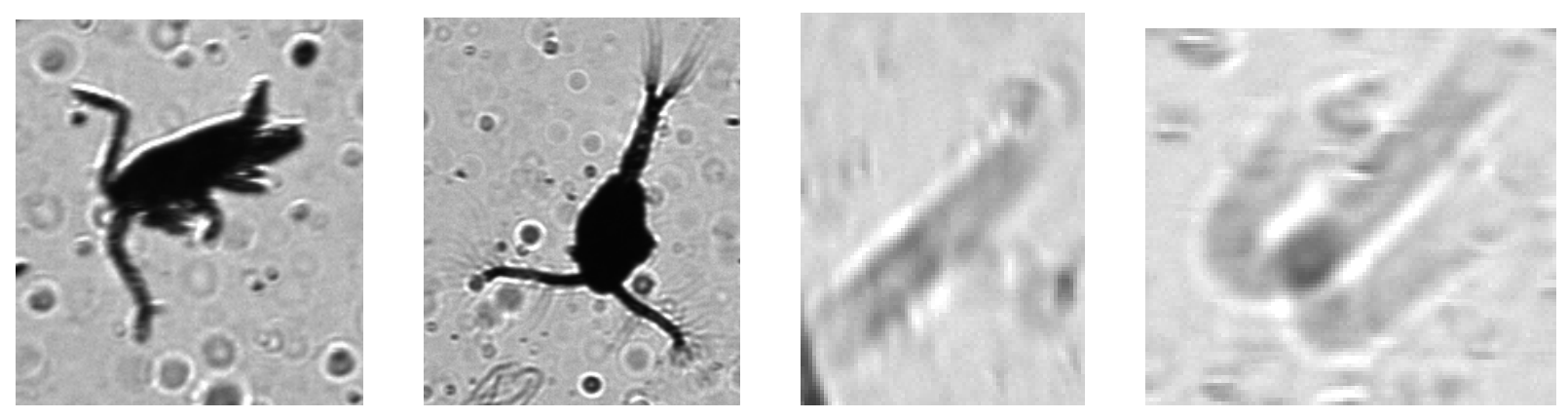

Figura 4.1: Da esquerda para a direita: Calanoida, Cyclopoida, Filamento grosso, e Neoceratium. As duas primeiras imagens apresentam contraste relativamente bom e contorno suficientemente claro enquanto as duas últimas estão borradas e sem contorno claro.

Um outro aspecto que deve ser considerado sobre a avaliação da segmentação, e especialmente no contexto da aplicação considerada neste trabalho, é o fato da segmentação ser apenas uma etapa no pipeline de processamento. Nesse sentido, é natural esperarmos que existam conexões entre a tarefa de segmentação em si e o objetivo da aplicação.

Ideias deste tipo são exploradas por exemplo no trabalho de Ding et al. (2002a). Os autores, a partir da observação de que a maioria dos erros na classificação são causados devido a resultados de segmentações ruins, utilizam a confiança do classificador como uma forma para decidir se a segmentação deve ou não ainda ser melhorada. Quando a confiança do classificador é baixa, a segmentação é refeita alterando-se os parâmetros do algoritmo de segmentação e o classificador é então aplicado novamente. O processo é repetido iterativamente até que uma alta confiança da classificação seja alcançada. De forma similar, no trabalho de Kavzoglu e Yildiz (2014), segmentos (super-pixels) de imagens de alta resolução (adquiridas por satélites ou sistemas aéreos) gerados por um método não-supervisionado são classificados usando o algoritmo de vizinhos mais próximos. A acurácia da classificação é usada para avaliar e reajustar os parâmetros do método de segmentação, dado que a configuração desses parâmetros afeta a segmentação e consequentemente o desempenho do classificador.

Levando-se as considerações acima, neste trabalho sugerimos que a escolha de um bom algoritmo de segmentação possa ser baseada em uma avaliação indireta, ou seja, na acurácia da classificação no final do pipeline, e não em uma avaliação direta das imagens segmentadas. 


\subsection{Uma proposta para a avaliação indireta da segmen- tação}

Conforme apontado acima, nos problemas nos quais o objetivo final não é a segmentação em si, mas algum processamento que depende da segmentação, o importante é o resultado final do processamento. Então podemos avaliar a segmentação indiretamente em termos do resultado final. No caso das imagens de plâncton, existe adicionalmente a vantagem de que prover informação ground truth em nível de classificação (i.e., associar à imagem um rótulo que identifica a espécie) é uma tarefa muito mais simples do que a de delinear manualmente o contorno esperado na segmentação dos objetos.

Para mostrar a generalidade do método a ser descrito, tomamos como exemplo o problema de reconhecimento óptico de caracteres (Kasturi et al., 2002). Com o propósito de reconhecer por exemplo o conteúdo em páginas de documentos digitalizados, é usualmente realizado uma sequência de processamentos. Uma típica cadeia de processamento inclui binarização de imagens, segmentação de caracteres, reconhecimento de caracteres, e detecção de componentes de uma página tais como figuras, títulos, parágrafos entre outros.

Nessa cadeia de processamento, a binarização é um passo muito importante porque afeta os passos subsequentes. Devido a essa importância, muitos algoritmos de binarização tem sido desenvolvidos. Por outro lado, a binarização é uma tarefa de um nível mais baixo comparado à tarefa global de reconhecimento do conteúdo da página de um documento. Dessa forma, a escolha de um algoritmo de binarização não deveria considerar unicamente seu desempenho na tarefa de binarização por si só, mas também o quanto ele afeta o desempenho das tarefas de nível mais alto. Mais especificamente, embora uma binarização "perfeita" seja desejada, visto da perspectiva do objetivo final, uma binarização "próxima da perfeita" poderia ser suficiente. Por exemplo, na binarização individual de caracteres como a mostrada na Fig. 4.2, o quanto a taxa de reconhecimento seria afetada pelas ligeiras diferenças entre as segmentações?

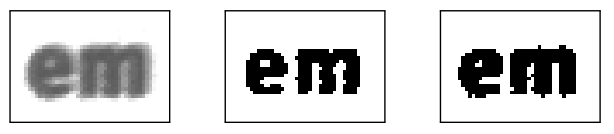

Figura 4.2: Exemplos de 2 binarizaçôes levemente diferentes.

Supondo que existem diversos algoritmos de binarização que levam a um desempenho equivalente para uma tarefa de mais alto nivel (por exemplo, no reconhecimento de caracteres ou até em reconhecimento de palavras), a escolha de um deles não precisaria estar baseado unicamente na otimização do seu resultado com respeito a um desejado ground truth ideal. Poderiam ser considerados outros aspectos dos algoritmos de binarização tais como velocidade de processamento, facilidade de implementação, eficácia, entre outros. 


\subsubsection{Descrição do método}

Consideremos a cadeia de processamento da figura 4.3 composto de vários componentes sequencialmente ligados, onde cada componente é responsável por uma tarefa específica e existem $n$ solucionadores (solvers) para cada tarefa. Assumimos também que componentes localizados à esquerda são responsáveis pelas tarefas de mais baixo-nível e aqueles que ficam à direita são responsáveis pelas tarefas de mais alto-nível. Outra característica que podemos observar é que a saída de um componente alimenta o próximo componente.

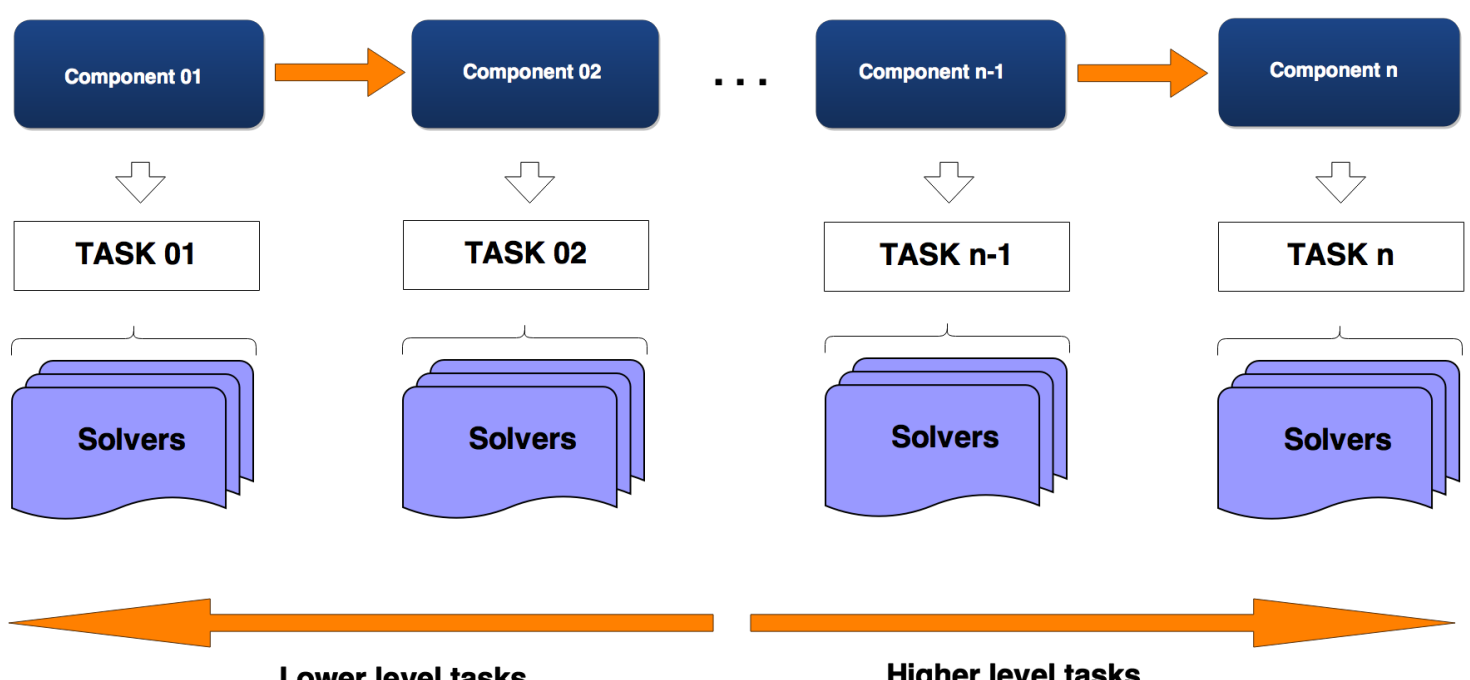

Figura 4.3: Diagrama de uma cadeia de processamento.

Por exemplo, no pipeline de classificação de imagens de plâncton, a segmentação de imagens é uma tarefa de relativo baixo nível quando comparada à etapa de classificação propriamente. A segmentação precede a extração de características que, por sua vez, precede a classificação.

Em nossa proposta, a ideia central é a de que soluções para uma tarefa específica possam ser avaliadas baseado no resultado de algum componente subsequente.

Sob as premissas descritas acima, na cadeia de processamento consideremos $\mathbf{A}$ como a tarefa para a qual desejamos escolher uma solução e B a tarefa que será usada para avaliar as soluções para a primeira. Vamos supor também que é dado um conjunto $D$ de dados de entrada para a tarefa $\mathbf{A}$ bem como as respectivas saídas da tarefa $\mathbf{B}$ esperadas para essas entradas. Além disso, consideremos $n$ algoritmos $A_{i}$ para a tarefa $\mathbf{A}$, uma solução fixa $B$ para a tarefa $\mathbf{B}$, e uma métrica de avaliação fixa para a saída. 
O procedimento de avaliação proposto consiste dos seguintes passos:

1. resolver a tarefa $\mathbf{A}$ para a entrada $D$ usando cada um dos $n$ algoritmos, $A_{i}, i=1, \ldots, n$, e sejam os respectivos resultados denotados por $A_{i}(D), i=1, \ldots, n$

2. resolver a tarefa $\mathbf{B}$ para cada conjunto de dados $A_{i}(D), i=1, \ldots, n$, usando a solução $B$, e sejam os respectivos resultados denotados por $B\left(A_{i}(D)\right), i=1, \ldots, n$

3. avaliar a medida de desempenho, com respeito à tarefa $\mathrm{B}$, para cada conjunto de dados resultante $B\left(A_{i}(D)\right), i=1, \ldots, n$

4. ordenar cada um dos algoritmos $A_{i}$ usados na tarefa $\mathbf{A}$ segundo o desempenho calculado na tarefa B. O algoritmo $A_{i}$ melhor posicionado será considerado a melhor solução para a tarefa $\mathbf{A}$.

Por exemplo, no caso do problema de reconhecimento de caracteres, A poderia ser o processo de binarização e $\mathbf{B}$ poderia representar o processo de reconhecimento de caracteres. Os dados de entrada $D$ seriam caracteres individuais obtidos a partir de um documento original digitalizado e a medida de desempenho poderia ser a taxa de reconhecimento dos caracteres em $D$.

No problema da classificação de plâncton, a tarefa A seria a segmentação e B seria a tarefa de classificação propriamente dita.

Um principal problema do método descrito acima surge, porém, em situações nas quais os componentes correspondentes às tarefas em questão estão bem afastados. Nesse caso há a possibilidade de uma interferência de componentes intermediários na avaliação. Para minimizar uma possível interferência de passos intermediários, podemos avaliar soluções de baixo-nível baseada no componente imediatamente subsequente da cadeia. Quando isso não for possível, a granularidade dos componentes pode ser modificada para que dois ou mais componentes consecutivos sejam combinados em um único componente e dessa forma seja reduzido o número de componentes da cadeia.

Por exemplo, no caso de classificação de plâncton, a extração de características é uma tarefa intermediária entre a segmentação e a classificação. Neste caso, a subsequência "extração de características" + "classificação" pode ser considerada como uma macro tarefa, imediatamente subsequente à segmentação. 


\subsection{Exemplos de avaliação usando o método proposto}

Para ilustrar a abordagem e as múltiplas informações que podem ser obtidas com o método de avaliação proposto na seção anterior, apresentamos sua aplicação sobre um conjunto de imagens de plâncton. O principal objetivo nesta seção é mostrar como diferentes aspectos relacionados à segmentação podem ser avaliados a partir da perspectiva de uma tarefa de mais alto nível.

Consideramos a classificação de plâncton como a tarefa de alto-nível que será efetivamente avaliada, e que indiretamente servirá para avaliar diferentes aspectos dos métodos de segmentação. Desta forma, baseado no pipeline descrito no capítulo 2, consideramos as seguintes tarefas:

$$
\begin{gathered}
\text { Segmentação } \rightarrow \text { Tarefa A (baixo-nível) } \\
\text { Extração de características }+ \text { Classificação } \rightarrow \text { Tarefa B (alto-nível) }
\end{gathered}
$$

Seis métodos de segmentação, a saber limiarização com um valor de limiar fixo (Fixo), limiarização com limiar adaptativo (Dinâmico), Watershed, limiarização de Yen, limiarização de Otsu, e limiarização Isodata são avaliados para a tarefa A. A descrição desses métodos pode ser encontrada no apêndice B.

O conjunto de imagens de plâncton utilizado é o mesmo que foi usado no trabalho de Matuszewski (2014). O dataset contém 1600 imagens de plâncton, já devidamente recortados, divididos em 16 classes de igual tamanho (ver mais detalhes no apêndice A). Os algoritmos de extração de características e o modelo de classificação são fixados. Consideramos um conjunto de 55 características e um classificador dentre os modelos SVM (C=13, kernel RBF e $\gamma=1$ ), Floresta-aleatória (Random Forest $-\mathrm{RF}$, com Seed =10, numTrees $=40$ ) e $k$-vizinhos-mais-próximos (KNN, com $k=10$ ) para cada experimento de avaliação. A escolha dos classificadores e de seus parâmetros foram adotados do trabalho de Matuszewski (2014). Tais parâmetros foram determinados de forma empírica. Na escolha dos classificadores, Matuszewski testou 8 classificadores e os comparou. O SVM apresentou alta acurácia na classificação.

O desempenho dos classificadores é obtido por meio de uma validação cruzada (CV) estratificada sobre o conjunto de dados.

\subsubsection{Avaliação visando a escolha de um algoritmo de segmentação}

Nesta primeira avaliação, ilustramos a ideia central da proposta de usar o desempenho na classificação, mais precisamente a acurácia, para avaliar os métodos de segmentação. 
Método de segmentação com melhor desempenho global

Com o classificador SVM, as maiores acurácias foram alcançadas usando os métodos de segmentação Watershed e Yen, conforme mostrado na tabela 4.1. Esses resultados são consistentes com a avaliação visual dos resultados da segmentação. Na figura 4.4 podemos ver algumas imagens segmentadas, nas quais é visualmente perceptível que os métodos Yen e Watershed produzem contornos melhor definidos.

\begin{tabular}{|c|c|}
\hline Métodos de segmentação & Acurácia na validação cruzada (\%) \\
\hline Fixo & $86,81 \pm 2,90$ \\
\hline Dinâmico & $80,13 \pm 1,83$ \\
\hline Watershed & $89,81 \pm 2,36$ \\
\hline Yen & $90,31 \pm 2,79$ \\
\hline Otsu & $85,63 \pm 2,34$ \\
\hline Isodata & $86,19 \pm 1,71$ \\
\hline
\end{tabular}

Tabela 4.1: 10-fold CV usando o SVM.
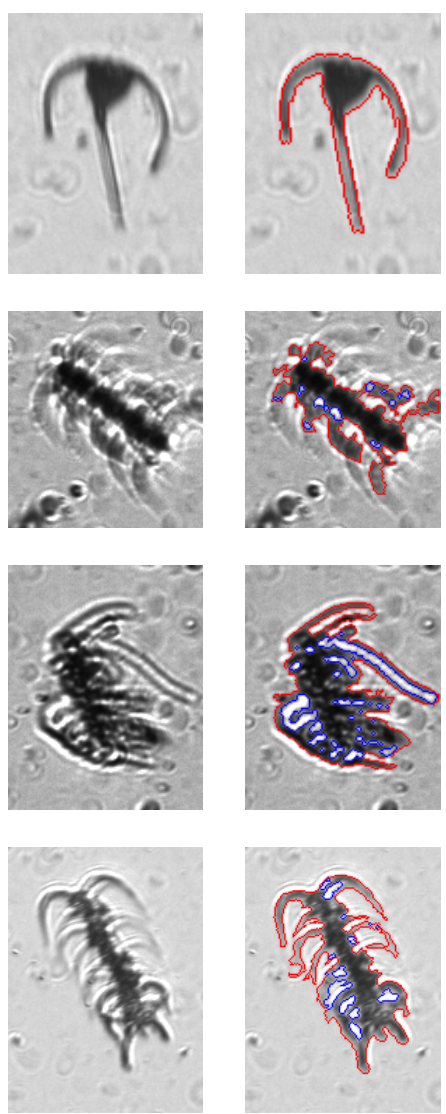

(a)

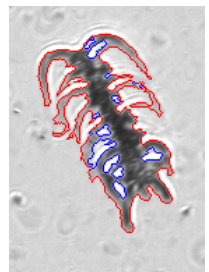

(b)
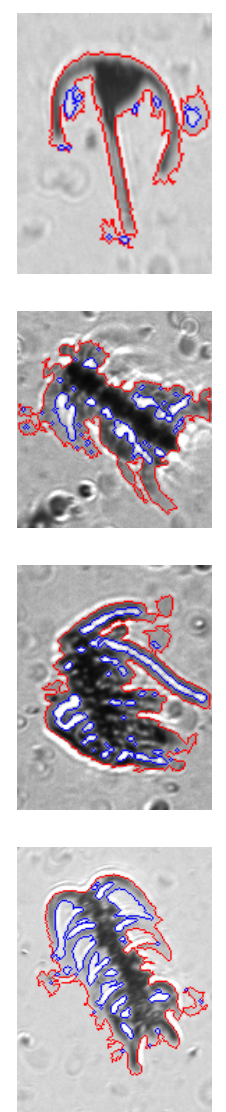

(c)
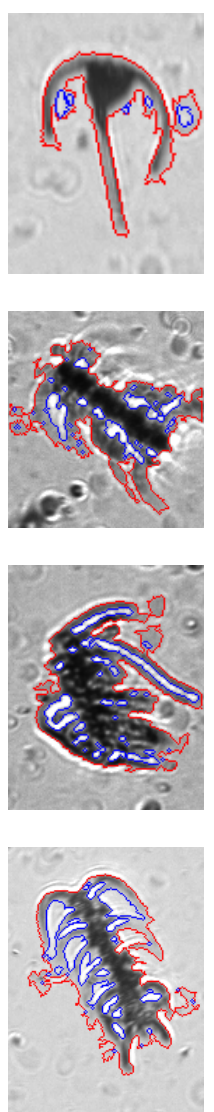

(d)
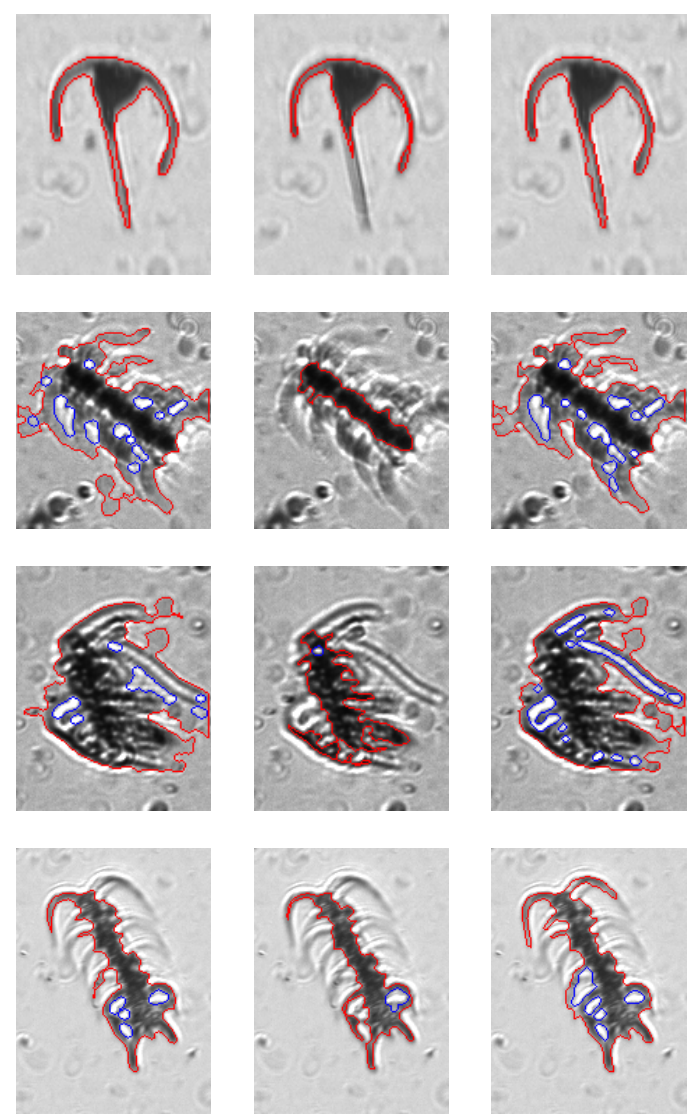

(e)
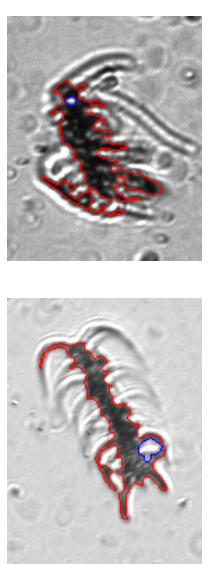

(f)
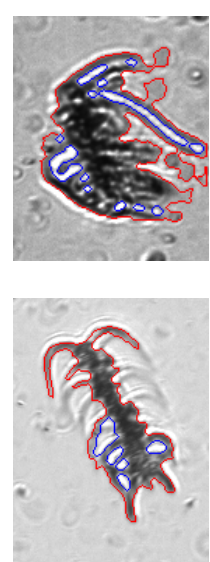

(g)

Figura 4.4: Amostras de 4 classes de plâncton e suas respectivas segmentações usando os 6 métodos. De cima para baixo, Neoceratium, Chaetoceros fora de foco, Copepoda morto, e Chaetoceros. (a) imagem de entrada, e segmentaçôes pelos métodos (b) Yen, (c) Otsu, (d) Isodata, (e) Fixo, (f) Dinâmico, $e(g)$ Watershed. 
A acurácia média na classificação indica qual ou quais métodos de segmentação podemos usar para segmentar as imagens em um pipeline para classificar imagens similares ao do dataset. Essa tarefa de escolher um algoritmo de segmentação dificilmente poderia ser feita apenas por meio de inspeção visual das imagens segmentadas, uma vez que isso implica um processo de alto custo em termos de tempo e esforço. No exemplo acima, poderíamos optar por usar os métodos Watershed ou Yen.

\section{Algoritmo de segmentação com melhor desempenho por classe}

Suponha agora que em vez de identificar cada um dos alvos, nosso objetivo seja detectar plâncton de uma classe em particular. Além disso, suponhamos também que essa detecção precise ocorrer em tempo real sem a possibilidade de se realizar um treinamento para gerar um classificador específico para reconhecer apenas plâncton dessa classe. Nesse caso, podemos simplesmente optar por usar um método de segmentação que mais favoreça a identificação das amostras dessa classe, sem considerar seu efeito na classificação geral média. A única alteração necessária no sistema de reconhecimento seria a troca do componente de segmentação. Na tabela 4.2 apresentamos a acurácia da classificação de plâncton por classe e método de segmentação, usando o modelo de classificação SVM.

\begin{tabular}{|l|c|c|c|c|c|c|}
\hline \multirow{2}{*}{ CLASSES } & \multicolumn{7}{|c|}{$\begin{array}{c}\text { Acurácia na validação cruzada } \\
\text { detalhada por classe (\%) }\end{array}$} \\
\cline { 2 - 7 } & Fixo & Dinâmico & Watershed & Yen & Otsu & Isodata \\
\hline \hline Chaetoceros (Chaet.) & 83,00 & 73,00 & 87,00 & 80,00 & 77,00 & 76,00 \\
\hline Chaet. fora de foco & 67,00 & 66,00 & 67,00 & 81,00 & 83,00 & 80,00 \\
\hline Copepoda calanoida & 87,00 & 82,00 & 90,00 & 85,00 & 79,00 & 84,00 \\
\hline Copepoda cyclopoida & 95,00 & 94,00 & 95,00 & 96,00 & 84,00 & 85,00 \\
\hline Copepoda fora de foco & 91,00 & 86,00 & 95,00 & 94,00 & 86,00 & 86,00 \\
\hline Copepoda pulando & 92,00 & 85,00 & 91,00 & 94,00 & 89,00 & 88,00 \\
\hline Copepoda morto & 84,00 & 73,00 & 83,00 & 87,00 & 79,00 & 80,00 \\
\hline Copepoda (sem antena) & 92,00 & 87,00 & 93,00 & 92,00 & 87,00 & 87,00 \\
\hline Coscinodiscus T. & 97,00 & 92,00 & 99,00 & 96,00 & 97,00 & 97,00 \\
\hline Filamentos Finos & 88,00 & 91,00 & 92,00 & 92,00 & 92,00 & 93,00 \\
\hline Filamentos grossos & 88,00 & 70,00 & 83,00 & 85,00 & 76,00 & 78,00 \\
\hline Nauplius fora de foco & 92,00 & 88,00 & 90,00 & 89,00 & 87,00 & 86,00 \\
\hline Neoceratium (Neoc.) & 88,00 & 83,00 & 95,00 & 92,00 & 90,00 & 91,00 \\
\hline Neoc. fora de foco & 80,00 & 73,00 & 87,00 & 88,00 & 78,00 & 82,00 \\
\hline Odontella sinensis & 83,00 & 66,00 & 91,00 & 95,00 & 90,00 & 88,00 \\
\hline Pyrocystis & 90,00 & 73,00 & 99,00 & 99,00 & 96,00 & 98,00 \\
\hline \hline Media & $\mathbf{8 6 , 8 1}$ & $\mathbf{8 0 , 1 3}$ & $\mathbf{8 9 , 8 1}$ & $\mathbf{9 0 , 3 1}$ & $\mathbf{8 5 , 6 3}$ & $\mathbf{8 6 , 1 9}$ \\
\hline
\end{tabular}

Tabela 4.2: $C V$ por classe usando SVM.

Por exemplo, suponha que o nosso interesse seja detectar ocorrências de Nauplius fora de foco. A partir dos resultados da tabela 4.2, podemos ver que usar o método de segmentação 
Fixo seria uma boa escolha, uma vez que a melhor taxa de reconhecimento de instâncias dessa classe ocorre quando utilizamos o método Fixo.

\section{Influência das variações na tarefa B}

Na tarefa B, conforme definido acima, foram utilizadas 55 características fixas e o modelo SVM para classificação. Com base apenas nos experimentos acima não é possível afirmar que as melhores segmentações são de fato as observadas nesses resultados. Alterações em outros componentes do pipeline podem, em princípio, levar a resultados distintos. Tendo isso em consideração, convém também avaliarmos os algoritmos de segmentação usando outras configurações de solução para a tarefa B.

Em relação aos modelos de classificação, repetimos o experimento anterior, usando os modelos RF e KNN. Os dois classificadores mostraram o mesmo comportamento que o SVM (tabela 4.3). Isto é, as melhores acurácias medias são obtidas novamente usando os métodos de segmentação Watershed e Yen, reforçando o resultado constatado anteriormente.

\begin{tabular}{|c|c|c|c|}
\hline \multirow{2}{*}{ Métodos de segmentação } & \multicolumn{4}{|c|}{ Acurácia na validação cruzada (\%) } \\
\cline { 2 - 4 } & SVM & RF & KNN \\
\hline \hline Fixo & $86,81 \pm 2,90$ & $84,13 \pm 2,47$ & $79,75 \pm 2,55$ \\
\hline Dinâmico & $80,13 \pm 1,83$ & $75,06 \pm 1,10$ & $71,81 \pm 3,61$ \\
\hline Watershed & $89,81 \pm 2,36$ & $86,56 \pm 2,81$ & $84,00 \pm 2,17$ \\
\hline Yen & $90,31 \pm 2,79$ & $86,38 \pm 2.69$ & $84.63 \pm 3.13$ \\
\hline Otsu & $85,63 \pm 2,34$ & $79,56 \pm 3,06$ & $77,63 \pm 3,27$ \\
\hline Isodata & $86,19 \pm 1,71$ & $81,13 \pm 3,69$ & $78,69 \pm 3,81$ \\
\hline
\end{tabular}

Tabela 4.3: Acurácia 10-fold CV: modelos de classificadores $\times$ métodos de segmentação.

Similarmente, o conjunto de características poderia também ter alguma influência nos resultados finais da classificação. Assim, repetimos o experimento variando também o conjunto de características. Para definir os subconjuntos de características, um algoritmo de seleção de características foi aplicado sobre o conjunto de 55 características extraídas. O algoritmo de seleção de características consiste de uma eliminação de características recursiva com ajuste automático do número de características selecionados com validação cruzada (Recursive Feature Elimination - RFECV) (Guyon et al., 2002). O algoritmo foi implementado no sklearn ${ }^{1}$ (Pedregosa et al., 2011).

Esse processo foi repetido para cada um dos seis métodos de segmentação, resultando portanto em seis subconjuntos de características. A partir desses seis subconjuntos, definiu-se três novos subconjuntos $\left(F_{1}, F_{2}\right.$ e $\left.F_{3}\right)$ que foram usados nos experimentos.

O primeiro subconjunto, $F_{1}$, foi construído tomando todas as características presentes

\footnotetext{
${ }^{1}$ scikit-learn é uma ferramenta open source de aprendizado computacional implementada em python para mineração de dados e análise de dados e construído sobre $N u m P y$, SciPy, e matplotlib.
} 
em pelo menos 5 dos 6 subconjuntos. O segundo e terceiro subconjuntos, $F_{2}$ e $F_{3}$, foram construídos de forma similar, considerando-se todas as características presentes em pelo menos 3 e 2 dos 6 subconjuntos, respectivamente. A tabela 4.4 mostra os resultados obtidos. Novamente, os algoritmos Watershed e Yen resultaram em melhor acurácia na classificação.

\begin{tabular}{|c|c|c|c|c|}
\hline \multirow{2}{*}{ Métodos } & \multicolumn{4}{|c|}{ Subconjunto de características (número de características) } \\
\cline { 2 - 5 } & $\mathbf{F}_{\mathbf{1}}(14)$ & $\mathbf{F}_{\mathbf{2}}(29)$ & $\mathbf{F}_{\mathbf{3}}(34)$ & Todas $(55)$ \\
\hline \hline Fixo & $81,94 \% \pm 2,58$ & $85,32 \% \pm 2,71$ & $85,69 \% \pm 2,72$ & $86,81 \% \pm 2,90$ \\
\hline Dinâmico & $73,75 \% \pm 1,51$ & $78,31 \% \pm 1,51$ & $79,06 \% \pm 1, .19$ & $80,13 \% \pm 1,83$ \\
\hline Watershed & $\mathbf{8 5 , 8 8 \%} \pm 2,31$ & $\mathbf{8 8 , 9 4 \%} \pm 1,94$ & $\mathbf{8 8 , 8 1 \%} \pm 1,95$ & $\mathbf{8 9 , 8 1 \% \pm 2 , 3 6}$ \\
\hline Yen & $\mathbf{8 5 , 5 6 \%} \pm 3,13$ & $\mathbf{8 9 , 2 5 \%} \pm 2,86$ & $\mathbf{8 9 , 6 3 \%} \pm 1,84$ & $\mathbf{9 0 , 3 1 \%} \pm 2,79$ \\
\hline Otsu & $78,81 \% \pm 4,84$ & $84,44 \% \pm 2.67$ & $84,44 \% \pm 3,09$ & $85.63 \% \pm 2,34$ \\
\hline Isodata & $78,88 \% \pm 4,30$ & $83,81 \% \pm 2,90$ & $85,06 \% \pm 2,76$ & $86,19 \% \pm 1,71$ \\
\hline
\end{tabular}

Tabela 4.4: Acurácia da CV 10-fold usando SVM com subconjuntos de características selecionadas.

\section{Comentários}

A partir da análise acima, podemos concluir que o método proposto de avaliação permite escolher, por meio de uma avaliação indireta, um método de segmentação para o pipeline de classificação. Em particular, para o conjunto de dados considerado, observa-se que o uso dos métodos Watershed ou Yen resulta em melhores acurácias de classificação sobre o conjunto todo. Por outro lado, a análise da acurácia por classe permite observar que um método de segmentação que leva a uma melhor acurácia global, sobre todo o conjunto de imagens, não necessariamente é aquele que resulta em melhor acurácia classe a classe. Para algumas classes, como o caso do Nauplius fora de foco, a maior taxa de reconhecimento é obtida com outro algoritmo de segmentação.

\subsubsection{Avaliação de outros aspectos da segmentação}

\section{Relevância do pre-processamento associado à segmentação}

Nos resultados apresentados acima, os algoritmos de segmentação foram aplicados às imagens acompanhados de alguns pre-processamentos tais como suavização gaussiana (ver mais detalhes no apêndice B). No entanto, da mesma forma que não conseguimos facilmente avaliar os resultados de segmentação por diferentes métodos baseado apenas em inspeção visual, não conseguimos avaliar a relevância de diferentes tipos de pre-processamento.

A tabela 4.5 mostra os resultados de classificação obtidos usando-se segmentação com préprocessamento (que corresponde aos resultados descritos acima) e sem pré-processamento. 


\begin{tabular}{|c|c|c|}
\hline \multirow{2}{*}{ Métodos } & \multicolumn{2}{|c|}{ Porcentagem das instâncias corretamente classificadas } \\
\hline & Com pre-processamento & Sem pre-processamento \\
\hline$\overline{\text { Fixo }}$ & $86,81 \% \pm 2,90$ & $87,00 \% \pm 2,60$ \\
\hline Dinâmico & $80,13 \% \pm 1,83$ & $79.56 \% \pm 2.11$ \\
\hline Watershed & $89,81 \% \pm 2,36$ & $90,25 \% \pm 1,75$ \\
\hline Yen & $90,31 \% \pm 2,79$ & $87,25 \% \pm 2,43$ \\
\hline Otsu & $85,63 \% \pm 2,34$ & $87,88 \% \pm 1,99$ \\
\hline Isodata & $86,19 \% \pm 1,71$ & $88,13 \% \pm 2, .32$ \\
\hline
\end{tabular}

Tabela 4.5: Acurácia da CV 10-fold usando SVM sobre imagens segmentadas com/sem preprocessamento.

Podemos ver que quatro dos métodos de segmentação testados (acurácias mostradas em azul) apresentam acurácias levemente superiores sem a aplicação do pre-processamento. Os resultados indicam que o pre-processamento poderia ser desnecessário para 4 dos métodos avaliados e ser importante para 2 deles. No entanto, para uma conclusão mais sólida, uma avaliação adicional é necessária e, se possível, usando uma quantidade maior de dados.

\section{Ajuste de parâmetros de algoritmos de segmentação}

Outra possibilidade de avaliação diz respeito ao ajuste de parâmetros de um algoritmo de segmentação, como feito por exemplo em Ding et al. (2002b); Kavzoglu e Yildiz (2014). De certa forma, esse tipo de avaliação não é diferente da avaliação feita acima em relação à escolha de um método de segmentação. Trata-se de um caso particular de escolha dos parâmetros de um dado método, para que sejam geradas segmentações que facilitem a tarefa de classificação.

Essa ideia é ilustrada por meio da aplicação do método proposto, usando o método de segmentação Fixo, e experimentando vários valores para o limiar fixo $T$. Os resultados são mostrados na tabela 4.6. Como pode ser visto, a acurácia da classificação sofre variações. O limiar $T=180$ resulta em uma melhor acurácia de classificação do que o valor $T=170$, que é o valor originalmente usado nos experimentos anteriores.

A escolha de um limiar apropriado baseada em inspeção visual não é uma tarefa trivial. Na figura 4.5 mostramos alguns exemplos nos quais o limiar $T=180$ gera uma melhor segmentação do que o limiar $T=170$. Já na figura 4.6 mostramos alguns exemplos nos quais acontece o contrário.

\begin{tabular}{|l|c|c|c|c|c|}
\hline Limiar (T) & $\mathbf{1 7 0}$ & $\mathbf{1 7 5}$ & $\mathbf{1 8 0}$ & $\mathbf{1 8 5}$ & $\mathbf{1 9 0}$ \\
\hline \hline Instâncias classificadas & $\mathbf{8 6 , 8 1 \%}$ & $86.93 \%$ & $\mathbf{8 8 , 1 9 \%}$ & $87,81 \%$ & $87,44 \%$ \\
corretamente & $\pm 2,90$ & $\pm 2,38$ & $\pm 3,71$ & $\pm 2,90$ & $\pm 2,58$ \\
\hline
\end{tabular}

Tabela 4.6: Acurácia da CV 10-fold usando SVM sobre imagens segmentadas com o método Fixo, para diferentes limiares ( $T$ ). 

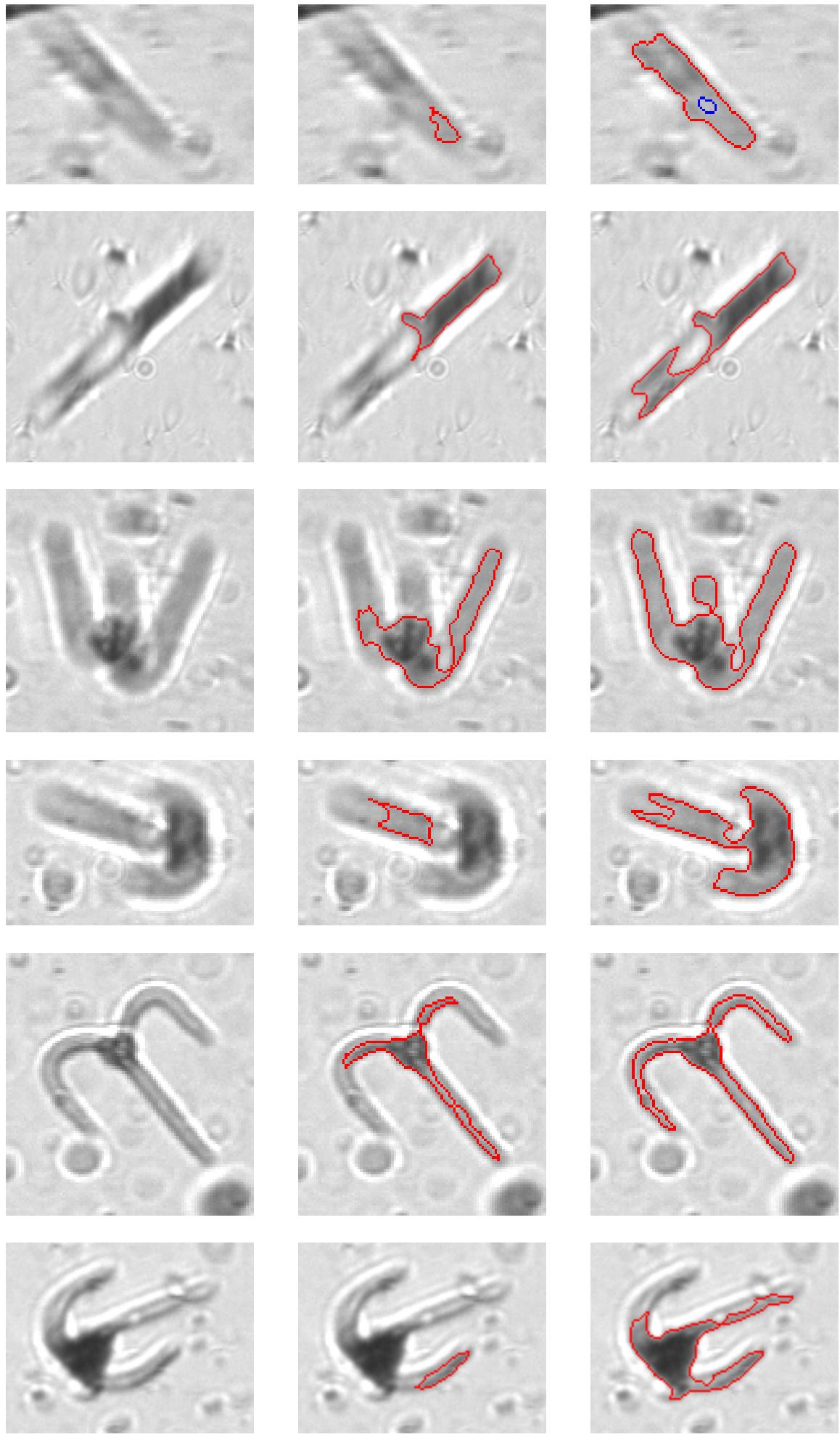

(a) Input

(b) $T=170$

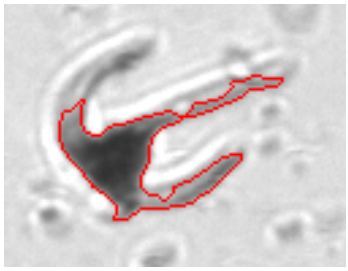

(c) $T=180$

Figura 4.5: Amostras de 3 classes de plâncton, segmentadas usando o método Fixo, com valores de limiarização 170 e 180. De cima para baixo: filamentos grossos (primeira e segunda linhas), Neoceratium fora de foco (terceira e quarta linhas), e Neoceratium (quinta e sexta linhas). Melhores resultados sẫo obtidos com $T=180$. 

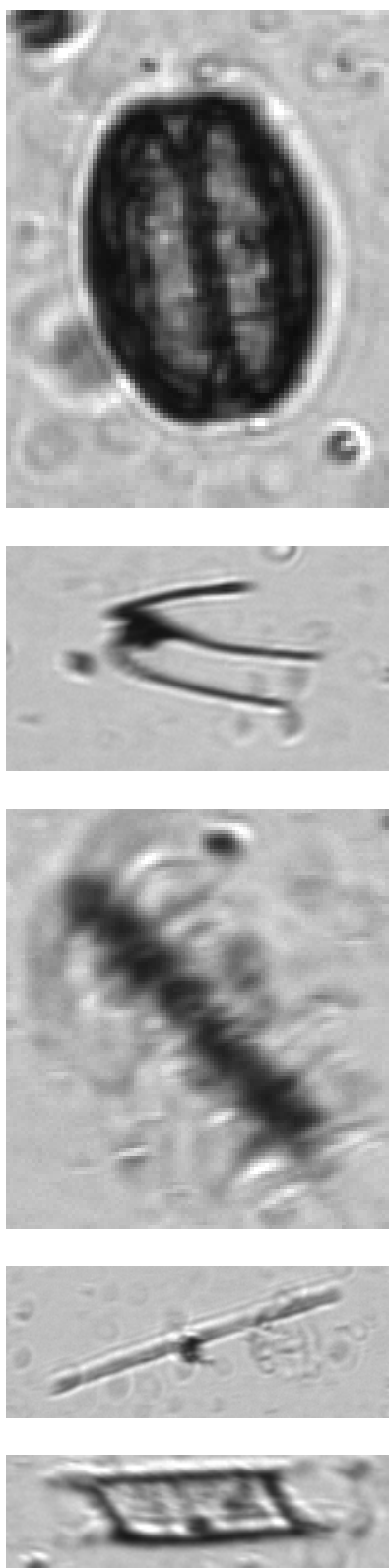

(a) Input
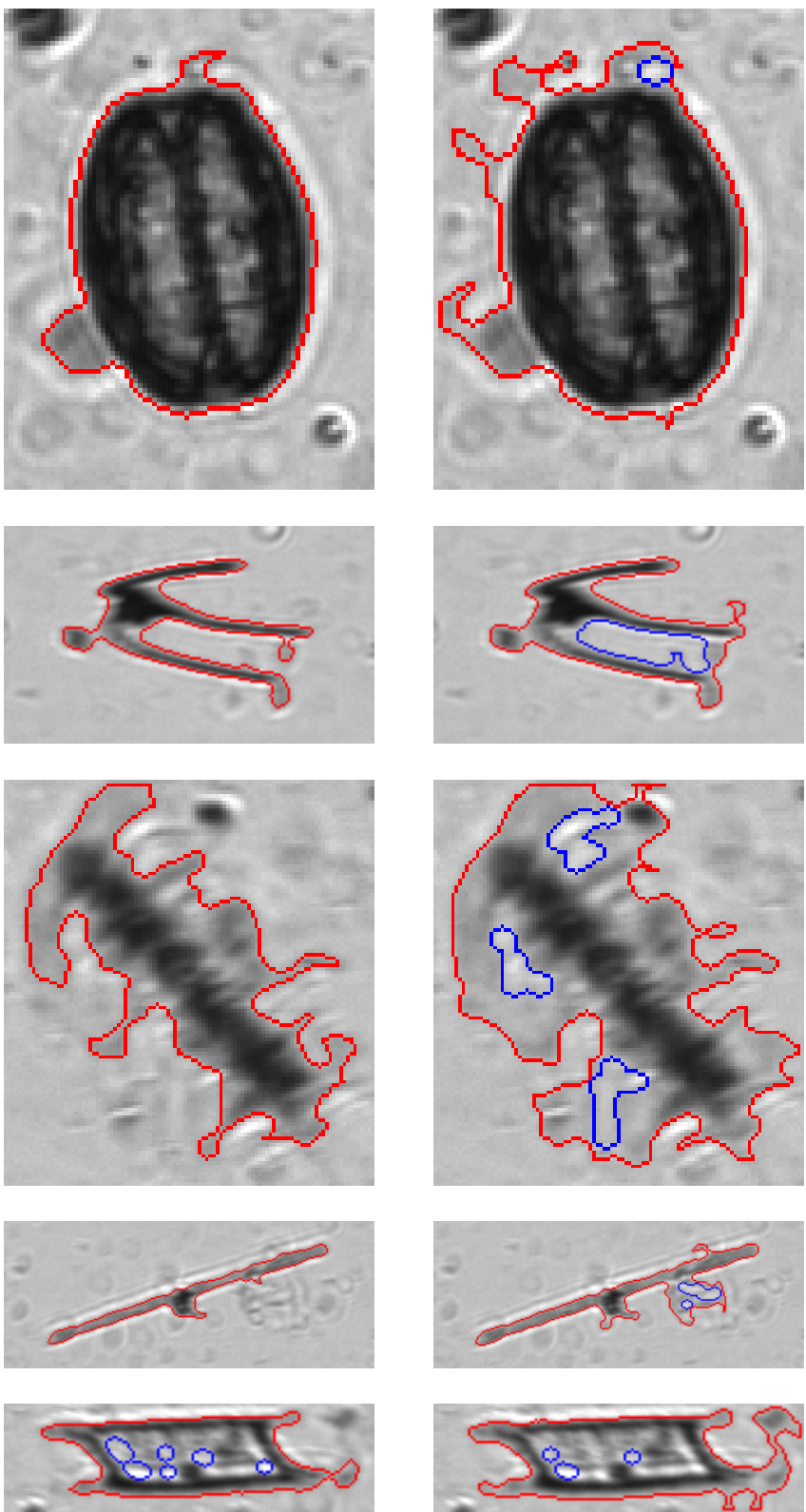

(b) $T=170$
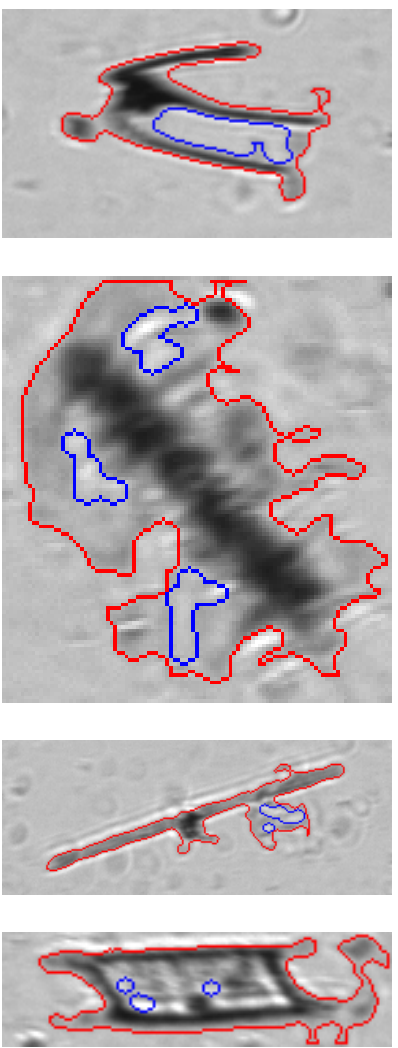

(c) $T=180$

Figura 4.6: Amostras de 5 classes de plâncton, segmentadas usando o método Fixo, com valores de limiarização 170 e 180. De cima para baixo, Coscinodiscus Thalassiosira, Neoceratium, chaetoceros desfocados, filamentos finos e Odontella sinensis. Melhores resultados são obtidos com $T=170$. 


\section{Capítulo 5}

\section{Classificação de imagens de plâncton}

No capítulo anterior vimos que, considerando-se o pipeline de processamento usado na classificação, algoritmos de segmentação podem ser avaliados indiretamente por meio da acurácia de classificação. Portanto, para implementar um pipeline para reconhecimento de plâncton podemos escolher, dentre os vários métodos de segmentação, aquele que resulta em melhor taxa de reconhecimento.

Por outro lado, observamos também que o algoritmo de segmentação que está associado à melhor taxa de reconhecimento global não necessariamente apresenta a melhor taxa de reconhecimento em relação a cada uma das classes. Podem existir algumas classes para as quais a taxa de reconhecimento é maior se um outro algoritmo de segmentação é utilizado.

Portanto, este fato é abordado neste capítulo. Mais precisamente, conjecturamos que se de alguma forma fosse possível escolher para cada alvo a ser classificado um algoritmo de segmentação que favoreça o seu reconhecimento, uma melhor taxa de reconhecimento global poderia ser atingido. Investigamos essa questão e propomos um método para combinar o resultado de múltiplas segmentações na classificação. Ilustramos a aplicação do método no mesmo conjunto de dados usado no capítulo anterior (dataset descrito no apêndice A).

\subsection{Notações}

Para discutir possíveis formas de se explorar classificadores treinados a partir de características extraídas de diferentes segmentações, introduzimos inicialmente algumas notações.

Seja $C$ o número de classes e $J$ o número de métodos de segmentação. Em um cenário mais geral, podemos também variar o conjunto de características e o algoritmo de classificação. Porém, na sequência iremos considerar que o conjunto de características e o modelo de classificador estão fixos. Consideramos também que para o treinamento dos classificadores é 
usada a estratégia OVR.

Para cada classe $c, c=1, \ldots, C$, seja $f_{c}^{j}$ o classificador binário treinado para reconhecer instâncias da classe $c$ usando características extraídas da segmentação obtida com o método $S_{j}, j=1, \ldots, J$.

De acordo com o método OVR, para um método de segmentação fixo $S_{j}$, o classificador final $f^{j}$ é definido, para qualquer instância $x$ a ser classificada, por

$$
f^{j}(x)=\underset{c}{\arg \max }\left\{f_{c}^{j}(x)\right\}
$$

Conforme visto no capítulo anterior, a validação cruzada fornece uma estimativa da acurácia média geral $a^{j}$ e seu respectivo desvio padrão $s^{j}$ para cada classificador $f^{j}$. Podemos também analisar o desempenho de $f^{j}$ por classe, examinando a matriz de confusão. Denotamos como $j^{*}$ o índice do método de segmentação que conduz à melhor classificação média global, e como $j_{c}^{*}$ o índice do método de segmentação que conduz à melhor taxa de reconhecimento restrita à classe $c$. Já sabemos que nem sempre $j_{c}^{*}$ é igual a $j^{*}$.

Assim, como já visto anteriormente, se o objetivo é a identificação de objetos de uma classe específica $c$, poderíamos simplesmente usar $S_{j_{c}^{*}}$ como o método de segmentação. Se o objetivo é a maximização da taxa de reconhecimento global, independentemente de classes específicas, deveríamos usar $S_{j^{*}}$.

Porém, dado que há a possibilidade de não haver um método de segmentação unanimemente melhor, a ideia aqui é desenvolver um método de classificação que explore esse fato para melhorar a taxa de reconhecimento geral.

\subsection{Combinação de múltiplas segmentações na classifica- ção}

Vamos inicialmente supor que sabemos a priori o melhor método de segmentação para cada amostra (embora não saibamos a classe). Dado um exemplo $x$, denotemos o melhor método de segmentação para $x$ por $S_{j_{x}^{*}}$ (i.e., se $x$ é da classe $c$, então $j_{x}^{*}=j_{c}^{*}$ ). Usando essa notação, um classificador poderia ser definido por:

$$
g(x)=\underset{c}{\arg \max }\left\{f_{c}^{j_{x}^{*}}(x)\right\}
$$

Este classificador do tipo OVR faz uso de classificadores binários individuais $f_{c}^{j_{x}^{*}}$, fazendo uso de uma informação privilegiada "supostamente disponível" que é $j_{x}^{*}$. 
Relembrando que o classificador que utiliza o melhor método de segmentação $S_{j^{*}}$ é dado por

$$
f(x)=\underset{c}{\arg \max }\left\{f_{c}^{j^{*}}(x)\right\}
$$

a comparação entre o desempenho dos classificadores $g$ e $f$ permite estimar o potencial de incremento na taxa de reconhecimento geral caso o classificador pudesse usar a informação sobre qual é a segmentação apropriada para cada exemplo a ser classificado.

No entanto, na prática não temos informação alguma sobre a segmentação apropriada para o exemplo a ser classificado. Portanto, apresentamos a seguir um método que pode ser usado para combinar a resposta dos vários classificadores binários individuais, treinados a partir de dados extraídos de diferentes segmentações.

\subsection{Método proposto}

Sejam os classificadores $f_{c}^{j_{c}^{*}}, c=1, \ldots, C\left(f_{c}^{j_{c}^{*}}\right.$ é o classificador treinado para reconhecer instâncias da classe $c$ como positiva, e o resto como negativo, usando características extraídas a partir da segmentação obtida com $S_{j_{c}^{*}}$, o método de segmentação apropriado para a classe $c)$.

Uma primeira ideia consiste em se utilizar os classificadores binários $f_{c}^{j_{c}^{*}}$, isto é, usar para cada classe $c$ o respectivo classificador apropriado (associado à melhor segmentação para aquela classe). Formalmente, o classificador final pode ser definido da seguinte forma:

$$
f(x)=\underset{c}{\arg \max }\left\{f_{c}^{j_{c}^{*}}(x)\right\}
$$

Neste caso, o classificador final $f$ precisa aplicar $C$ classificadores binários sobre o exemplo $x$. Note que quando apenas um método de segmentação é utilizado, digamos o de índice $j_{1}$, os scores $f_{1}^{j_{1}}(x), f_{2}^{j_{1}}(x), \ldots, f_{C}^{j_{1}}(x)$ são diretamente comparáveis (todos os classificadores foram treinados usando a mesma segmentação). No entanto, a comparação entre os scores $f_{c}^{j_{1}}(x) \mathrm{e}$ $f_{c}^{j_{2}}(x)$ (entre diferentes métodos de segmentação) ou entre $f_{c_{1}}^{j_{1}}(x)$ e $f_{c_{2}}^{j_{2}}(x)$ (entre diferentes métodos de segmentações e classes distintas), por exemplo, podem não fazer sentido. Isso pode acontecer pois um mesmo valor absoluto de score pode não corresponder ao mesmo grau de confiança quando considerados entre entradas distintas (no caso, características extraídas a partir de segmentações distintas). 
MultSeg (método proposto): Para evitar o problema no método acima descrito, consideramos o conjunto de todos os scores e a seguinte regra de decisão:

$$
f(x)=\underset{c}{\arg \max }\left\{f_{c}^{j}(x): 1 \leq j \leq J\right\} .
$$

Neste caso, o classificador final precisa calcular um total de $C J$ scores.

A figura 5.1 mostra o diagrama correspondente ao método MultSeg, que será utilizado neste trabalho. 

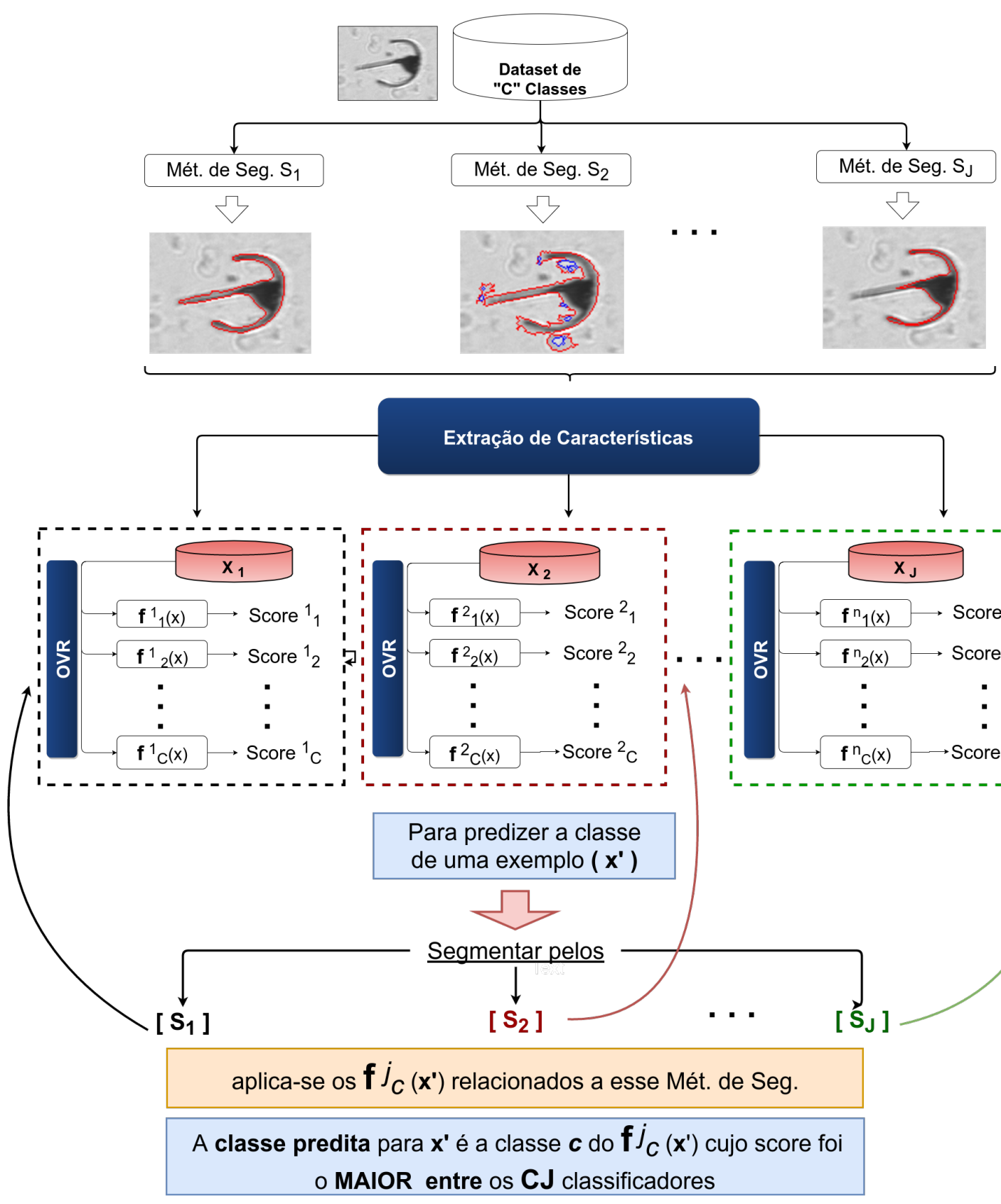

Figura 5.1: Diagrama do método de classificação proposto MultSeg. Dado J métodos de segmentação e um dataset de $C$ classes. $O$ dataset correspondente a cada método de segmentação passa por um processo de extração de características, o qual gera um vetor de características $X_{i}, 1 \leq i \leq J$. Para cada $X_{i}$, classificadores binários são treinados utilizando o esquema OVR. Para predizer a classe de um exemplo $x$ ', o classificador final calcula CJ scores. A classe predita para $x$ 'é a classe c do $f_{c}^{j}\left(x^{\prime}\right)$ cujo score foi o maior entre os CJ classificadores binários. 
Os scores dos classificadores relativos a diferentes métodos de segmentação podem ser normalizados, fazendo com que scores obtidos com um dado método de segmentação sejam comparáveis com os obtidos com outro método. Esses scores normalizados poderiam ser usados tanto no classificador expresso pela equação 5.5 como pela equação 5.4. Em especial, no caso da equação 5.4, o problema indesejado discutido acima seria reduzido.

Cabe observar que as ideias discutidas acima estão fortemente relacionados com o problema de combinação de classificadores e, em particular, com os métodos que consideram a combinação de classificadores treinados utilizando-se diferentes tipos de entrada (por exemplo, diferentes subconjuntos de características).

\subsection{Exemplos de aplicação}

Nesta seção o objetivo é ilustrar a aplicação do método MultSeg (equação 5.5 e figura 5.1). Para tanto utilizamos o mesmo conjunto de dados utilizado no capítulo anterior (ver mais detalhes do dataset no apêndice A). Especificamente, mostramos a escolha da segmentação apropriada para cada classe, e baseado nessa informação também mostramos o cálculo do potencial de melhoramento e a aplicação do método MultSeg proposto acima.

Para tal, os dados são divididos, sendo $75 \%$ para o conjunto de treinamento $S$ e $25 \%$ para o conjunto de teste $T$.

\subsubsection{Segmentação apropriada para cada classe}

A escolha de um método de segmentação apropriada para cada classe pode ser feita analisando-se o desempenho classe a classe dos classificadores treinados a partir de diferentes segmentações, tal como foi descrita na seção 4.3.1.

O 10-fold CV para determinar os métodos de segmentação apropriados para cada classe é aplicado sobre o conjunto $S$. Para cada método de segmentação, temos $C$ classificadores binários, cada um associado a uma classe.

Note que aqui não se utiliza os dados de $T$, pois a informação sobre qual segmentação é mais apropriada para cada classe será usada posteriormente para a classificação. O conjunto $T$ deve ser reservado para avaliar o desempenho da classificação (avaliação do potencial e o método de combinação MultSeg).

A tabela 5.1 mostra os resultados do 10-fold CV aplicados sobre $S$, com respeito aos métodos de segmentação Watershed, Dinâmico e Otsu. Para algumas classes, há uma diferença significativa na acurácia entre os diferentes métodos de segmentação. No entanto, 
dado que o desvio padrão é alto, não é possível afirmar em geral que um método de segmentação é melhor que outro. As taxas mostradas em azul são as maiores acurácias para cada classe (ignorando-se os desvios). Assim, vamos supor, por exemplo, que o método Dinâmico é apropriado para a classe Copepoda calanoida, enquanto o método Otsu é apropriado para as classes Copepoda morto, Coscinodiscus T., Filamentos finos, Nauplios fora de foco e Dinoflagellate fora de foco enquanto o Watershed é apropriado para o restante das classes.

\begin{tabular}{|l|c|c|c|}
\hline \multirow{2}{*}{ Classe } & \multicolumn{3}{|c|}{ Métodos de segmentação } \\
\cline { 2 - 4 } & Watershed & Dinâmico & Otsu \\
\hline \hline Chaetoceros (Chaet.) & $83,036 \pm 14,269$ & $73,929 \pm 14,555$ & $80,179 \pm 11,803$ \\
\hline Chaet, fora de foco & $75,714 \pm 12,247$ & $57,857 \pm 21,132$ & $64,286 \pm 22,602$ \\
\hline Copepoda calanoida & $82,679 \pm 11,765$ & $85,536 \pm 13,727$ & $81,071 \pm 14,357$ \\
\hline Copepoda cyclopoida & $94,821 \pm 6,361$ & $89,286 \pm 10,070$ & $92,143 \pm 8,534$ \\
\hline Copepoda fora de foco & $98,571 \pm 4,286$ & $89,107 \pm 10,116$ & $91,786 \pm 10,839$ \\
\hline Copepoda pulando & $93,393 \pm 8,677$ & $89,107 \pm 8,431$ & $87,857 \pm 9,442$ \\
\hline Copepoda morto & $82,500 \pm 12,106$ & $71,786 \pm 14,214$ & $88,214 \pm 14,268$ \\
\hline Copepoda (sem antena) & $90,893 \pm 8,201$ & $76,429 \pm 13,406$ & $89,821 \pm 14,618$ \\
\hline Coscinodiscus T. & $97,321 \pm 5,372$ & $93,214 \pm 6,814$ & $97,500 \pm 5,000$ \\
\hline Filamentos Finos & $87,321 \pm 14,800$ & $90,357 \pm 12,758$ & $90,893 \pm 11,391$ \\
\hline Filamentos grossos & $82,679 \pm 15,237$ & $69,107 \pm 14,963$ & $74,643 \pm 12,289$ \\
\hline Nauplius fora de foco & $91,964 \pm 9,184$ & $89,107 \pm 8,431$ & $94,643 \pm 6,585$ \\
\hline Dinoflagellate (Dino.) & $95,000 \pm 10,000$ & $80,357 \pm 16,618$ & $89,643 \pm 14,656$ \\
\hline Dino. fora de foco & $85,536 \pm 17,080$ & $77,143 \pm 13,334$ & $86,071 \pm 14,304$ \\
\hline Odontella sinensis & $91,786 \pm 12,956$ & $70,893 \pm 19,870$ & $85,714 \pm 15,152$ \\
\hline Pyrocystis & $100,00 \pm 0,00$ & $71,964 \pm 21,325$ & $92,500 \pm 10,000$ \\
\hline Média & $\mathbf{8 9 , 5 7 6 \pm 2 , 3 6 3}$ & $79,699 \pm 3,521$ & $86,685 \pm 2,964$ \\
\hline
\end{tabular}

Tabela 5.1: Avaliação das segmentaçôes usando 10-fold CV sobre o conjunto de dados $S$.

\subsubsection{Avaliação do potencial}

Para avaliar o potencial, é suposto que para cada amostra a ser classificada o método de segmentação apropriado é conhecido. A equação 5.2 define o classificador que usa essa informação privilegiada. Note que, embora na seção anterior tenhamos verificado que não há uma clara indicação de qual método de segmentação é o apropriado para cada classe, o objetivo aqui é o de ilustrar a aplicação (e não realizar a avaliação) do método. Supomos, portanto, para o restante desta seção, que os métodos apropriados são aqueles destacados na tabela 5.1.

Os classificadores usados neste experimento foram treinados usando todos os exemplos em $S$. Os resultados foram calculados sobre o conjunto de teste $T$. Na tabela 5.2 mostramos nas colunas 2 a 4 as acurácias obtidas quando utiliza-se uma segmentação fixa, no caso um dentre os métodos Watershed, Dinâmico e Otsu, e na coluna 5 a acurácia do classificador que usa informação privilegiada (equação 5.2). A tabela indica que quando a segmentação 
apropriada é utilizada, há um aumento geral na taxa de reconhecimento geral, de cerca de $1 \%$.

\begin{tabular}{|l|c|c|c|c|}
\hline \multirow{2}{*}{ Classe } & \multicolumn{4}{|c|}{ Métodos de segmentação } \\
\cline { 2 - 5 } & Watershed & Dinâmico & Otsu & Potencial \\
\hline \hline Chaetoceros (Chaet.) & 76,000 & 60,000 & 72,000 & 80,000 \\
\hline Chaet. fora de foco & 60,000 & 64,000 & 68,000 & 64,000 \\
\hline Copepoda calanoida & 80,000 & 88,000 & 80,000 & 88,000 \\
\hline Copepoda cyclopoida & 100,00 & 96,000 & 100,00 & 100,00 \\
\hline Copepoda fora de foco & 84,000 & 84,000 & 88,000 & 84,000 \\
\hline Copepoda pulando & 88,000 & 80,000 & 88,000 & 88,000 \\
\hline Copepoda morto & 84,000 & 72,000 & 88,000 & 84,000 \\
\hline Copepoda (sem antena) & 96,000 & 92,000 & 88,000 & 96,000 \\
\hline Coscinodiscus T. & 100,00 & 80,000 & 100,00 & 100,00 \\
\hline Filamentos Finos & 96,000 & 92,000 & 92,000 & 92,000 \\
\hline Filamentos grossos & 84,000 & 72,000 & 96,000 & 84,000 \\
\hline Nauplius fora de foco & 88,000 & 92,000 & 88,000 & 88,000 \\
\hline Dinoflagellate (Dino.) & 96,000 & 80,000 & 96,000 & 96,000 \\
\hline Dino. fora de foco & 92,000 & 68,000 & 88,000 & 92,000 \\
\hline Odontella sinensis & 92,000 & 56,000 & 76,000 & 92,000 \\
\hline Pyrocystis & 96,000 & 84,000 & 88,000 & 96,000 \\
\hline Média & $\mathbf{8 8 , 5 0 0}$ & $\mathbf{7 8 , 7 5 0}$ & $\mathbf{8 7 , 2 5 0}$ & 89,000 \\
\hline
\end{tabular}

Tabela 5.2: Estimação do potencial usando informação privilegiada. Segmentação fixa versus segmentação "correta" para cada classe (de acordo com os resultados da tabela 5.1).

Uma melhora de menos de $1 \%$ é pouco significativa e não justificaria o uso de múltiplas segmentações. Podemos ponderar que o grande desvio padrão observado no desempenho dos classificadores na 10-fold CV pode estar relacionado a esse resultado. De fato, como não há para cada classe um método de segmentação que seja claramente melhor, é plausível que a informação privilegiada não seja confiável e esta pode ser uma explicação para o fato do potencial de melhora ser pouco significativa.

\subsubsection{Método de combinação}

Em uma situação realística onde não se conta com informação relativa à melhor segmentação dos alvos a serem classificados, interessa-nos saber se a combinação de classificadores treinados a partir de diferentes segmentações pode aproximar o potencial de melhora (quando o mesmo existe).

A seguir ilustramos a aplicação do método proposto MultSeg, no qual a decisão é dada pela regra expressa na equação 5.5. Neste caso também os classificadores foram treinados usando os exemplos em $S$ e testados sobre $T$. A tabela 5.3 mostra os resultados obtidos. 


\begin{tabular}{|c|c|c|c|c|}
\hline \multicolumn{5}{|c|}{ Classificação } \\
\hline \multirow{2}{*}{ Classe } & \multicolumn{3}{|c|}{ Segmentação fixa } & Múltiplas segmentações \\
\hline & Watershed & Dinâmico & Otsu & MultSeg \\
\hline "Chaetoceros (Chaet.) & 76,000 & 60,000 & 72,000 & 72,000 \\
\hline Chaet. fora de foco & 60,000 & 64,000 & 68,000 & 60,000 \\
\hline Copepoda calanoida & 80,000 & 88,000 & 80,000 & 80,000 \\
\hline Copepoda cyclopoida & 100,00 & 96,000 & 100,00 & 100,00 \\
\hline Copepoda fora de foco & 84,000 & 84,000 & 88,000 & 88,000 \\
\hline Copepoda pulando & 88,000 & 80,000 & 88,000 & 88,000 \\
\hline Copepoda morto & 84,000 & 72,000 & 88,000 & 92,000 \\
\hline Copepoda (sem antena) & 96,000 & 92,000 & 88,000 & 88,000 \\
\hline Coscinodiscus $T$. & 100,00 & 80,000 & 100,00 & 100,00 \\
\hline Filamentos Finos & 96,000 & 92,000 & 92,000 & 96,000 \\
\hline Filamentos grossos & 84,000 & 72,000 & 96,000 & 96,000 \\
\hline Nauplius fora de foco & 88,000 & 92,000 & 88,000 & 84,000 \\
\hline Dinoflagellate (Dino.) & 96,000 & 80,000 & 96,000 & 96,000 \\
\hline Dino. fora de foco & 92,000 & 68,000 & 88,000 & 92,000 \\
\hline Odontella sinensis & 92,000 & 56,000 & 76,000 & 96,000 \\
\hline Pyrocystis & 96,000 & 84,000 & 88,000 & 96,000 \\
\hline Media & 88.250 & 78.750 & 87.250 & 89,000 \\
\hline
\end{tabular}

Tabela 5.3: Acurácia da classificação calculada sobre T: comparação entre uso de segmentação fixa e método MultSeg.

A tabela mostra um aumento na taxa de reconhecimento geral, de 88,25\% (obtido usando Watershed) para 89,00\% (usando o método de combinação). Este exemplo ilustra, portanto, uma situação na qual a combinação de classificadores treinados sobre distintas segmentações resulta em pequena melhora na taxa de classificação.

Temos, novamente, uma melhora pouco significativa. No próximo capítulo, será descrita a aplicação do mesmo procedimento sobre um conjunto mais realista e maior de imagens de plâncton. 



\section{Capítulo 6}

\section{Resultados Experimentais}

Neste capítulo descrevemos diferentes experimentos relacionados ao processo de classificação de imagens de plâncton. Esses experimentos visam demonstrar a aplicação das abordagens descritas nos capítulos 4 e 5 sobre dados reais. Especificamente, os experimentos versam sobre três aspectos: $(i)$ a avaliação da segmentação, (ii) o potencial da combinação de múltiplas segmentações na classificação, e (iii) a classificação propriamente dita.

Inicialmente descrevemos os dados e a configuração experimental utilizadas. Em seguida descrevemos os experimentos realizados e os resultados obtidos, juntamente com comentários pertinentes.

\subsection{Dataset}

O dataset utilizado nos experimentos deste capítulo consiste de alvos (targets) recortados a partir de imagens obtidas por um sistema óptico (LAPS Camera Recorder System - LCRS) desenvolvido pelo LAPS ${ }^{1}$. O equipamento é uma versão embarcada do SMCP, este último usado no trabalho de Matuszewski (2014).

Vários vídeos foram coletados in situ, em três localidades distintas (Ubatuba e São Sebastião no Brasil, e Piriápolis no Uruguai). Alvos foram detectados desses vídeos usando-se o LPD (LAPS Plankton Detector). Um subconjunto dos alvos recortados foi selecionado, considerando-se os tipos de plâncton mais abundantes encontrados no conjunto total de imagens adquiridas.

O dataset gerado $D$ possui um total de 5074 amostras, agrupadas em 18 classes de tamanhos diversos, variando de $2 \%$ a $13 \%$ do número total de amostras. A figura 6.1 mostra

\footnotetext{
${ }^{1}$ LAPS: Laboratório de Sistemas Planctônicos (LAPS) do Departamento de Oceanografia Biológica, pertencente ao Instituto Oceanográfico da Universidade de São Paulo (IOUSP)
} 


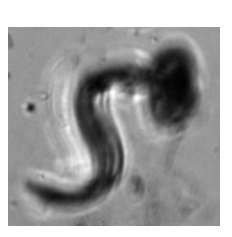

Appendicularia

553

$(10,89 \%)$

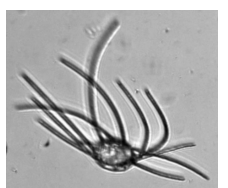

Cnidaria

$96(1,89 \%)$

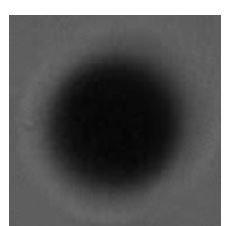

Bubble $393(7,75 \%)$

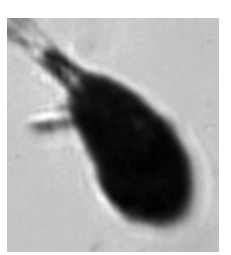

Copepoda (no antenna) $295(5,81 \%)$

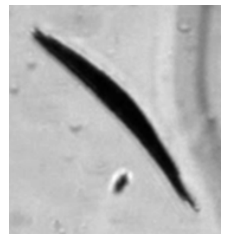

Filaments $257(5,07 \%)$

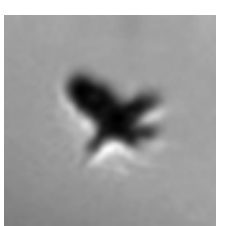

Nauplii

690

$13,60 \%)$

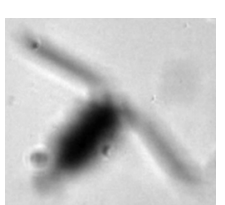

Calanoida $437(8,61 \%)$

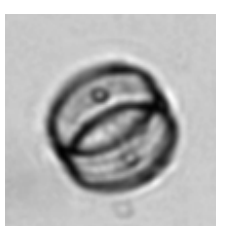

Coscinodiscus $170(3,35 \%)$

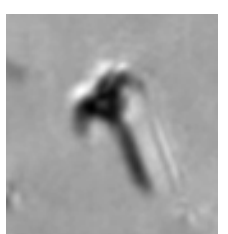

Dinoflagellate $283(5,58 \%)$

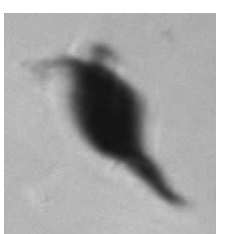

Cyclopoida $172(3,39 \%)$

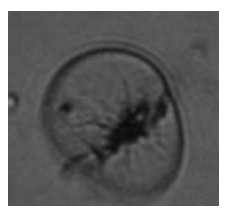

Noctiluca $167(3,29 \%)$

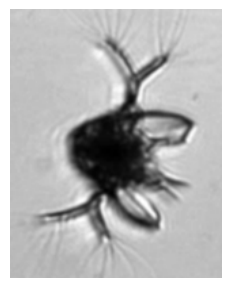

Penilia $427(8,42 \%)$

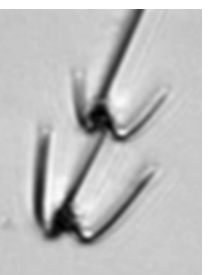

Dinoflagellate (multiple) $202(3,98 \%)$

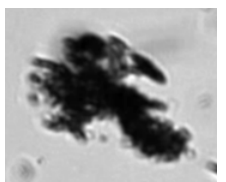

Detritus $389(7,67 \%)$

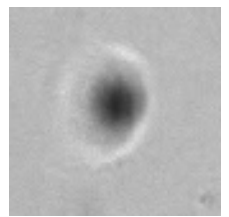

Detritus ball 199 (3, 92\%)

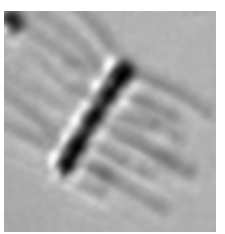

Chaetoceros $145(2,86 \%)$

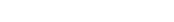

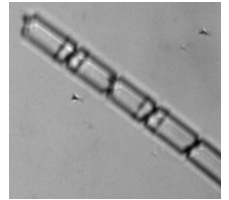

Phyto.

Dactylioso-

len

$98(1,93 \%)$

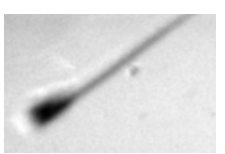

Stalked ciliate $101(1,99 \%)$

Figura 6.1: Exemplares das 18 classes do dataset. A identificaçâo da classe, número de exemplares na classe (e percentagem com repeito ao total de 5074 amostras) são apresentados abaixo de cada exemplar.

um exemplar de cada classe, indicando o nome da classe, o número de alvos por classe, e a distribuição de cada classe em relação ao total de amostras do dataset.

As classes definidas não correspondem necessariamente a espécies distintas de plâncton. Uma mesma espécie pode ter sido dividida em mais de uma classe, baseada em critérios estabelecidos pelos especialistas do LAPS, que foram os responsáveis pela rotulação dos alvos do dataset. Além disso, artefatos como detritos e bolhas são frequentemente recortados como possíveis alvos. Portanto, foi criada uma classe para as bolhas, para detritos circulares e para os demais tipos de detritos (de formatos diversos). 


\subsection{Configuração dos experimentos}

Seguindo o pipeline já descrito, após recortados, os alvos são segmentados, em seguida são extraídas as características, e essas por sua vez são utilizadas para treinar um classificador ou para a aplicação de um classificador já treinado.

\subsubsection{Segmentação}

Consideramos três métodos de segmentação: Watershed, Otsu, e Dinâmico (os quais estão descritos no Apêndice B).

As segmentações foram calculadas utilizando-se o OpenCV.

\subsubsection{Extração de características}

Nos experimentos, consideramos um total de 55 características. Essas foram escolhidas baseadas em relatos na literatura e naquelas usadas no trabalho de Matuszewski (2014). As características referem-se a descritores simples de forma e textura, medidas morfológicas mais elaboradas, medidas de escala de cinzas, e momentos de Hu. Na tabela 6.1 mostramos a lista das características consideradas. Note que neste trabalho a definição, escolha ou avaliação de características interessantes para a discriminação de classes não foi objeto de estudo. Os valores das características foram normalizadas segundo a equação 3.1.

Assim como os métodos de segmentação, a extração de características foi realizada usando-se o OpenCV (Bradski et al., 2000; Its, 2014; Itseez, 2015), versão 2.4.9. As principais características tais como descritores de forma: área (1), momentos de Hu (42-48), convex hull (5) foram utilizadas seguindo-se a documentação de OpenCV (Its, 2014). Outras características (por exemplo alongamento (15) (elongation), circularidade de Wadell (12), diâmetros de Feret, solidez, e convexidade) foram calculadas a partir dos descritores de forma e de histograma.

\subsubsection{Classificadores}

Para a classificação usamos o algoritmo SVM ( $\operatorname{com} \mathrm{C}=13$, kernel RBF e $\gamma=1)$, treinados pelo esquema OVR. Foi utilizada a implementação disponível no sklearn ${ }^{2}$ (Pedregosa et al., 2011).

\footnotetext{
${ }^{2}$ scikit-learn é uma ferramenta open source de aprendizado computacional implementada em python para mineração de dados e análise de dados e construído sobre NumPy, SciPy, e matplotlib.
} 


\begin{tabular}{|c|c|}
\hline \multicolumn{2}{|c|}{ CARACTERÍSTICAS } \\
\hline 1. Área do objeto & 23. Área da caixa delimitadora do objeto \\
\hline 2. Área do objeto sem buracos & $\begin{array}{l}\text { 24. Raio do círculo da área mínima } \\
\text { que encerra o objeto }\end{array}$ \\
\hline 3. Solidez (Solidity) & 25. Eixo menor da elipse que encaixa o objeto \\
\hline 4. Perímetro do objeto & 26. Eixo principal da elipse que encaixa o objeto \\
\hline $\begin{array}{l}\text { 5. Perímetro da envolvente convexa } \\
\text { (Convex hull perimeter) }\end{array}$ & 27. Área da elipse que encaixa o objeto \\
\hline 6. Convexidade & $\begin{array}{l}\text { 28. Distância relativa do centroide do objeto ao } \\
\text { centroide do caixa delimitadora (bounding box) }\end{array}$ \\
\hline 7. Convexidade máxima definida & $\begin{array}{l}\text { 29. Distância relativa do centroide do objeto ao } \\
\text { centroide da envolvente convexa (convex hull) }\end{array}$ \\
\hline 8. Fator de compacidade & $\begin{array}{l}\text { 30. Distância relativa do centroide do objeto } \\
\text { ao centroide da melhor elipse que encaixa o objeto }\end{array}$ \\
\hline 9. Circularidade & $\begin{array}{l}\text { 31. Distância relativa do centroide do objeto ao } \\
\text { centroide do círculo de menor área que encaixa o objeto }\end{array}$ \\
\hline $\begin{array}{l}\text { 10. Circularidade da bacia de drenaguem } \\
\text { (Drainage-basin circularity) }\end{array}$ & $\begin{array}{l}\text { 32. Intensidade média } \\
\text { 32. Intensidade média }\end{array}$ \\
\hline 11. Circularidade de Heywood & 33. Intensidade média excluindo buracos \\
\hline 12. Circularidade de Wadell & $\begin{array}{l}\text { 34. Desvio padrão (intensidade) } \\
\text { da região retangular que encerra o objeto }\end{array}$ \\
\hline 13. Retangularidade & $\begin{array}{l}\text { 35. Desvio padrão (intensidade) excl. buracos } \\
\text { da região retangular que encerra o objeto }\end{array}$ \\
\hline 14. Excentricidade (Eccentricity) & 36. Intensidade mínima \\
\hline 15. Alongamento (Elongation) & 37. Intensidade Máxima \\
\hline 16. Dimensão menor do objeto & 38. Intensidade mediana (Median Intensity) \\
\hline 17. Número Euler & 39. Entropia (intensidade) \\
\hline $\begin{array}{l}\text { 18. Nro. de buracos nos componentes } \\
\text { conexos (No. of holes in conn. comp.) }\end{array}$ & 40. Assimetria ou obliquidade (intensidade) \\
\hline 19. Área do buraco maior no objeto & 41. Curtose (intensidade) \\
\hline $\begin{array}{l}\text { 20. Proporção da área total dos buracos } \\
\text { em relação à área do target }\end{array}$ & 42-48. Momentos de $\mathrm{Hu}(1-7)$ \\
\hline 21. Diâmetro de Feret 1 & 49-55. Logaritmo dos momentos de $\mathrm{Hu}(1-7)$ \\
\hline 22. Diâmetro de Feret 2 & \\
\hline
\end{tabular}

Tabela 6.1: Características extraídas de uma imagem de plâncton segmentada. 


\subsection{Experimentos e resultados}

O conjunto de dados $D$ (ver seção 6.1) foi separado em 4 partes aproximadamente iguais, $D_{1}, D_{2}, D_{3}, D_{4}$, preservando-se a proporção de amostras de cada classe, de forma similar à partição realizada em uma CV estratificada com 4 folds. Antes da divisão, a ordem dos exemplos no conjunto foi aleatorizada para evitar possíveis vieses na criação dessas partes.

\subsubsection{Avaliação da segmentação}

Nesta seção avaliamos os três métodos de segmentação (Watershed, Dinâmico e Otsu) segundo a abordagem proposta no capítulo 4. Apenas para relembrar, a ideia básica consiste em avaliar segmentações por meio da acurácia na classificação.

Seguindo o método proposto, o conjunto de características e o classificador foram fixados conforme descrito acima na seção sobre configuração dos experimentos.

Das partes resultantes da divisão do dataset em 4 folds, $D_{1}, D_{2}, D_{3}, D_{4}$, foram criados 4 pares $\left(S_{i}, T_{i}\right), i=1,2,3,4$, da seguinte forma:

$$
\begin{aligned}
& S_{1}=D_{2} \cup D_{3} \cup D_{4} \text { e } T_{1}=D_{1} \\
& S_{2}=D_{1} \cup D_{3} \cup D_{4} \text { e } T_{2}=D_{2} \\
& S_{3}=D_{1} \cup D_{2} \cup D_{4} \text { e } T_{3}=D_{3} \\
& S_{4}=D_{1} \cup D_{2} \cup D_{3} \text { e } T_{4}=D_{4}
\end{aligned}
$$

Para cada par $\left(S_{i}, T_{i}\right)$, o conjunto $T_{i}(25 \%$ do total $)$ não foi utilizado para que pudesse ser utilizado posteriormente nos outros experimentos. Portanto, o método de avaliação de segmentação por meio do desempenho da classificação foi repetido 4 vezes, uma vez para cada conjunto $S_{i}$ (75\% do conjunto original). O desempenho dos classificadores, para cada método de segmentação considerado, foi avaliado por meio de uma CV estratificada com 10 folds (conforme descrito no capítulo 4) sobre cada conjunto $S_{i}$.

Na tabela 6.2 podemos ver as acurácias médias da validação cruzada para cada método de segmentação e para as 4 iterações. Em todas elas o método de Watershed e Otsu praticamente tem a mesma acurácia, com pequena diferença, não permitindo afirmar que um seja melhor que o outro. Já o método Dinâmico apresenta um desempenho claramente inferior aos dois. Essas diferenças relativas são consistentes nas quatro iterações.

A tabela 6.3 detalha as acurácias por classe, destacando em azul a maior acurácia por classe, do resultado referente à primeira iteração (conjunto $S_{1}$ ). A coluna 6 (Melhor Mét. seg.) indica o método de segmentação que resultou em melhor acurácia para a respectiva 


\begin{tabular}{|c|c|c|c|}
\hline \multirow{2}{*}{ Iterações } & \multicolumn{3}{|c|}{ Acurácia - 10-fold CV (\%) } \\
\cline { 2 - 4 } & Watershed & Dinâmico & Otsu \\
\hline \hline Iteração 1 & $\mathbf{8 4 , 7 3 0} \pm 1,975$ & $82,157 \pm 1,694$ & $\mathbf{8 4 , 6 2 2} \pm 1,166$ \\
\hline Iteração 2 & $\mathbf{8 5 , 2 9 0} \pm 1,732$ & $82,183 \pm 1,783$ & $\mathbf{8 5 , 6 4 8} \pm 0,988$ \\
\hline Iteração 3 & $\mathbf{8 4 , 2 7 2} \pm 1,632$ & $81,564 \pm 1,626$ & $\mathbf{8 4 , 6 1 4} \pm 1,083$ \\
\hline Iteração 4 & $\mathbf{8 4 , 3 2 5} \pm 1,731$ & $81,650 \pm 2,145$ & $\mathbf{8 4 , 3 9 5} \pm 1,487$ \\
\hline
\end{tabular}

Tabela 6.2: Avaliação global dos métodos de segmentação.

classe. Note-se que dois métodos de segmentação apresentam bom desempenho no mesmo número de classes. O método Watershed (em verde) e o método Otsu (em preto) são melhores em 7 e 8 classes respectivamente, enquanto o método Dinâmico (em magenta) foi melhor em 3 classes.

Esse quadro é compatível com as acurácias médias globais. Também indica que há chances de se melhorar a classificação combinando-se classificadores baseados em diferentes métodos de segmentação.

Baseado nesses resultados, se tivéssemos que escolher um único método de segmentação para ser usado no problema de classificação de plâncton, poderíamos escolher ou Watershed ou Otsu, que apresentaram resultados praticamente equivalentes. Caso o interesse seja a maximização da classificação de instâncias de uma determinada classe, então a segmentação pelo método Dinâmico poderia ser escolhida para as classes nas quais ele apresentou melhor desempenho.

\begin{tabular}{|l|c|c|c|c|}
\hline \multicolumn{1}{|c|}{ CLASSES } & \multicolumn{4}{|c|}{ Acurácias das $\mathbf{~ 1 0 - C V ~ p o r ~ m e ́ t o d o ~ d e ~ s e g m e n t a c ̧ a ̃ o ~ e ~ p o r ~ c l a s s e ~ ( \% ) ~}$} \\
\hline Nome da classe & Watershed & Dinâmico & Otsu & Melhor Mét,Seg, \\
\hline \hline Appendicularia & $86,980 \pm 4,123$ & $82,149 \pm 4,749$ & $90,575 \pm 4,746$ & Otsu \\
\hline Bubble & $99,655 \pm 1,034$ & $99,655 \pm 1,034$ & $100,00 \pm 0$ & Otsu \\
\hline Calanoida & $89,924 \pm 2,683$ & $84,129 \pm 7,376$ & $91,411 \pm 5,005$ & Otsu \\
\hline Dinoflagellate & $87,251 \pm 7,992$ & $80,130 \pm 9,317$ & $82,468 \pm 10,071$ & Wat. \\
\hline Dinoflagellate (multiple) & $79,458 \pm 9,654$ & $66,833 \pm 12,029$ & $63,500 \pm 11,016$ & Wat. \\
\hline Chaetoceros & $64,091 \pm 14,243$ & $58,455 \pm 12,662$ & $54,636 \pm 13,669$ & Wat. \\
\hline Cnidaria & $90,357 \pm 9,007$ & $73,393 \pm 17,024$ & $90,179 \pm 12,809$ & Wat. \\
\hline Cop. (no antenna) & $84,130 \pm 9,400$ & $81,028 \pm 6,219$ & $81,008 \pm 8,041$ & Wat. \\
\hline Coscinodiscus & $95,385 \pm 6,154$ & $92,821 \pm 6,740$ & $96,923 \pm 3,768$ & Otsu \\
\hline Cyclopoida & $42,436 \pm 15,644$ & $21,731 \pm 9,656$ & $30,897 \pm 8,198$ & Wat. \\
\hline Detritus & $46,736 \pm 6,742$ & $50,828 \pm 9,258$ & $50,851 \pm 5,181$ & Otsu \\
\hline Detritus ball & $88,619 \pm 8,945$ & $90,619 \pm 9,510$ & $88,619 \pm 7,304$ & Din. \\
\hline Filaments & $83,263 \pm 9,400$ & $95,342 \pm 3,601$ & $92,711 \pm 6,726$ & Din. \\
\hline Nauplii & $95,162 \pm 3,020$ & $95,354 \pm 2,471$ & $95,754 \pm 2,543$ & Otsu \\
\hline Noctiluca & $98,397 \pm 3,208$ & $93,782 \pm 8,299$ & $99,231 \pm 2,308$ & Otsu \\
\hline Penilia & $92,500 \pm 4,002$ & $92,812 \pm 4,851$ & $92,812 \pm 4,204$ & Din. \\
\hline Phyto. dactyliosolen & $88,929 \pm 15,021$ & $83,571 \pm 5,285$ & $97,143 \pm 5,714$ & Otsu \\
\hline Stalked ciliate & $86,607 \pm 15,756$ & $86,607 \pm 8,536$ & $84,107 \pm 10,147$ & Wat. \\
\hline \multicolumn{1}{|c|}{ Média da ACC } & $\mathbf{8 4 , 7 3 0} \pm \mathbf{1 , 9 7 5}$ & $\mathbf{8 2 , 1 5 7} \pm \mathbf{1 , 6 9 4}$ & $\mathbf{8 4 , 6 2 2} \pm \mathbf{1 , 1 6 6}$ & \multirow{2}{|c}{} \\
\hline
\end{tabular}

Tabela 6.3: Avaliação das segmentações usando 10-CV sobre $S_{1}$. 
Esse mesmo experimento, sobre $S_{1}$, foi repetido trocando-se a 10 -fold $\mathrm{CV}$ pela 4 -fold $\mathrm{CV}$. Os resultados podem ser vistos na tabela 6.4. Comparando as colunas "Melhor Mét. Seg." correspondentes ao 10-fold CV (tabela 6.3) e ao 4-fold CV (tabela 6.4) nota-se que a única diferença está na classe Detritus, para a qual de acordo com o 10-fold CV o melhor método de segmentação é o Otsu e de acordo com o 4-fold CV é o Dinâmico. Essas diferenças podem estar relacionadas com as diferenças na quantidade de dados usada no treinamento ( $90 \%$ versus $75 \%$ de $S$ ) e validação ( $10 \%$ versus $25 \%$ de $S$ ). Por outro lado, a comparação indica que os resultados observados são em geral consistentes, a despeito das diferenças nos conjuntos de treinamento e de validação.

\begin{tabular}{|c|c|c|c|c|}
\hline CLASSES & \multicolumn{4}{|c|}{ Acurácias das 4-CV por método de segmentação e por classe (\%) } \\
\hline Nome da classe & Watershed & Dinâmico & Otsu & Melhor Mét,Seg, \\
\hline Appendicularia & $87,442 \pm 4,136$ & $81,399 \pm 1,441$ & $89,360 \pm 2,691$ & Otsu \\
\hline Bubble & $99,658 \pm 0,593$ & $99,320 \pm 0,680$ & $100,00 \pm 0$ & Otsu \\
\hline Calanoida & $89,916 \pm 2,755$ & $84,414 \pm 6,039$ & $90,515 \pm 3,711$ & Otsu \\
\hline Dinoflagellate & $87,264 \pm 3,861$ & $78,774 \pm 5,058$ & $83,962 \pm 3,890$ & Wat. \\
\hline Dinoflagellate (multiple) & $80,139 \pm 2,894$ & $63,620 \pm 10,292$ & $63,620 \pm 5,763$ & Wat. \\
\hline Chaetoceros & $62,037 \pm 6,612$ & $59,259 \pm 3,704$ & $56,481 \pm 6,612$ & Wat. \\
\hline Cnidaria & $93,056 \pm 4,606$ & $75,000 \pm 14,959$ & $90,278 \pm 8,217$ & Wat. \\
\hline Cop. (no antenna) & $83,263 \pm 1,439$ & $81,469 \pm 4,217$ & $81,940 \pm 5,252$ & Wat. \\
\hline Coscinodiscus & $94,531 \pm 4,059$ & $92,087 \pm 3,631$ & $96,875 \pm 2,210$ & Otsu \\
\hline Cyclopoida & $42,637 \pm 10,443$ & $21,709 \pm 5,853$ & $28,693 \pm 3,474$ & Wat. \\
\hline Detritus & $44,340 \pm 6,661$ & $47,094 \pm 5,206$ & $47,070 \pm 3,807$ & Din. \\
\hline Detritus ball & $88,602 \pm 5,157$ & $91,963 \pm 2,634$ & $87,962 \pm 5,423$ & Din. \\
\hline Filaments & $86,458 \pm 4,774$ & $95,312 \pm 2,706$ & $93,229 \pm 3,719$ & Din. \\
\hline Nauplii & $94,972 \pm 1,936$ & $95,745 \pm 2,599$ & $96,134 \pm 1,968$ & Otsu \\
\hline Noctiluca & $98,412 \pm 1,588$ & $92,843 \pm 3,354$ & $99,219 \pm 1,353$ & Otsu \\
\hline Penilia & $91,875 \pm 1,875$ & $92,188 \pm 2,232$ & $91,250 \pm 3,187$ & Din. \\
\hline Phyto. dactyliosolen & $91,740 \pm 6,245$ & $82,164 \pm 4,687$ & $95,906 \pm 4,586$ & Otsu \\
\hline Stalked ciliate & $87,865 \pm 12,221$ & $86,623 \pm 5,994$ & $83,991 \pm 3,741$ & Wat. \\
\hline Média da ACC & $84,703 \pm 1,129$ & $81,621 \pm 1,560$ & $84,123 \pm 1,002$ & \\
\hline
\end{tabular}

Tabela 6.4: Avaliação das segmentações usando 4-CV sobre $S_{1}$.

\subsubsection{Potencial da combinação de múltiplas segmentações}

A partir dos resultados de avaliação de segmentação descritos acima, foram realizados experimentos para avaliar o potencial de combinação de múltiplas segmentações na classificação. Aqui comparamos o desempenho entre os classificadores para cada segmentação e a classificação que utiliza a informação privilegiada. Neste último, para cada instância de teste aplica-se o classificador treinado com o método de segmentação que foi considerado o melhor para a classe daquela instância.

Usamos inicialmente como melhor segmentação para cada classe aqueles indicados na tabela 6.3, referentes ao conjuntos $S_{1}$, usado na primeira iteração das 4 realizadas.

Assim, neste experimento, treinamos $C=18$ classificadores no esquema OVR para cada 
método de segmentação, usando todos os dados de $S_{1}$. Portanto, foram gerados $3 * C$ classificadores binários, 3 por classe. Note que, neste experimento, usam-se todos os dados de $S_{1}$ para o treinamento (enquanto que no experimento anterior foi aplicado um 10-fold $\mathrm{CV}$ sobre $\left.S_{1}\right)$.

Para calcular o potencial, para cada amostra de teste $x \in T_{1}$, aplicou-se o classificador treinado com a segmentação apropriada para classe de $x$. Por exemplo, se $x$ é uma amostra de uma classe para a qual a melhor segmentação é Watershed, então aplicam-se os $C$ classificadores binários obtidos a partir das características extraídas das imagens segmentadas pelo Watershed. Atribui-se a $x$ a classe associada ao classificador binário que devolveu o maior score. Os resultados são apresentados na tabela 6.5 .

\begin{tabular}{|c|c|c|c|c|c|}
\hline \multicolumn{6}{|c|}{ Potencial usando resultados da tab. 6.3} \\
\hline \multicolumn{2}{|r|}{ CLASSES } & \multicolumn{4}{|c|}{ Acurácia detalhada por classe (\%) } \\
\hline$\#$ & Nome da classe & Watershed & Dinâmico & Otsu & Potencial \\
\hline $\mathrm{C} 1$ & Appendicularia & 88,489 & 84,173 & 89,928 & 89,928 \\
\hline $\mathrm{C} 2$ & Bubble & 100,00 & 98,990 & 100,00 & 100,00 \\
\hline C3 & Calanoida & 87,273 & 98,990 & 88,182 & 90,000 \\
\hline $\mathrm{C} 4$ & Dinoflagellate & 76,056 & 78,873 & 73,239 & 76,056 \\
\hline C5 & Dinoflagellate multiple & 72,549 & 49,020 & 64,706 & 72,549 \\
\hline C6 & Chaetoceros & 70,270 & 62,162 & 64,865 & 70,270 \\
\hline $\mathrm{C} 7$ & Cnidaria & 83,333 & 87,500 & 91,667 & 95,833 \\
\hline $\mathrm{C} 8$ & Cop. (no antenna) & 86,486 & 89,189 & 79,730 & 89,189 \\
\hline C9 & Coscinodiscus & 93,023 & 86,047 & 93,023 & 93,023 \\
\hline $\mathrm{C} 10$ & Cyclopoida & 48,837 & 48,837 & 41,860 & 46,512 \\
\hline C11 & Detritus & 57,143 & 59,184 & 57,143 & 55,102 \\
\hline $\mathrm{C} 12$ & Detritus ball & 88,000 & 90,000 & 90,000 & 88,000 \\
\hline C13 & Filaments & 80,000 & 95,385 & 89,231 & 96,923 \\
\hline $\mathrm{C} 14$ & Nauplii & 89,595 & 93,642 & 94,798 & 94,798 \\
\hline $\mathrm{C} 15$ & Noctiluca & 100,00 & 97,619 & 97,619 & 97,619 \\
\hline $\mathrm{C} 16$ & Penilia & 91,589 & 91,589 & 93,458 & 92,523 \\
\hline $\mathrm{C} 17$ & Phyto. dactyliosolen & 92,000 & 80,000 & 96,000 & 96,000 \\
\hline $\mathrm{C} 18$ & Stalked ciliate & 84,615 & 96,154 & 88,462 & 88,462 \\
\hline & Média da ACC & 83,947 & 83,477 & 84,573 & 86,218 \\
\hline
\end{tabular}

Tabela 6.5: Classificação de plâncton usando segmentaçôes fixas versus o potencial sobre $T_{1}$ usando 10-fold CV na avaliação das segmentações.

De forma geral, o potencial de melhora da acurácia global (86,218\%, em vermelho) é superior às acurácias obtidas usando segmentação fixa (83, 947\% para Watershed, 83, 477\% para Dinâmico e $84,573 \%$ para Otsu). Além disso, um ponto que podemos destacar na tabela 6.5 são os resultados referentes às classes Cyclopoida (C10) e Detritus (C11). Os resultados referentes aos três métodos de segmentação são relativamente inferiores em relação aos de outras classes. Uma explicação para isso é o fato das amostras da classe Cyclopoida terem características parecidas com as das classes Calanoida (C3) e Cop. no antenna (C8). 
No caso da classe Detritus, a baixa acurácia é provavelmente devida à variações na forma e aspectos das amostras por esses serem de plâncton mortos e organismos não-plânctonicos em decomposição ou partículas de sujeira.

Por exemplo, várias amostras da classe Detritus foram classificadas como Appendicularia(C1), Ceratium(C4), Cop. no antenna (C8), Nauplio (C14) e Penilia (C16). Na figura 6.2 podemos ver amostras da classe Detritus parecidas com de outras classes.

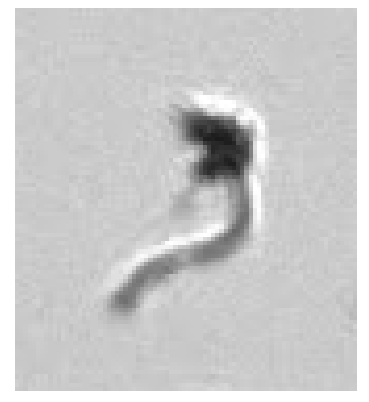

(a)

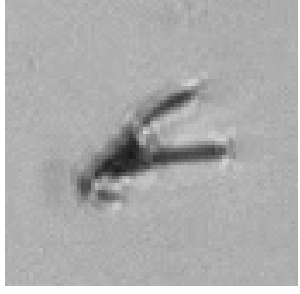

(b)

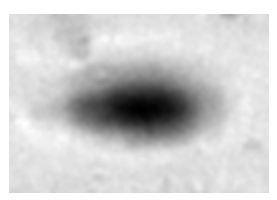

(c)

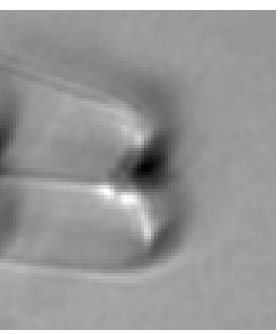

(g)

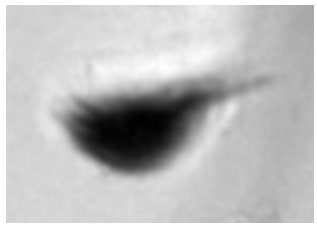

(h)

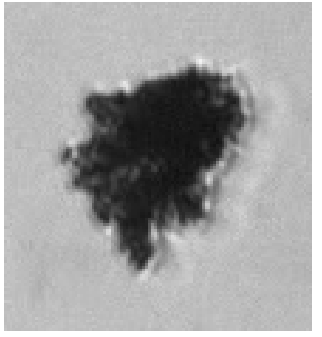

(d)

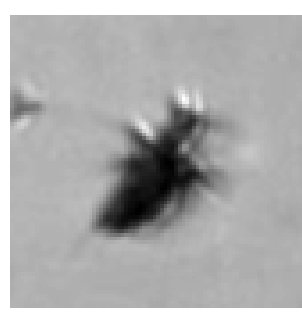

(i)

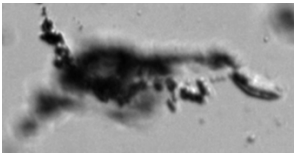

(e)

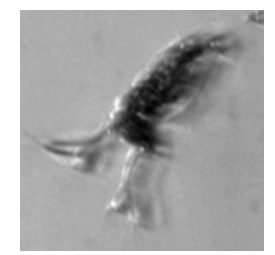

(j)

Figura 6.2: Exemplos de similaridade de amostras da classe Detritus e de outras classes. (a) (e) amostras da classe detritus; (f) Appendicularia; (g) Dinoflagellate; (h) Cop.(no antenna); (i) Nauplii; (j) Penilia.

Esta avaliação de potencial foi repetida para os outros três pares, das 3 últimas iterações descritas na seção anterior. Os resultados referentes às quatro iterações estão sumarizados na tabela 6.6. O potencial obtido nas quatro iterações apresenta comportamento similar ao discutido acima, sendo consistente entre eles.

\begin{tabular}{|c|c|c|c|c|}
\hline \multicolumn{5}{|c|}{ Potencial nas 4 iterações usando resultados da tab. 6.3 } \\
\hline \multirow{2}{*}{ Tteração } & \multicolumn{3}{|c|}{ Total de instâncias corretamente classificadas (\%) } \\
\cline { 2 - 5 } & Watershed & Dinâmico & Otsu & Potencial \\
\hline \hline 01 & 83,947 & 83,477 & 84,573 & 86,218 \\
\hline \hline 02 & 84,646 & 82,598 & 84,646 & 85,669 \\
\hline \hline 03 & 85,624 & 83,649 & 86,019 & 87,520 \\
\hline \hline 04 & 85,964 & 83,426 & 85,646 & 86,281 \\
\hline \hline Média & $\mathbf{8 5 , 0 4 5} \pm \mathbf{0 , 7 9 8}$ & $\mathbf{8 3 , 2 8 8} \pm \mathbf{0 , 4 0 6}$ & $\mathbf{8 5 , 2 2 1} \pm \mathbf{0 , 6 2 6}$ & $\mathbf{8 6 , 3 4 2} \pm \mathbf{0 , 4 2 9}$ \\
\hline
\end{tabular}

Tabela 6.6: Médias das acurácias globais obtidas nas 4 iterações. Em todos os casos foi utilizada 10-fold CV na avaliação de segmentações. 
Na tabela 6.7 apresentamos as médias das acurácias por classes e as médias das acurácias globais obtidas nas 4 iterações usando os 3 métodos de segmentação e a abordagem. Podemos observar nesse resultado o mesmo padrão de comportamento que vimos na tabela. 6.5.

\begin{tabular}{|c|l|c|c|c|}
\hline \multicolumn{5}{|c|}{ Média do Potencial nas 4 iterações usando resultados da tab. 6.3 } \\
\hline \multirow{2}{*}{$\begin{array}{c}\text { ID } \\
\text { Classes }\end{array}$} & \multicolumn{3}{|c|}{ Média das Acurácias detalhada por classe (\%) } \\
\cline { 2 - 5 } & Watershed & Dinâmico & Otsu & Potencial \\
\hline \hline C1 & $86,615 \pm 2,392$ & $83,362 \pm 0,554$ & $88,062 \pm 1,117$ & $88,424 \pm 1,051$ \\
\hline C2 & $99,490 \pm 0,884$ & $99,237 \pm 0,845$ & $100,00 \pm 0$ & $99,490 \pm 0,884$ \\
\hline 3 & $88,791 \pm 2,262$ & $84,443 \pm 3,350$ & $90,394 \pm 1,481$ & $92,454 \pm 2,162$ \\
\hline C4 & $84,472 \pm 5,137$ & $78,788 \pm 1,865$ & $82,334 \pm 5,493$ & $84,477 \pm 5,507$ \\
\hline C5 & $77,755 \pm 3,599$ & $60,951 \pm 8,148$ & $63,373 \pm 5,858$ & $78,745 \pm 4,113$ \\
\hline C6 & $64,095 \pm 4,660$ & $62,763 \pm 2,294$ & $64,827 \pm 4,089$ & $64,095 \pm 3,741$ \\
\hline C7 & $87,500 \pm 5,103$ & $76,042 \pm 9,490$ & $88,542 \pm 3,455$ & $89,583 \pm 4,658$ \\
\hline C8 & $83,728 \pm 1,914$ & $82,363 \pm 4,625$ & $82,710 \pm 3,873$ & $85,760 \pm 3,109$ \\
\hline C9 & $94,131 \pm 3,545$ & $91,764 \pm 4,198$ & $95,293 \pm 2,354$ & $95,889 \pm 3,062$ \\
\hline C10 & $51,163 \pm 8,222$ & $41,860 \pm 4,933$ & $43,023 \pm 4,193$ & $43,023 \pm 6,262$ \\
\hline C11 & $55,523 \pm 3,091$ & $58,610 \pm 2,367$ & $57,842 \pm 1,878$ & $53,982 \pm 2,281$ \\
\hline C12 & $87,449 \pm 1,582$ & $90,969 \pm 2,195$ & $87,959 \pm 3,698$ & $87,969 \pm 4,199$ \\
\hline C13 & $84,062 \pm 3,638$ & $92,206 \pm 3,332$ & $87,933 \pm 4,053$ & $94,934 \pm 2,041$ \\
\hline C14 & $93,918 \pm 2,594$ & $95,366 \pm 1,465$ & $95,945 \pm 1,076$ & $95,799 \pm 1,107$ \\
\hline C15 & $98,795 \pm 1,205$ & $93,423 \pm 3,077$ & $98,810 \pm 1,190$ & $98,200 \pm 1,040$ \\
\hline C16 & $92,038 \pm 2,990$ & $92,977 \pm 3,129$ & $92,735 \pm 2,925$ & $92,268 \pm 3,138$ \\
\hline$C 17$ & $90,792 \pm 1,905$ & $80,583 \pm 3,562$ & $94,917 \pm 3,394$ & $95,917 \pm 2,947$ \\
\hline C18 & $87,154 \pm 3,186$ & $88,038 \pm 8,039$ & $86,115 \pm 4,528$ & $91,115 \pm 5,133$ \\
\hline Média & $\mathbf{8 5 , 0 4 5} \pm \mathbf{0 , 7 9 8}$ & $\mathbf{8 3 , 2 8 8} \pm \mathbf{0 , 4 0 6}$ & $\mathbf{8 5 , 2 2 1} \pm \mathbf{0 , 6 2 6}$ & $\mathbf{8 6 , 4 2 2} \pm \mathbf{0 , 6 7 7}$ \\
\hline
\end{tabular}

Tabela 6.7: Médias das acurácias obtidas nas 4 iterações, detalhadas por classe.

\subsubsection{Classificação}

Nesta seção descrevemos experimentos com o método MultSeg proposto no capítulo 5.

Os mesmos classificadores treinados na avaliação do potencial são usados aqui. A diferença é que a decisão sobre a classificação final não utiliza a informação sobre qual é o método de segmentação adequado para o exemplo de teste. A regra de decisão é a descrita na equação 5.5. Isto é, dentre todos os $3 * 18$ classificadores binários, aquele que resulta em maior score determina a classe a ser atribuída à amostra de teste.

A tabela 6.8 mostra a acurácia por classe e a acurácia média geral para os casos de segmentação fixa (colunas 3, 4 e 5) e para o caso de combinação de segmentações (coluna 6), para a partição $\left(S_{1}, T_{1}\right)$ usada na primeira iteração. Como pode ser visto, a combinação resultou em uma melhora de cerca de $2 \%$ na acurácia global.

A seguir apresentamos a matriz de confusão. As classes com maiores erros são a 10 - 13 instâncias de classe 10 (Cyclopoida) foram classificadas como sendo da classe 8 (Copepoda), e a classe 11 - um número significativo de Detritus foram classificados como pertencentes a outras classes. 


\begin{tabular}{|l|l|c|c|c|c|}
\hline \multicolumn{5}{|c|}{ Classificação } \\
\hline \multirow{2}{*}{ Nome da Classe } & \multicolumn{2}{|c|}{ Segmentação fixa } & Múlt. segmentações \\
\cline { 3 - 6 } & Watershed & Dinâmico & Otsu & MultSeg \\
\hline \hline C1 & Appendicularia & 88,489 & 84,173 & 89,928 & 90,647 \\
\hline C2 & Bubble & 100,00 & 98,990 & 100,00 & 98,989 \\
\hline C3 & Calanoida & 87,273 & 98,990 & 88,182 & 90,909 \\
\hline C4 & Dinoflagellate & 76,056 & 78,873 & 73,239 & 77,464 \\
\hline C5 & Dinoflagellate (multiple) & 72,549 & 49,020 & 64,706 & 76,470 \\
\hline C6 & Chaetoceros & 70,270 & 62,162 & 64,865 & 75,675 \\
\hline C7 & Cnidaria & 83,333 & 87,500 & 91,667 & 91,666 \\
\hline C8 & Cop. no antenna & 86,486 & 89,189 & 79,730 & 85,135 \\
\hline C9 & Coscinodiscus & 93,023 & 86,047 & 93,023 & 93,023 \\
\hline C10 & Cyclopoida & 48,837 & 48,837 & 41,860 & 46,511 \\
\hline C11 & Detritus & 57,143 & 59,184 & 57,143 & 56,122 \\
\hline C12 & Detritus ball & 88,000 & 90,000 & 90,000 & 94,000 \\
\hline C13 & Filaments & 80,000 & 95,385 & 89,231 & 93,846 \\
\hline C14 & Nauplii & 89,595 & 93,642 & 94,798 & 93,641 \\
\hline C15 & Noctiluca & 100,00 & 97,619 & 97,619 & 97,619 \\
\hline C16 & Penilia & 91,589 & 91,589 & 93,458 & 93,457 \\
\hline C17 & Phyto. dactyliosolen & 92,000 & 80,000 & 96,000 & 100,00 \\
\hline C18 & Stalked ciliate & 84,615 & 96,154 & 88,462 & 92,307 \\
\hline \hline & Média (ACC.) & $\mathbf{8 3 , 9 4 7}$ & $\mathbf{8 3 , 4 7 7}$ & $\mathbf{8 4 , 5 7 3}$ & $\mathbf{8 6 , 6 0 9}$ \\
\hline
\end{tabular}

Tabela 6.8: Acurácia sobre $T_{1}$ usando o método Multseg versus segmentação fixa.

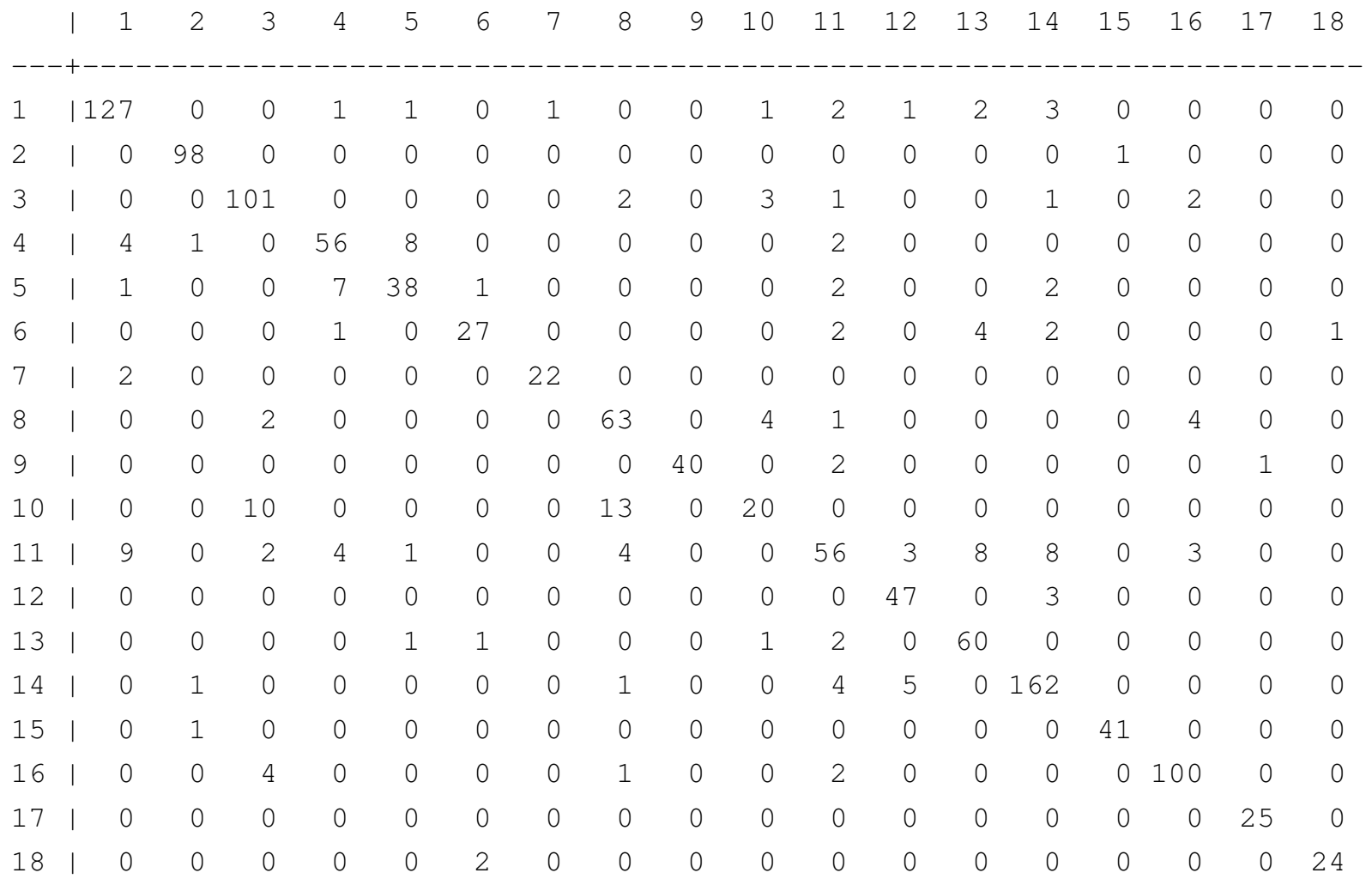




\subsubsection{Sumário e discussão}

Os resultados apresentados acima são sumarizados na tabela 6.9. Nela mostramos as acurácias obtidas utilizando-se segmentação fixa, o potencial de melhoria da acurácia caso tenhamos conhecimento da segmentação adequada (de acordo com a forma de avaliação proposta nesta dissertação) para cada instância, e a acurácia obtida com o método MultSeg que combina classificadores treinados a partir de múltiplas segmentações.

\begin{tabular}{|c|c|c|c|c|c|}
\hline \multicolumn{5}{|c|}{ Média das Acurácias detalhada por classe (\%) } \\
\hline \multirow{2}{*}{ Classe } & \multicolumn{3}{|c|}{ Segmentação fixa } & Múltiplas segmentações \\
\cline { 2 - 6 } & Watershed & Dinâmico & Otsu & Potencial & MultSeg \\
\hline \hline C1 & 88,489 & 84,173 & 89,928 & 89,928 & 90,647 \\
\hline C2 & 100,00 & 98,990 & 100,00 & 100,00 & 98,989 \\
\hline C3 & 87,273 & 98,990 & 88,182 & 90,000 & 90,909 \\
\hline C4 & 76,056 & 78,873 & 73,239 & 76,056 & 77,464 \\
\hline C5 & 72,549 & 49,020 & 64,706 & 72,549 & 76,470 \\
\hline C6 & 70,270 & 62,162 & 64,865 & 70,270 & 75,675 \\
\hline C7 & 83,333 & 87,500 & 91,667 & 95,833 & 91,666 \\
\hline C8 & 86,486 & 89,189 & 79,730 & 89,189 & 85,135 \\
\hline C9 & 93,023 & 86,047 & 93,023 & 93,023 & 93,023 \\
\hline C10 & 48,837 & 48,837 & 41,860 & 46,512 & 46,511 \\
\hline C11 & 57,143 & 59,184 & 57,143 & 55,102 & 56,122 \\
\hline C12 & 88,000 & 90,000 & 90,000 & 88,000 & 94,000 \\
\hline C13 & 80,000 & 95,385 & 89,231 & 96,923 & 93,846 \\
\hline C14 & 89,595 & 93,642 & 94,798 & 94,798 & 93,641 \\
\hline C15 & 100,00 & 97,619 & 97,619 & 97,619 & 97,619 \\
\hline C16 & 91,589 & 91,589 & 93,458 & 92,523 & 93,457 \\
\hline C17 & 92,000 & 80,000 & 96,000 & 96,000 & 100,00 \\
\hline C18 & 84,615 & 96,154 & 88,462 & 88,462 & 92,307 \\
\hline \hline Média & $\mathbf{8 3 , 9 4 7}$ & $\mathbf{8 3 , 4 7 7}$ & $\mathbf{8 4 , 5 7 3}$ & $\mathbf{8 6 , 2 1 8}$ & $\mathbf{8 6 , 6 0 9}$ \\
\hline
\end{tabular}

Tabela 6.9: Tabela resumo das acurácias obtidas: classificação usando métodos de segmentação fixo, avaliação do potencial e classificação final.

Uma análise por classe mostra, porém, que embora a acurácia global da combinação seja superior, ela apresenta para algumas classes um desempenho pior do que os classificadores com segmentação fixa. Isto significa que a regra simples da equação 5.5, de decidir pela classe baseando-se simplesmente no classificador com maior score, não é capaz de capturar totalmente o melhor dos classificadores individuais.

Conforme já discutido no capítulo 5, uma possível forma para abordar esse problema seria por meio de normalização dos scores entre diferentes segmentações. Neste trabalho não testamos essa possibilidade. 


\section{Capítulo 7}

\section{Conclusões}

Nesta dissertação, estudamos o problema de classificação de plâncton. Descrevemos cada uma das etapas do pipeline típico para classificação de imagens de plâncton, e examinamos como elas são tratadas em alguns trabalhos da literatura relacionados e que serviram como referências para esta dissertação. Também fizemos uma breve descrição dos principais métodos sobre avaliação de segmentações e comentamos as características desses métodos que os fazem inadequados para as necessidades deste trabalho. Em seguida apresentamos o método proposto nesta dissertação para avaliar a segmentação de forma indireta. A avaliação é feita por meio da avaliação do desempenho na classificação, reduzindo desta forma o esforço necessário para a geração de dados a serem usados para a avaliação (por exemplo ground truths). Ilustramos a aplicação da avaliação proposta em um conjunto de imagens de plâncton e mostramos que o método é útil para escolher, dentre os vários métodos de segmentação, aquele que resulta em melhor taxa de reconhecimento. Observamos também que o método de segmentação que está associado à melhor taxa de reconhecimento global não necessariamente apresenta a melhor taxa de reconhecimento em relação a cada uma das classes.

A partir da informação encontrada sobre os melhores algoritmos de segmentação para cada classe, conjecturamos que se de alguma forma fosse possível escolher para cada alvo a ser classificado um método de segmentação que favoreça o seu reconhecimento, uma melhor taxa de reconhecimento global poderia ser atingido. Baseado nessa ideia propomos um método para combinar os resultados de múltiplas segmentações na classificação.

Os métodos propostos para a avaliação de segmentação e para a combinação de múltiplas segmentações na classificação foram aplicadas sobre um conjunto de imagens de plâncton coletadas in situ, contendo um total 5074 amostras distribuídas em 18 classes de tamanho não-uniforme. A combinação de múltiplas segmentações resultou em uma melhora na acurácia global de cerca $2 \%$. 


\subsection{Sugestões para pesquisas futuras}

Os experimentos com o método de avaliação das segmentações por meio de um esquema de validação cruzada apresentaram em geral alta variância, não permitindo em alguns casos afirmar que um método de segmentação fosse superior a outro. Como discutido no texto, uma variância muito grande pode afetar a posterior etapa de combinação. Portanto, os resultados sugerem que um número grande de imagens, maiores que os considerados neste trabalho, devem ser usados para a avaliação de algoritmos de segmentação, para que resultados mais robustos sejam obtidos. Nesse sentido, pesquisas que facilitem a construção e extensão de datasets existentes, devem ser realizadas.

Os experimentos com o método de classificação baseado na combinação de múltiplas segmentações mostraram que alguns pontos merecem uma investigação maior. Embora o classificador usando múltiplas segmentações tenha apresentado uma acurácia global superior, essa superioridade não ocorreu uniformemente sobre todas as classes. Para algumas classes específicas, observou-se um desempenho pior em relação aos classificadores associados a um método de segmentação fixo.

Além de uma avaliação mais robusta sobre o método de segmentação apropriado para cada classe, como possíveis formas para abordar esse ponto, mencionamos a normalização dos scores de classificadores obtidos a partir de diferentes segmentações, de forma que os scores correspondentes aos distintos classificadores binários associados aos diferentes métodos de segmentação possam ser diretamente comparáveis entre si.

Devido ao fato da classe Detritus ser composta de partículas que não tem formas bem definidas a priori, um método de classificação hierárquica que primeiramente realiza uma separação grosseira (por exemplo detrito versus não-detrito) pode ter impacto na redução da complexidade dos demais classificadores binários.

Alguns trabalhos que utilizam deep learning para a classificação de imagens de plâncton (Ellen et al., 2015; Krizhevsky et al., 2012; Py et al., 2016a; Simonyan e Zisserman , 2015) vem sendo propostos mais recentemente. Contrastar métodos de classificação baseados nessa técnica com os métodos que seguem o pipeline clássico pode ser útil para, eventualmente, produzir técnicas híbridas que combinam os pontos fortes de cada uma delas.

Adicionalmente, investigações relacionadas às características utilizadas, desde efeitos da seleção de características a novos tipos de características (tais como descritores de Fourier elípticos do contorno (Kuhl e Giardina, 1982), estatísticas de uma matriz de co-ocorrência de níveis de cinza do Roi (Haralick et al., 1973; Walker et al., 1995), medidas de simetria (Fischer et al., 2000), padrões binários locais invariantes à rotação (Ahonen et al., 2009), entre outras) poderiam ser incorporadas no estudo realizado nesta dissertação. 


\section{Apêndice A}

\section{Dataset usado no trabalho de Matuszewski (2014)}

O dataset utilizado nos experimentos do capítulo 4 e 5 é o mesmo utilizado por Matuszewski (2014). A aquisição dessas imagens foi feita em ambientes controlados (laboratório) através do SMCP. Depois as imagens foram rotuladas por pesquisadores do Laboratório de Sistemas Planctônicos (LAPS) do Departamento de Oceanografia Biológica, pertencente ao Instituto Oceanográfico da Universidade de São Paulo (IOUSP).

As classes dos datasets não correspondem precisamente a espécies diferentes de plâncton. Uma mesma espécie pode ter sido dividida em mais de uma classe, baseada em algum critério conveniente e subjetivo.

O dataset consiste de 16 classes com 100 imagens cada, somando um total de 1600 imagens de plâncton. A figura A.1 mostra um exemplar de cada classe do dataset. 


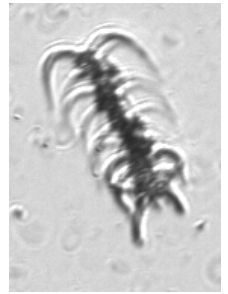

Chaetoceros

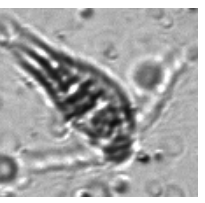

Copepoda morto

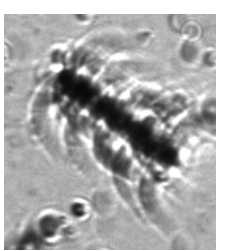

Chaetoceros

sem foco

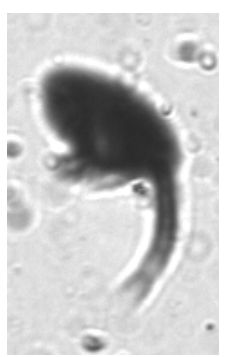

Copepoda (no antenna)

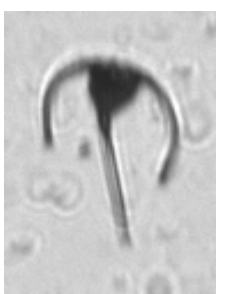

Neoceratium

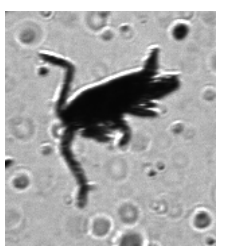

Calanoida

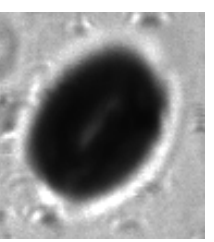

Coscinodiscus $T$.

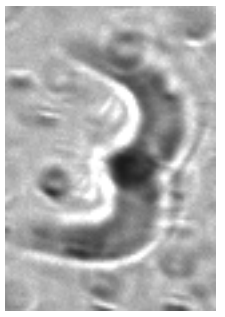

Neoceratium sem foco

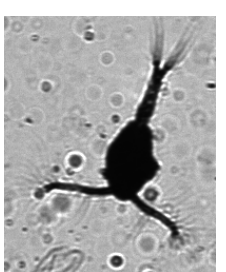

Cyclopoida

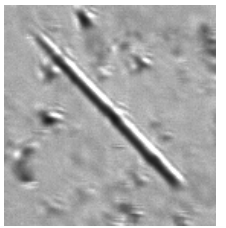

Filamento

fino

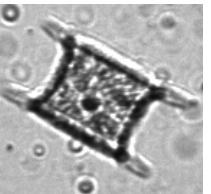

Odontella

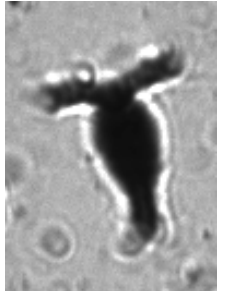

Copepoda

sem foco

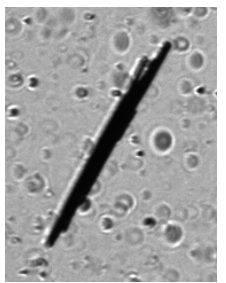

Filamento grosso

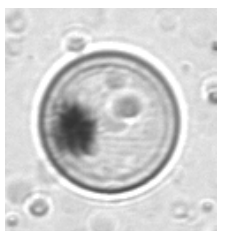

Pyrocystis

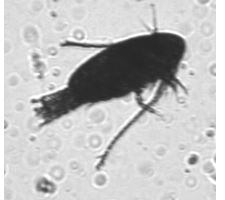

Copeoda pulando

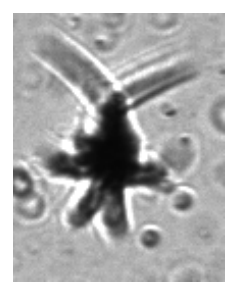

Nauplios sem foco

Figura A.1: Exemplares do dataset com 16 classes, cedido por Matuszewski (2014). 


\section{Apêndice B}

\section{Algoritmos de Segmentação}

Neste apêndice são descritos os 6 algoritmos de segmentação utilizados neste trabalho. Os algoritmos foram escolhidos considerando-se a relativa simplicidade computacional dos mesmos, e ao mesmo tempo o fato de apresentarem no geral um desempenho aceitável nos tipos de imagens consideradas nesta dissertação (imagens em tons de cinza, nas quais o alvo é relativamente mais escuro que o fundo).

Para efeito de descrição dos algoritmos, denotamos como $I$ uma imagem, como $p$ um ponto no domínio da imagem, como $I(p)$ a intensidade de $I$ em $p$, como $\bar{I}$ a intensidade média de uma imagem $I$ e como $\sigma$ o desvio padrão das intensidades. É assumido também que os alvos são relativamente mais escuros que o fundo.

Inicialmente definimos limiarização e em seguida descrevemos os algoritmos. Dado um valor de limiar $t$ entre 0 e 255, a imagem limiarizada $T$ no nível $t$ de uma imagem de entrada $I$ é definida, para cada pixel $p$, como:

$$
T(p)= \begin{cases}1, & \text { se } I(p)<=t \\ 0, & \text { caso contrário }\end{cases}
$$

Limiarização Fixa Na limiarização fixa é usado um valor fixo $t$ que é estabelecido independentemente dos valores da imagem. Por exemplo, nos casos em que as imagens apresentam bom contraste, com os pixels na região do alvo tendo valores bem escuros e o fundo tendo aspecto homogêneo com valores altos, o limiar $t=128$ poderia ser suficiente para separar o alvo do fundo.

Na limiarização Fixa usa-se um mesmo limiar para a binarização de todas as imagens adquiridas. em seguida, o componente conexo localizado na parte central da imagem é selecionado como resultado da segmentação. 
Limiarização dinâmica Na limiarização dinâmica aplica-se a mesma equação da limiarização fixa, porém o valor do limiar $t$ é estabelecido para cada imagem da seguinte forma:

$$
t=\bar{I}-c * \sigma
$$

na qual $\bar{I}$ e $\sigma$ são respectivamente a média e o desvio padrão dos valores dos pixeis, e $c \geq 1$ é uma constante que controla o desvio do limiar em torno da média em função do desvio padrão.

\section{Watershed a partir de marcadores (Deng et al., 1999)}

Watershed é um algoritmo de segmentação também conhecido por segmentação morfológica. Para cada mínimo regional na superfície definida pela imagem, é criada uma região contendo todos os pixels para os quais existe um caminho descendente (em termos de intensidade) de pixel para pixel até esse mínimo. Portanto, a imagem resultante resulta em uma partição da imagem em regiões, sendo uma região para cada mínimo regional.

Para evitar a super-segmentação, pode-se considerar, em lugar dos mínimos regionais, apenas alguns pontos estrategicamente marcados. Neste trabalho, o objetivo é a separação do plâncton do fundo da imagem. Assim, precisam ser definidos marcadores para o objeto de interesse (foreground) e para o fundo (background). Neste trabalho, os marcadores do objeto são tomados como todos os pixeis $p$ tal que:

$$
I(p)<\bar{I}-2 \sigma
$$

enquanto os marcadores do fundo são tomados como todos os pixeis $p$ tal que:

$$
I(p)>\bar{I}-\sigma
$$

\section{Limiarizaçao de Yen (Yen et al., 1995)}

A limiarização de Yen é um algoritmo que implementa a limiarização automática baseada no critério de correlação máxima como uma alternativa eficiente computacionalmente a medidas de entropia. 


\section{Limiarização de Otsu (Otsu, 1979)}

O algoritmo de Otsu cria um histograma de intensidades e seleciona um limiar de valor $t$ que separa os valores de intensidade em dois intervalos $[0, t-1]$ e $[t, 255]$. A seleção do valor de $t$ é feita de forma a minimizar a variância intra-classe e a maximizar a variância entre-classes.

\section{Algoritmo Isodata (Ridler e Calvard, 1978)}

O método de limiarização Isodata é um algoritmo que estabelece o limiar $t$ iterativamente. Nesse processo, o histograma é inicialmente segmentado em duas partes usando um valor de limiar inicial $t_{0}$ (por exemplo, o ponto médio do intervalo de valores). Pixels com valor menor que $t_{0}$ são considerados objeto e maiores que $t_{0}$ são considerados fundo. A média $\left(m_{f, 0}\right)$ dos valores cinza associados aos pixels do objeto e a média $\left(m_{b, 0}\right)$ dos valores cinza associados aos pixels do fundo são calculados. Um novo valor $t_{1}$ para o limiar é calculado como sendo a média entre $m_{f, 0}$ e $m_{b, 0}$. Esse processo é repetido, a partir desse novo limiar, até que o valor do limiar não mude mais. Isto é, dados $m_{f, 0}$ e $m_{b, 0}$, repete-se

$$
t_{k}=\frac{\left(m_{f, k-1}+m_{b, k-1}\right)}{2}, k=1,2,3, \ldots
$$

até que $t_{k}=t_{k-1}$.

Pré-processamento e pós-processamento na segmentação. Os métodos de segmentação podem incluir um passo de pré-processamento (por exemplo, equalização de histograma ou suavização gaussiana da imagem), e um passo de pós-processamento (por exemplo, seleção do maior componente conexo). Esses passos podem reduzir o ruído do fundo da imagem e evitar, por exemplo, a sobre-segmentação.

Os pré-processamentos e pós-processamentos considerados neste trabalho estão sumarizados na tabela B.1. Os 3 primeiros métodos foram implementados como descritos no trabalho de Matuszewski (2014).

\begin{tabular}{|c|l|l|}
\hline Métodos & Pre-processamento & Pós-processamento \\
\hline \hline Fixo & suavização & $\begin{array}{l}\text { operação morfológica de fechamento e } \\
\text { seleção do maior componente }\end{array}$ \\
\hline Dinâmico & suavização & seleção do maior componente \\
\hline Watershed & suavização & seleção do maior componente \\
\hline Yen & equalização de histograma & seleção do maior componente \\
\hline Otsu & equalização de histograma & seleção do maior componente \\
\hline Isodata & equalização de histograma & seleção do maior componente \\
\hline
\end{tabular}

Tabela B.1: Métodos de segmentação considerados neste trabalho. 
A suavização aplicada foi baseada em uma máscara gaussiana de tamanho $5 x 5$. O fechamento (dilatação seguida de erosão) foi realizado com o elemento estruturante $5 \times 5$. Ele é útil para preencher buracos e reentrâncias menores que o elemento estruturante.

Os métodos de segmentação foram implementados usando OpenCV (Bradski et al., 2000; Its, 2014; Itseez, 2015), versão 2.4.9. O OpenCV é uma biblioteca escrita em $\mathrm{C} / \mathrm{C}++$ otimizada, que foi desenhada para ter eficiência computacional e com foco em aplicações em tempo-real.

As figuras B.1 e B.2 mostram exemplos das 16 classes de imagens de plâncton segmentadas usando os seis métodos descritos acima. 

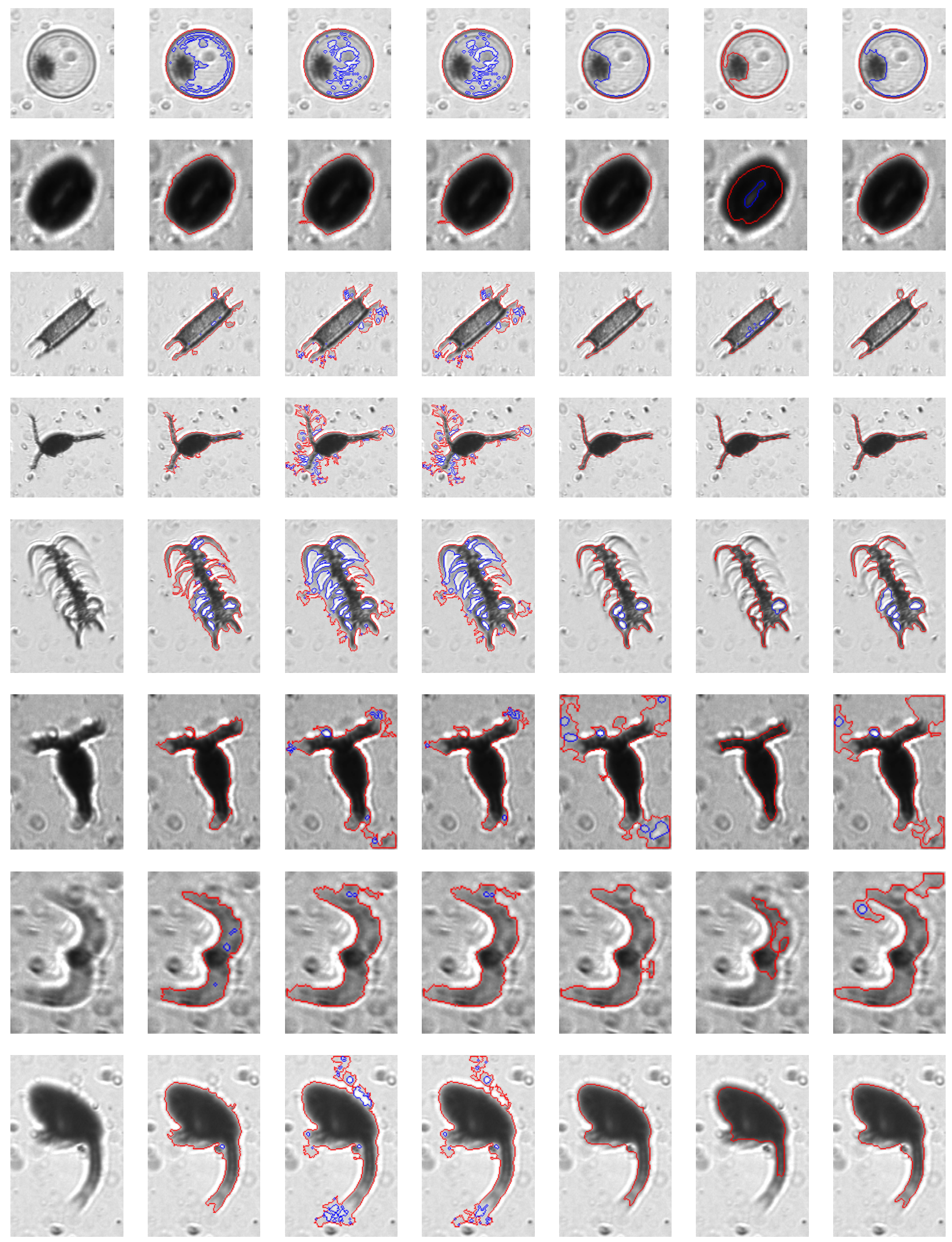

(a) Entrada

(b) Yen

(c) Otsu

(d) Iso.

(e) Fixo

(f) Din.

(g) Wat.

Figura B.1: Amostras de 8 classes de plâncton e suas respectivas segmentaçôes usando os 6 métodos. De cima para baixo, Pyrocystis, Coscinodiscus, Odontella sinesis, Copepoda Cyclopoida, Chaetoceros, Copepoda (Oithona) fora de foco, Neoceratium fora de foco, e Copepoda sem antena. 

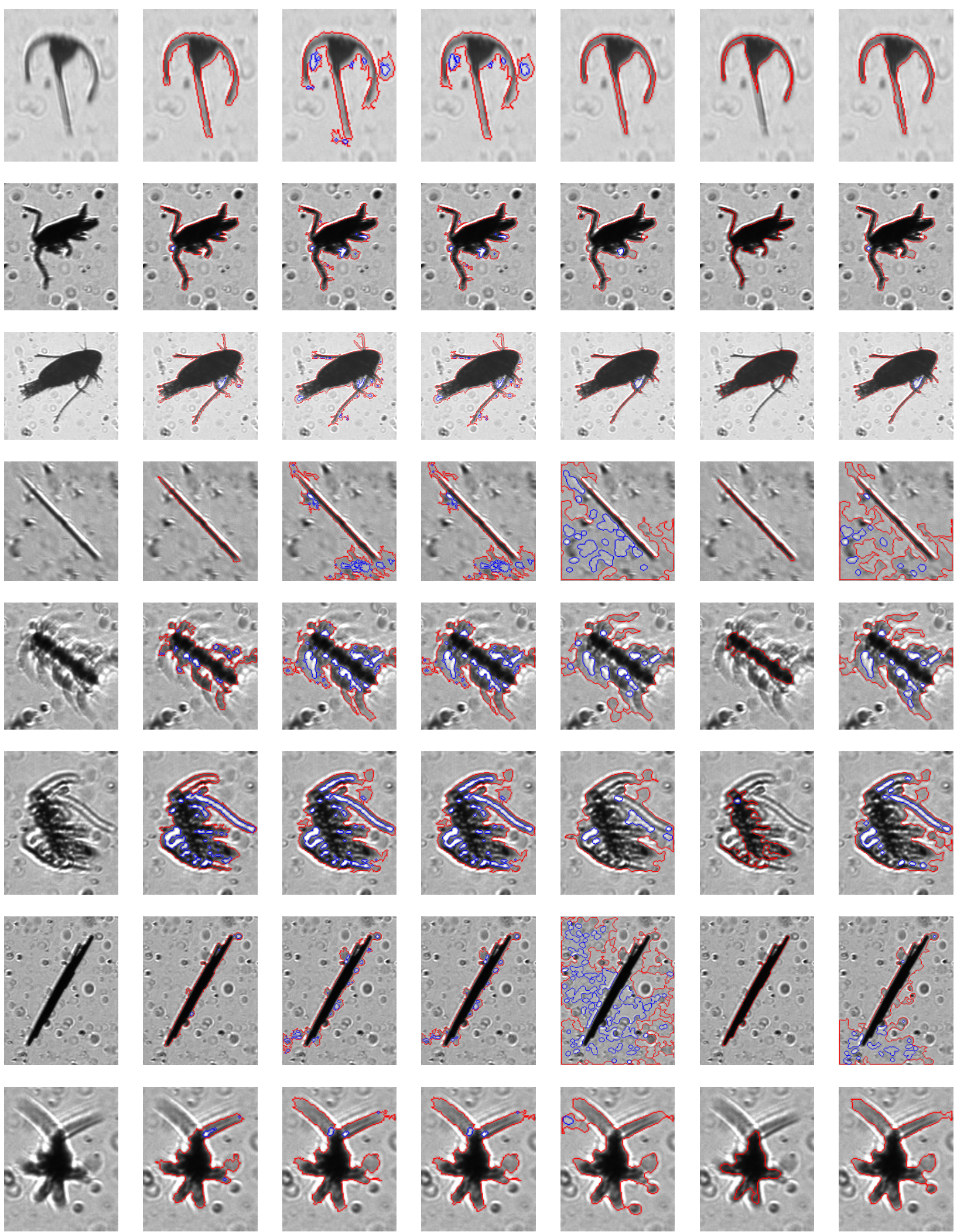

(c) Otsu

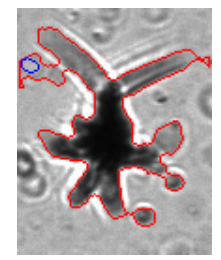

(e) Fixo

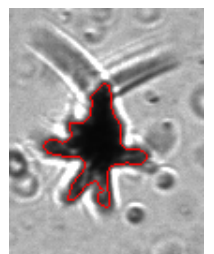

(f) Din.

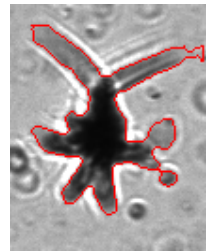

(g) Wat.

Figura B.2: Amostras de 8 classes de plâncton e suas respectivas segmentações usando os 6 métodos. De cima para baixo, Neoceratium, Copepoda Calanoida (Acartia), Copepoda pulando, filamentos finos, Chaetoceros fora de foco, Copepoda morto, Filamento grosso, e Nauplius fora de foco. 


\section{Referências Bibliográficas}

Ahonen et al. (2009) Timo Ahonen, Jiří Matas, Chu He e Matti Pietikäinen. Rotation Invariant Image Description with Local Binary Pattern Histogram Fourier Features, páginas 61-70. Springer Berlin Heidelberg, Berlin, Heidelberg. Citado na pág. 62

Arlot e Celisse (2010) Sylvain Arlot e Alain Celisse. A survey of cross-validation procedures for model selection. Statistics Surveys, 4:40-79. Citado na pág. 21

Aslan e Kapdan (2006) Sebnem Aslan e Ilgi Karapinar Kapdan. Batch kinetics of nitrogen and phosphorus removal from synthetic wastewater by algae. Ecological Engineering, 28 (1):64 - 70. ISSN 0925-8574. Citado na pág. 1

Barange (2010) M. Barange. Marine Ecosystems and Global Change. Oxford biology. OUP Oxford. Citado na pág. 1

Bell e Hopcroft (2008) Jenefer L. Bell e Russell R. Hopcroft. Assessment of ZooImage as a tool for the classification of zooplankton. Journal of Plankton Research, 30(12): 1351-1367. Citado na pág. 10, 15

Benfield et al. (2007) Mark C Benfield, Philippe Grosjean, Phil F Culverhouse, Xabier Irigoien, Michael E Sieracki, Angel Lopez-Urrutia, Hans G Dam, Qiao Hu, Cabell S Davis, Allen Hansen et al. Rapid: research on automated plankton identification. Citado na pág. 10, 15

Bi et al. (2015) Hongsheng Bi, Zhenhua Guo, Mark C. Benfield, Chunlei Fan, Michael Ford, Suzan Shahrestani e Jeffery M. Sieracki. A semi-automated image analysis procedure for in situ plankton imaging systems. PLoS ONE, 10(5):1-17. Citado na pág. 15

Bishop (2006) Christopher M. Bishop. Pattern Recognition and Machine Learning (Information Science and Statistics). Springer-Verlag New York, Inc., Secaucus, NJ, USA. Citado na pág. 20

Blaschko et al. (2005) M.B. Blaschko, G. Holness, M.A. Mattar, D. Lisin, P.E. Utgoff, A.R. Hanson, H. Schultz e E.M. Riseman. Automatic in situ identification of plankton. Em Seventh IEEE Workshop on Application of Computer Vision, volume 1, páginas 79-86. Citado na pág. 10, 11, 13, 14, 15

Boykov e Jolly (2001) Y. Y. Boykov e M. P. Jolly. Interactive graph cuts for optimal boundary amp; region segmentation of objects in N-D images. Em Eighth IEEE International Conference on Computer Vision, volume 1, páginas 105-112. Citado na pág. 14

Bradski et al. (2000) Gary Bradski et al. The opencv library. Doctor Dobbs Journal, 25 (11):120-126. Citado na pág. 51, 68 
Brennan e Owende (2010) Liam Brennan e Philip Owende. Biofuels from microalgae - a review of technologies for production, processing, and extractions of biofuels and coproducts. Renewable and Sustainable Energy Reviews, 14(2):557 - 577. ISSN 1364-0321. Citado na pág. 1

Cardoso e Corte-Real (2005) J. S. Cardoso e L. Corte-Real. Toward a generic evaluation of image segmentation. IEEE Transactions on Image Processing, 14:1773-1782. Citado na pág. 25

Castellani (2010) Claudia Castellani. Plankton: A guide to their ecology and monitoring for water quality. Journal of Plankton Research, 32(2):261-262. Citado na pág. 15

Castellani (2009) Claudia Castellani. Plankton: A Guide to their Ecology and Monitoring for Water Quality. CSIRO Publishing, 2nd ed. Editado por Iain M. Suthers and David Rissik. Citado na pág. 1

Chabrier et al. (2004a) S. Chabrier, B. Emile, H. Laurent, C. Rosenberger e P. Marche. Unsupervised evaluation of image segmentation application to multi-spectral images. Em International Conference on Pattern Recognition, volume 1, páginas 576-579. Citado na pág. 26

Chabrier et al. (2004b) S Chabrier, H Laurent, B Emile, C Rosenberger e P Marche. A comparative study of supervised evaluation criteria for image segmentation. Em European Signal Processing Conference, páginas 1143-1146. IEEE. Citado na pág. 26

Chabrier et al. (2006) Sebastien Chabrier, Bruno Emile, Christophe Rosenberger e Helene Laurent. Unsupervised performance evaluation of image segmentation. EURASIP Journal on Advances in Signal Processing, 2006(1):096306. ISSN 1687-6180. Citado na pág. 26

Chalvidan et al. (1998) V. Chalvidan, J. P. Chambard, G. Craig, A. Diard, G. L. Foresti, B. Forre, S. Gentili, P. R. Hobson, R. S. Lampitt, P. Maine, J. T. Malmo, H. Nareid, A. Pescetto, G. Pieroni, S. Serpico, K. Tipping e A. Trucco. High-resolution in situ holographic recording and analysis of marine organisms and particles (HOLOMAR). Em OCEANS '98 Conference Proceedings, volume 3, páginas 1599-1603. Citado na pág. 10

Chen et al. (2009) Jingnian Chen, Houkuan Huang, Shengfeng Tian e Youli Qu. Feature selection for text classification with naïve bayes. Expert Syst. Appl., 36(3):5432-5435. ISSN 0957-4174. Citado na pág. 19

Chuntapa et al. (2003) Benjamas Chuntapa, Sorawit Powtongsook e Piamsak Menasveta. Water quality control using spirulina platensis in shrimp culture tanks. Aquaculture, 220 (1-4):355 - 366. ISSN 0044-8486. Citado na pág. 1

Culverhouse et al. (2006) Phil F Culverhouse, Robert Williams, Mark Benfield, Per R Flood, Anne F Sell, Maria Grazia Mazzocchi, Isabella Buttino e Mike Sieracki. Automatic image analysis of plankton: future perspectives. Marine Ecology Progress Series, 312:297309. Citado na pág. 2, 15

da Fontoura Costa e Cesar (2009) L. da Fontoura Costa e R.M. Cesar. Shape Classification and Analysis: Theory and Practice, Second Edition. Image Processing Series. CRC Press. Citado na pág. 15

Davis et al. (2004) Cabell S Davis, Qiao Hu, Scott M Gallager, Xiaoou Tang e Carin J Ashjian. Real-time observation of taxa-specific plankton distributions: an optical sampling method. Marine Ecology Progress Series, 284:77-96. Citado na pág. 10 
Davis et al. (2005) Cabell S Davis, Fredrik T Thwaites, Scott M Gallager e Qiao Hu. A three-axis fast-tow digital video plankton recorder for rapid surveys of plankton taxa and hydrography. Limnol. Oceanogr.: Methods, 3:59-74. Citado na pág. 15

Davis et al. (1992) CS Davis, SM Gallager, MS Berman, LR Haury e JR Strickler. The video plankton recorder (vpr): design and initial results. Arch. Hydrobiol. Beih, 36:67-81. Citado na pág. 10

De Bernardi (1984) Riccardo de De Bernardi. Methods for the estimation of zooplankton abundance. A manual on methods for the assessment of secondary productivity in fresh waters, 2nd ed. IBP Handbook, 17:59-86. Citado na pág. 9

Deng et al. (1999) Yining Deng, B Shin Manjunath e Hyundoo Shin. Color image segmentation. Em IEEE Computer Society Conference on Computer Vision and Pattern Recognition, volume 2. IEEE. Citado na pág. 14, 66

Ding et al. (2002a) Yuhua Ding, G. J. Vachtsevanos, A. J. Yezzi, Yinchuan Zhang e Y. Wardi. A recursive segmentation and classification scheme for improving segmentation accuracy and detection rate in real-time machine vision applications. Em International Conference on Digital Signal Processing, volume 2, páginas 1009-1013. Citado na pág. 27

Ding et al. (2002b) Yuhua Ding, G.J. Vachtsevanos, A.J. Yezzi, Yinchuan Zhang e Y. Wardi. A recursive segmentation and classification scheme for improving segmentation accuracy and detection rate in real-time machine vision applications. Em 14th International Conference on Digital Signal Processing, volume 2, páginas 1009-1013 vol.2. Citado na pág. 36

Dominguez-Caballero et al. (2007) Jose A. Dominguez-Caballero, Nick Loomis, Weichang Li, Qiao Hu, Jerome Milgram, George Barbastathis e Cabell Davis. Advances in plankton imaging using digital holography. Em Adaptive Optics: Analysis and Methods/Computational Optical Sensing and Imaging/Information Photonics/Signal Recovery and Synthesis Topical Meetings on CD-ROM, página DMB5. Optical Society of America. Citado na pág. 2

Dyomin et al. (2011) V. V. Dyomin, A. S. Olshukov e E. V. Dzyuba. Digital holographic video for studies of plankton dynamics. Russian Physics Journal, 53(8):857-866. ISSN 1573-9228. Citado na pág. 2

Efron e Tibshirani (1994) B. Efron e R.J. Tibshirani. An Introduction to the Bootstrap. Chapman \& Hall/CRC Monographs on Statistics \& Applied Probability. Taylor \& Francis. Citado na pág. 21

Ellen et al. (2015) J. Ellen, Hongyu Li e M. D. Ohman. Quantifying california current plankton samples with efficient machine learning techniques. Em OCEANS $2015-M T S / I$ EEE Washington, páginas 1-9. doi: 10.23919/OCEANS.2015.7404607. Citado na pág. 62

Falkowski (2012) Paul Falkowski. Ocean science: the power of plankton. Nature, 483 (7387):S17-S20. Citado na pág. 1

Fernandes et al. (2009) Jose A. Fernandes, Xabier Irigoien, Guillermo Boyra, Jose A. Lozano e Iñaki Inza. Optimizing the number of classes in automated zooplankton classification. Journal of Plankton Research, 31(1):19-29. Citado na pág. 15 
Fernandez et al. (2015) M. A. Fernandez, R. M. Lopes e N. S. T. Hirata. Image segmentation assessment from the perspective of a higher level task. Em Conference on Graphics, Patterns and Images (SIBGRAPI), páginas 111-118. Citado na pág. 7

Finkel et al. (2010) Zoe V. Finkel, John Beardall, Kevin J. Flynn, Antonietta Quigg, T. Alwyn V. Rees e John A. Raven. Phytoplankton in a changing world: cell size and elemental stoichiometry. Journal of Plankton Research, 32(1):119-137. Citado na pág. 1

Fischer et al. (2000) S. Fischer, M. Binkert e H. Bunke. Symmetry based indexing of diatoms in an image database. Em International Conference on Pattern Recognition, volume 2, páginas 895-898. Citado na pág. 62

Froese et al. (1990) R Froese, KG Barthel, W Welsch, M Rolke, C Schubert, B Hermann, S Mees, D Schnack, J Lenz e Dtisternbrooker Weg. Development of an underwater video system for recording of ichthyoplankton and zooplankton. ICES CM Documents, páginas $1-5$. Citado na pág. 10

Gorsky et al. (2010) Gaby Gorsky, Mark D. Ohman, Marc Picheral, Stéphane Gasparini, Lars Stemmann, Jean-Baptiste Romagnan, Alison Cawood, Stéphane Pesant, Carmen García-Comas e Franck Prejger. Digital zooplankton image analysis using the ZooScan integrated system. Journal of Plankton Research, 32(3):285-303. Citado na pág. 1, 2, 4, 10, $14,15,19$

Grosjean et al. (2004) Philippe Grosjean, Marc Picheral, Caroline Warembourg e Gabriel Gorsky. Enumeration, measurement, and identification of net zooplankton samples using the ZOOSCAN digital imaging system. ICES Journal of Marine Science: Journal du Conseil, 61(4):518-525. Citado na pág. 1, 2, 4, 10, 15

Guyon et al. (2002) Isabelle Guyon, Jason Weston, Stephen Barnhill e Vladimir Vapnik. Gene selection for cancer classification using support vector machines. Machine Learning, 46(1):389-422. ISSN 1573-0565. Citado na pág. 34

Haralick et al. (1973) R. M. Haralick, K. Shanmugam e I. Dinstein. Textural features for image classification. IEEE Transactions on Systems, Man, and Cybernetics, SMC-3(6): 610-621. ISSN 0018-9472. Citado na pág. 62

Hays et al. (2005) Graeme C. Hays, Anthony J. Richardson e Carol Robinson. Climate change and marine plankton. Trends in Ecology and Evolution, 20(6):337 - 344. ISSN 0169-5347. \{SPECIAL $\}$ ISSUE: $\{$ BUMPER $\{$ BOOK $\}\{$ REVIEW $\}$. Citado na pág. 1

He e Garcia (2009) H. He e E. A. Garcia. Learning from imbalanced data. IEEE Transactions on Knowledge and Data Engineering, 21(9):1263-1284. ISSN 1041-4347. Citado na pág. 23

Henson et al. (2012) Stephanie A. Henson, Richard Sanders e Esben Madsen. Global patterns in efficiency of particulate organic carbon export and transfer to the deep ocean. Global Biogeochemical Cycles, 26(1):n/a-n/a. ISSN 1944-9224. GB1028. Citado na pág. 1

Hirata et al. (2016) N. S. T. Hirata, M. A. Fernandez e R. M. Lopes. Plankton image classification based on multiple segmentations. Em 2016 ICPR 2nd Workshop on Computer Vision for Analysis of Underwater Imagery (CVAUI), páginas 55-60. doi: 10.1109/CVAUI.2016.022. Citado na pág. 7

Hoffmann (1998) James P. Hoffmann. Wastewater treatment with suspended and nonsuspended algae. Journal of Phycology, 34(5):757-763. ISSN 1529-8817. Citado na pág. 1 
Hooff e Peterson (2006) Rian C Hooff e William T Peterson. Copepod biodiversity as an indicator of changes in ocean and climate conditions of the northern California current ecosystem. Limnology and Oceanography, 51(6):2607-2620. Citado na pág. 1

Hu (1962) Ming-Kuei Hu. Visual pattern recognition by moment invariants. IRE Transactions on Information Theory, 8(2):179-187. ISSN 0096-1000. Citado na pág. 14

Its (2014) The OpenCV Reference Manual. Itseez, 2.4.9.0 ed., April 2014. Citado na pág. 51, 68

Itseez (2015) Itseez. Open source computer vision library. https://github.com/itseez/ opencv, 2015. Citado na pág. 51, 68

Jeffries et al. (1984) H. P. Jeffries, M. S. Berman, A. D. Poularikas, C. Katsinis, I. Melas, K. Sherman e L. Bivins. Automated sizing, counting and identification of zooplankton by pattern recognition. Marine Biology, 78(3):329-334. ISSN 1432-1793. Citado na pág. 9, 10

Jeffries et al. (1980) H. Perry Jeffries, Kenneth Sherman, Ray Maurer e Costantin Katsinis. Computer-processing $\{\mathrm{OF}\}$ ZZOOPLANKTON\} \{SAMPLES\}. Em VICTOR S. KENNEDY, editor, Estuarine Perspectives, páginas 303 - 316. Academic Press. Citado na pág. 9,10

Kasturi et al. (2002) Rangachar Kasturi, Lawrence O'Gorman e Venu Govindaraju. Document image analysis: A primer. Sadhana, 27(1):3-22. ISSN 0973-7677. Citado na pág. 28

Kavzoglu e Yildiz (2014) T. Kavzoglu e M. Yildiz. Parameter-Based Performance Analysis of Object-Based Image Analysis Using Aerial and Quikbird-2 Images. Em ISPRS Annals of Photogrammetry, Remote Sensing and Spatial Information Sciences, volume II-7, páginas 31-37. Citado na pág. 27, 36

Kohavi (1995) Ron Kohavi. A study of cross-validation and bootstrap for accuracy estimation and model selection. Em Proceedings of the 14th International Joint Conference on Artificial Intelligence - Volume 2, IJCAI'95, páginas 1137-1143, San Francisco, CA, USA. Morgan Kaufmann Publishers Inc. Citado na pág. 21

Kohavi e John (1997) Ron Kohavi e George H. John. Wrappers for feature subset selection, 1997. Citado na pág. 20

Krizhevsky et al. (2012) A. Krizhevsky, I. Sutskever e G. Hinton. Imagenet classification with deep convolutional neural networks. Advances in Neural Information Processing Systems (NIPS), páginas 1-9. URL www.scopus.com. Citado na pág. 62

Kuhl e Giardina (1982) Frank P Kuhl e Charles R Giardina. Elliptic fourier features of a closed contour. Computer graphics and image processing, 18(3):236-258. Citado na pág. 62

Kuncheva (2004) L.I. Kuncheva. Combining Pattern Classifiers: Methods and Algorithms. Wiley. Citado na pág. 17

Le Bourg et al. (2015) Baptiste Le Bourg, Véronique Cornet-Barthaux, Marc Pagano e Jean Blanchot. FlowCAM as a tool for studying small (80-1000 um) metazooplankton communities. Journal of Plankton Research, 37(4):666-670. Citado na pág. 1, 2, 4, 10, 11

Li et al. (2008) Yuanhong Li, Ming Dong e Jing Hua. Localized feature selection for clustering. Pattern Recognition Letters, 29(1):10 - 18. ISSN 0167-8655. Citado na pág. 19 
Little e Copley (2003) William S Little e Nancy J Copley. Whoi silhouette digitizer version 1.0 user's guide. Relatório técnico, Woods Hole Oceanographic Institution. Citado na pág. 10

Luo et al. (2004) Tong Luo, K. Kramer, D. B. Goldgof, L. O. Hall, S. Samson, A. Remsen e T. Hopkins. Recognizing plankton images from the shadow image particle profiling evaluation recorder. IEEE Transactions on Systems, Man, and Cybernetics, Part B (Cybernetics), 34(4):1753-1762. ISSN 1083-4419. Citado na pág. 10

Malkiel et al. (1999) Edwin Malkiel, Omar Alquaddoomi e Joseph Katz. Measurements of plankton distribution in the ocean using submersible holography. Measurement Science and Technology, 10(12):1142. Citado na pág. 2

Marcolin et al. (2015) Catarina R. Marcolin, Salvador Gaeta e Rubens M. Lopes. Seasonal and interannual variability of zooplankton vertical distribution and biomass size spectra of Ubatuba, Brazil. Journal of Plankton Research, 37(4):808-819. Citado na pág. 1, 2

Martin et al. (2006) Arnaud Martin, Hicham Laanaya e Andreas Arnold-Bos. Evaluation for uncertain image classification and segmentation. Pattern Recognition, 39(11):1987 1995. ISSN 0031-3203. Citado na pág. 25

Martinez et al. (2000) M.E Martinez, S Sanchez, J.M Jimenez, F El Yousfi e L Muñoz. Nitrogen and phosphorus removal from urban wastewater by the microalga scenedesmus obliquus. Bioresource Technology, 73(3):263 - 272. ISSN 0960-8524. Citado na pág. 1

Mata et al. (2010) Teresa M. Mata, António A. Martins e Nidia. S. Caetano. Microalgae for biodiesel production and other applications: A review. Renewable and Sustainable Energy Reviews, 14(1):217 - 232. ISSN 1364-0321. Citado na pág. 1

Mattiello (2014) Izadora De La Volpe Mattiello. Avaliação de corantes para a deteç̧ão da viabilidade do fitoplâncton marinho. Tese de Doutorado, Universidade de São Paulo. Citado na pág. 2

Matuszewski (2014) Damian Janusz Matuszewski. Computer vision for continuous plankton monitoring. Dissertação de Mestrado, Universidade de São Paulo. Citado na pág. viii, xi, xii, 2, 3, 4, 10, 13, 15, 31, 49, 51, 63, 64, 67

Matuszewski et al. (2013) D.J. Matuszewski, R.M. Lopes e R.M. Cesar. Visual rhythmbased method for continuous plankton monitoring. Em IEEE 9th International Conference on eScience, páginas 204-211. Citado na pág. xi, 1, 2, 10, 12

Ortner et al. (1979) Peter B Ortner, Shailer R Cummings, R Paul Aftring e HAROLD E EDGERTON. Silhouette photography of oceanic zooplankton. páginas 50-51. Citado na pág. 10

Ortner et al. (1981) Peter B. Ortner, Leonard C. Hill e Harold E. Edgerton. In-situ silhouette photography of Gulf Stream zooplankton. Deep Sea Research Part A. Oceanographic Research Papers, 28(12):1569 - 1576. ISSN 0198-0149. Citado na pág. 10

Otsu (1979) Nobuyuki Otsu. A threshold selection method from gray-level histograms. IEEE Transactions on Systems, Man and Cybernetics, 9(1):62-66. ISSN 0018-9472. Citado na pág. 67

Pedregosa et al. (2011) F. Pedregosa, G. Varoquaux, A. Gramfort, V. Michel, B. Thirion, O. Grisel, M. Blondel, P. Prettenhofer, R. Weiss, V. Dubourg, J. Vanderplas, A. Passos, 
D. Cournapeau, M. Brucher, M. Perrot e E. Duchesnay. Scikit-learn: Machine learning in Python. Journal of Machine Learning Research, 12:2825-2830. Citado na pág. 34, 51

Py et al. (2016a) O. Py, H. Hong e S. Zhongzhi. Plankton classification with deep convolutional neural networks. Em 2016 IEEE Information Technology, Networking, Electronic and Automation Control Conference, páginas 132-136. doi: 10.1109/ITNEC.2016.7560334. Citado na pág. 62

Py et al. (2016b) O. Py, H. Hong e S. Zhongzhi. Plankton classification with deep convolutional neural networks. Em IEEE Information Technology, Networking, Electronic and Automation Control Conference, páginas 132-136. Citado na pág. 9

Richardson (2008) Anthony J. Richardson. In hot water: zooplankton and climate change. ICES Journal of Marine Science: Journal du Conseil, 65(3):279-295. Citado na pág. 1

Ridler e Calvard (1978) T.W. Ridler e S. Calvard. Picture thresholding using an iterative selection method. IEEE Transactions on Systems, Man and Cybernetics, 8(8):630-632. ISSN 0018-9472. Citado na pág. 67

Rother et al. (2004) Carsten Rother, Vladimir Kolmogorov e Andrew Blake. Grabcut: Interactive foreground extraction using iterated graph cuts. Em ACM transactions on graphics (TOG), volume 23, páginas 309-314. ACM. Citado na pág. 14

Sieburth et al. (1978) John McN Sieburth, Victor Smetacek e Jürgen Lenz. Pelagic ecosystem structure: heterotrophic compartments of the plankton and their relationship to plankton size fractions. Limnology and oceanography, 23(6):1256-1263. Citado na pág. 1

Simonyan e Zisserman (2015) K. Simonyan e A. Zisserman. Int.Conf.on Learning Representations, página 1. URL www.scopus.com. Citado na pág. 62

Sun et al. (2008) H Sun, P.W Benzie, N Burns, D.C Hendry, M.A Player e J Watson. Underwater digital holography for studies of marine plankton. Philosophical Transactions of the Royal Society of London A: Mathematical, Physical and Engineering Sciences, 366 (1871):1789-1806. ISSN 1364-503X. Citado na pág. 2

Tang et al. (1998) Xiaoou Tang, W. Kenneth Stewart, Luc Vincent, He Huang, Marty Marra, Scott M. Gallager e Cabell S. Davis. Automatic Plankton Image Recognition, páginas 177-199. Springer Netherlands, Dordrecht. Citado na pág. 9

Udupa et al. (2006) Jayaram K Udupa, Vicki R Leblanc, Ying Zhuge, Celina Imielinska, Hilary Schmidt, Leanne M Currie, Bruce E Hirsch e James Woodburn. A framework for evaluating image segmentation algorithms. Computerized Medical Imaging and Graphics, $30(2): 75-87$. Citado na pág. 25

Unnikrishnan et al. (2007) Ranjith Unnikrishnan, Caroline Pantofaru e Martial Hebert. Toward objective evaluation of image segmentation algorithms. IEEE Trans. Pattern Anal. Mach. Intell., 29(6):929-944. Citado na pág. 25

Walker et al. (1995) Ross F Walker, Paul Jackway e ID Longstaff. Improving co-occurrence matrix feature discrimination. Em 3rd Conference on Digital Image Computing: Techniques and Application (DICTA), páginas 643-648. Citado na pág. 62

Watson et al. (2003) J. Watson, S. Alexander, V. Chalvidan, G. Craig, A. Diard, G. L. Foresti, S. Gentili, D. C. Hendry, P. R. Hobson, R. S. Lampitt, H. Nareid, J. J. Nebrensky, A. Pescetto, G. G. Pieroni, M. A. Player, K. Saw, S. Serpico, K. Tipping e A. Trucco. A holographic system for subsea recording and analysis of plankton and other marine 
particles (HOLOMAR). Em OCEANS Proceedings, volume 2, páginas 830-837. Citado na pág. 10

Yang et al. (1995) Luren Yang, Fritz Albregtsen, Tor Lønnestad e Per Grøttum. A supervised approach to the evaluation of image segmentation methods. Em International Conference on Computer Analysis of Images and Patterns, páginas 759-765. Springer. Citado na pág. 26

Yen et al. (1995) Jui-Cheng Yen, Fu-Juay Chang e Shyang Chang. A new criterion for automatic multilevel thresholding. IEEE Transactions on Image Processing, 4(3):370-378. ISSN 1057-7149. Citado na pág. 66

Yu e Liu (2003) Lei Yu e Huan Liu. Feature selection for high-dimensional data: A fast correlation-based filter solution. páginas 856-863. Citado na pág. 20

Zeebe (2012) Richard E Zeebe. History of seawater carbonate chemistry, atmospheric CO2, and ocean acidification. Annual Review of Earth and Planetary Sciences, 40:141-165. Citado na pág. 1

Zhang et al. (2008) Hui Zhang, Jason E. Fritts e Sally A. Goldman. Image segmentation evaluation: A survey of unsupervised methods. Computer Vision and Image Understanding, 110(2):260 - 280. Citado na pág. 25

Zhang (1996) Y. J. Zhang. A survey on evaluation methods for image segmentation. Pattern Recognition, 29(8):1335-1346. Citado na pág. 25

Álvarez et al. (2011) Eva Álvarez, Ángel López-Urrutia, Enrique Nogueira e Santiago Fraga. How to effectively sample the plankton size spectrum? A case study using FlowCAM. Journal of Plankton Research, 33(7):1119-1133. Citado na pág. 11

Âlvarez et al. (2012) Eva Álvarez, Ángel López-Urrutia e Enrique Nogueira. Improvement of plankton biovolume estimates derived from image-based automatic sampling devices: application to FlowCAM. Journal of Plankton Research, 34(6):454-469. Citado na pág. 1, 2, 14,15 